\author{
THE UNIVERSITY OF MANITOBA
}

\title{
PURIFICATION AND CHARACTERIZATION OF \\ OVINE PLACENTAL LACTOGEN
}

by

\author{
JOHN S.D. CHAN
}

\begin{abstract}
A THESIS
SUBMTTTED TO THE FACULTY OF GRADUATE STUDIES

IN PARTIAL FULfillment OF THE REQUiREMENTS FOR THE DEgREE OF MASTERS OF SCIENCE.
\end{abstract}

DEPARTMENT OF PHYSIOLOGY

WINNIPEG, MAN ITOBA

MAY 1975 


\section{PURIFICATION AND CHARACTERIZATION OF \\ OVINE PLACENTAL LACTOGEN}

by

JOHN S. D. CHAN

A dissertation submitted to the Faculty of Graduate Studies of the University of Manitoba in partial fulfillment of the requirements of the degree of

MASTER OF SCIENCE

(C) 1975

Permission has been granted to the LIBRARY OF THE UNIVERSITY OF MANITOBA to kend or sell copies of this dissertation, to the NATIONAL LIBRARY OF CANADA to microfilm this dissertation and to lend or sell copies of the film, and UNIVERSITY MICROFILMS to publish an abstract of this dissertation.

The author reserves other publication rights, and neither the dissertation nor extensive extracts from it may be printed or otherwise reproduced without the author's written permission.

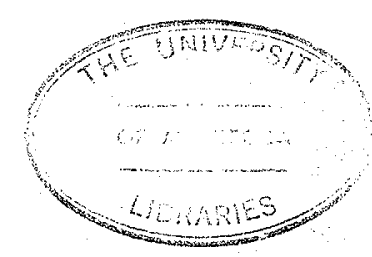


My parents and Fiancée:

Mr : \& Mrs,Kai-0n Chan

and

Miss.Ting-Mei Feng 
PURIFICATION AND CHARACTERIZATION OF OVINE PLACENTAL LACTO-

GEN.John S,D, Chan, Department of Physiology, Faculty of Medicine, University of Manitoba, Winnipeg, Manitoba, Canada.

A placental hormone, ovine placental lactogen(oPL); has been identified and measured in serum and placental extracts at different stages of pregnancy using radioreceptorassays for prolactin (RRA-PRL) and for growth hormone (RRA-GH) to monitor the hormonal activities. Using conventional protein purification procedures, oPL was purified 1,000-fold from sheep cotyledons. The molecular weight of oPL is similar to human growth hormone (hGH) approximately 22,000 and its isoelectric point is 8.8 as determined by isoelectric focusing. A radioimmunoassay for oPL has been developed in which sheep pituitary growth hormone and prolactin as we 11 as other pituitary and placental hormones from several species exhibit no cross-reaction. In the 2 radioreceptorassays (RRA's), the displacement curve of oPL is parallel to ovine prolactin (oPRL) and hGH standards and the ratio of prolactin activity to growth hormone activity (PRL/GH) of oPL is $2: 1$ as compared with a ratio of $1: 1$ for hGH and 100:1 for human placental lactogen (hPL). In a hypophysectomized rat weightrgain bioassay, oPL is 1.5 times. more potent than a boyine growth hormone $(0.9 \mathrm{U} / \mathrm{mg})$ standard. 
In rabbit mammary gland explants, oPL is equipotent with ovine prolactin standard (NIH-P-S-10, $26 \mathrm{U} / \mathrm{mg})$ in stimulät-. ing casein synthesis. Non-primate growth hormone preparations cross-react only with 1 abel1ed-GH in the RRA-GH, but not with labelled-PRL in the RRA-PRL, whereas $h G H$ and oPL crossreact equally well in both RRA's. The similarity with which oPL and hGH crossrreact in the 2 RRA's suggests that structurally oPL may resemble hGH more closely than hPL and nonprimate pituitary growth hormone preparations. This hypothesis was supported by the finding that oPL is able to bind to growth hormone-receptors in human tissues, whereas non-primate growth hormones do not. Human tissue receptors for growth hormone fail to distinguish between oPL and hGH, suggesting that the active sites of oPL and hGH are similar, and raising the possibility that $O P L$ may potentially have therapeutic use in the treatment of growth hormone-deficient patients. 


\section{ACKNOWLEDGEMENTS}

This investigation was carried out in the Protein and Polypeptide Hormone Laboratory, Dept. of Physiology, Faculty of Medicine, University of Manitoba, Winnipeg.

First of a11, the author wishes to express his deepest gratitude and most sincere appreciation to Dr. H.G. Friesen for his guidance, encouragement and invaluable advice during the course of the investigation.

Secondly, the author wishes to express his most sincere respect and thanks to his fiancée, Miss.Ting-Mei Feng, for her support, understanding, patience, and encouragement during the preparation of this thesis.

Thirdly, the author would like to express his thanks to Drs, R.P.C. Shiu, P.A, Ke11y, M, Robertson, D, Carr, W. B.Currie, and H.Knul1 for their most helpful discussion and advice.

The author gratefully acknowledges Drs.H.Robertson, V. Chernick, and N.E.Stanger for providing sheep placental tissues for the purification of ovine placental lactogen. In addition, the author wishes to acknowledge the kind of comoperation given by the following investigators in sending the samples for analysis: Drs. J.Roth, H,Niall, C. Nicol1, D. Garr, and R.C.P.Shì.

Last, but not least, special acknowledgement and thanks are given to all the staff of the laboratory, 
particularly to Mr. Jeff Harris and Mrs. He11e Cosby, for their co-operation and technical assistance. 


\section{CONTENT}

I. GENERAL TNTRODUCTTON ................ Page

A brief review on the early investigations

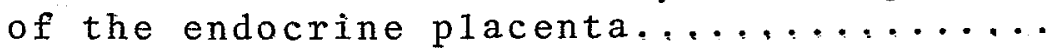

Discovery of human chorionic gonadotropin $(h C G) \ldots \ldots \ldots \ldots \ldots \ldots \ldots \ldots \ldots \ldots \ldots$

Discovery of human placental 1actogen(hPL) .

Comparative assessment of placental 1actogen production and effects in three orders of mammals ......................

Order Brimates $\ldots \ldots \ldots \ldots \ldots \ldots \ldots \ldots$

Order Rodentia ............. 13

Order Artiodactyla ........... 17

II. NEW DATA ON NON-PRIMATE PLACENTAL LACTOGEN ......

Brief introduction of a new assay system-

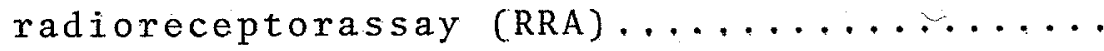

Rat Placenta1 Lactogen (rPL) ......

Sheep Placental Lactogen (oPL) , ...

IIT.OBJECTIVES OF THE PRESENT INVESTIGATION .......

IV. METHODS OF PURTFTCATION AND CHARACTERIZATION....

Materials and methods $\ldots \ldots \ldots \ldots \ldots \ldots \ldots$

Assays for monitoring hormonal

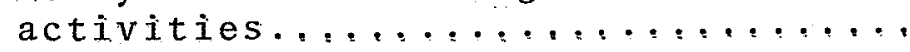

1. Method of isolation of specific

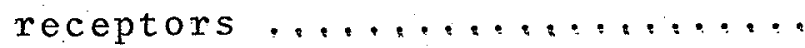

2. Iodination procedure for hormone preparations.............

3. Incubation procedure......... 
starting materials $\ldots \ldots \ldots \ldots \ldots$

Hormone preparations $\ldots \ldots \ldots \ldots \ldots$

Protein measurement.............

Concentration of volume by ultra-

filtration.................. 34

Purification procedures.......... 34

1. Extraction ........... 34

2. Ammonium sulfate precipitation. $\quad 35$

3 . Dialysis $\ldots \ldots \ldots \ldots \ldots \ldots \ldots \ldots$

4, Diethylaminoethy (DEAE) anion exchange chromatography...... 35

$5, G e 1$ filtration .......... 36

6. Carboxymethy 1 -ce 11 ulose. ( CMC) cation exchange chromatography. $\quad 36$

7.Gel filtration.......... 36

Characterization procedures...... 37

1. Chemica1:

(a) Ana1ytical ge1 electrophoresis...............

(b) Analytical ge1 isoelectrie focusing electrophoresis.

(c) Preparative isoelectricfocusing $\ldots \ldots \ldots \ldots \ldots$

(d) Molecular weight estimation.

2. Immunologica 1:

(1) Immunization procedures, :

(2) Iodination of oPL $\ldots \ldots \ldots$

(3) Test for integrity of ${ }^{125} \mathrm{I}$ -

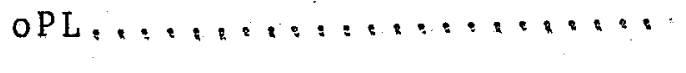

(4) Radioimmonossay procedures. 
3, Biologica $1 \ldots \ldots \ldots \ldots \ldots, \ldots$

(a) Bioassay of growth promoting activity ............

(b) Lactogenic bioassay ,.....

4, Receptor assays .........

(a) Displacement of oPL in the 2 RRA's using rabbit mam-. mary glands and liver.....

(b) Displacement of oPL in the RRA-BH using human 1 iver...

$\mathrm{V}$. RESULTS $\ldots \ldots \ldots \ldots \ldots \ldots \ldots \ldots \ldots \ldots \ldots \ldots \ldots \ldots \ldots \ldots \ldots \ldots \ldots$

Radioreceptorassays for prolactin (RRA-PRL) and for growth hormone (RRA-GH) using rabbit mammary gland and 1 iver respectively,.....

purification..................

OPL concentration in placental

tissues at different gestational

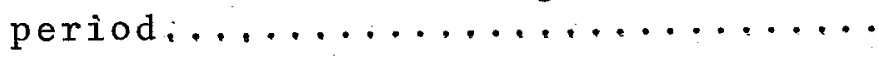

Extraction of oPL from frozen

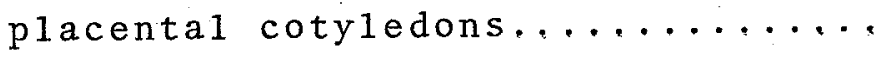

Fractionation of $O P L$ from crude extracts.................

DEAE-ce11ulose chromatography,....

Gel filtration $\ldots \ldots \ldots \ldots \ldots \ldots \ldots$

CM-cel1ulose chromatography,.....

Column chromatography..........

Characterization. ................

Analytical polyacrylamide gel

electrophoresis :............

Analytical gel isoelectric-focusing.

Preparative isoelectric-focusing : : 
Molecular weight estimation...... 66

Radioimmunoassay for oPL........ 66

Bioassay of growth promoting activity 70

Lactogenic bioassay............. 70

Displacement curve of oPL in the 2

RRA's using rabbit mammary glands

and 1 iver tissues..............

70

Displacement curve of oPL in the

RRA-GH using human liver tissue...

VI, DISCUSSIONS $\ldots \ldots \ldots \ldots \ldots \ldots \ldots \ldots \ldots \ldots \ldots \ldots \ldots$

A) Extraction and Purification......... 78

1.Preliminary extraction........ 78

2. Ammonium sulfate precipitation... 78

3. Anion exchange chromatography... $\quad 79$

4. Cation exchange chromatography... $\quad 79$

B) Analysis and Characterization......... 79

1. Analytical polyacrylamide ge 1 electrophoresis............

2.Analytical gel isoelectric-focusing

3. Estimation of molecular weight by ge1 filtration............. 80

4. Immunologica1 relationships......

5. Bioassay of growth promoting activity ................

6. Bioassay of 1 actogenic activity...

7. Displacement curve of oPL in RRA-GH using rabbit liver tissue.......

8.RRA-GH using human liver ...... 
Comparative data on placental lactogen.....

1. Chemistry ................ 85

2. Secretion................. 86

3. Biological effects........... 88

4. Immunological relationships...... 89

5 . Secretion pattern............ 90

Possible role of oPL in the sheep......... 92

1. Mammotropic effect............ 92

2. Somatotropic (metabolic) effect... 93

3. Luteotropic effect ........... 95

Possible experiments to demonstrate the bio-

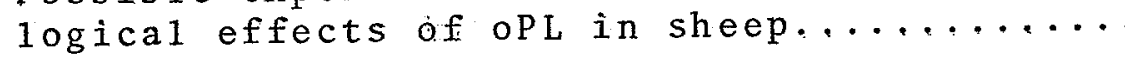

1. Mammotropic effect........... 97

2. Metabolic effect ........... 97

3. Luteotropic effect ........... 98

VII， SUMMARY $\ldots \ldots \ldots \ldots \ldots \ldots \ldots \ldots \ldots \ldots \ldots$

VIII. BIBLTOGRAPHY $\ldots \ldots \ldots \ldots \ldots \ldots \ldots \ldots \ldots \ldots$ 


\section{LIST OF ABBREVIAT TON}

Peptide hormones:

ACTH

CG

FSH

GH

LH

PRL

PL

Prefix to hormones:

b

$\mathrm{h}$

0

$\mathrm{r}$

c

Others:

${ }^{\mathrm{o}} \mathrm{C}$

$\mathrm{cpm}$

g

$\mathrm{mg}$

ug

$M$

$\mathrm{mM}$

$\mathrm{m} 1$

$\mathrm{u} 1$
Adrenocorticotropic hormone

Chorionic Gonadotropin

Follicle Stimulating hormone

Growth Hormone

Luteinizing Hormone

Prolactin

Placental Lactogen

bovine

human

ovine

rat

caprine

Degree Centigrade

Counts Per Minute

Gram

Mi11 ìgram

Microgram

Molar

Millimolar

Mi11îter

Microliter 
Liter

g

Gravitational force

Internationa 1 unit

Unit 


\section{LIST OF FIGURES}

FIGURE

PAGE

1 Epiphyseal cartilage width in hypophysectomized rats after administration of bGH, $\mathrm{mPL}$,

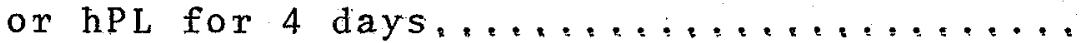

2a Radioreceptorassay for prolactin using particulate fraction derived from rabbit mammary glands (RRA-PRL) ................

Radioreceptorassay for growth hormone using particulate fraction derived from rabbit

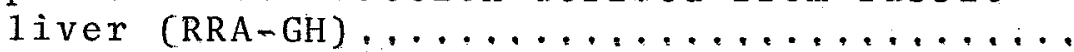

OPL concentration in placental tissues at different gestational period...........

Fractionation of oPL from crude extract...

Diethylaminoethyl (DEAE)-cellulose chromatography of oPL rich fraction...........

Gel filtration of oPL on a Sephadex G-100..

CM-cellulose chromatography of oPL rich

fractions......................

Gel filtration on Sephadex G-100 column...

Polyacrylamide ge1 electrophoresis pattern

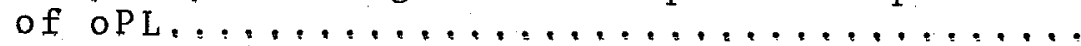

10. Pattern of oPL activity eluted from poly-

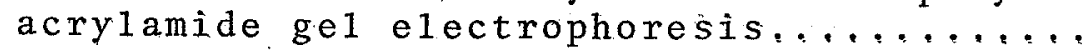

11 Analytical polyacrylamide gel isoelectric focusing pattern of oPL,............

12 Pattern of oPL activity eluted from polyacrylamide gel isoelectric focusing.......

13 The elution profile of oPL after isoelectrịc focusing....................

14 Molecular weight determination of oPL by

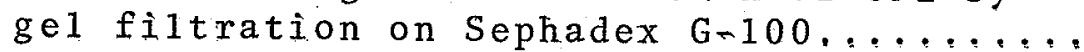


$18 \mathrm{a}$ Displacement curve of a highly purified preparation of $O P L$ in the radioreceptorassay for prolactin (RRA-PRL) using rabbit mammary gland .......................

18b Displacement curve of a highly purified preparation of $O P L$ in the radioreceptorassay for growth hormone (RRA-GH) using rabbit liver........................

Radioreceptorassay for growth hormone (RRAGH) using human 1 iver................ 76 


\section{LIST OF TABLES}

TAB LE

PAGE

I

Extraction of oPL from frozen placental

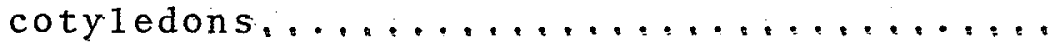

II Table of purification............ 
The placenta occupies a unique position among the endocrine glands. It is a temporary organ with a genetic constitution which is partly foreign to the mother. It thus constitutes a natural homograft which, however, for a prolonged period of time escapes immunological destruction. During this time it plays an important role in the endocrine changes of pregnancy, producing hormones with a profound metabolic influence on the mother, yet it operates with a high degree of autonomy and apparently is independent of ordinary homeostatic and regulatory mechanisms in the maternal organism. One of the best known capabilities of this highly developed, though transitory, tissue is the maintenance of foetalmaternal gradients of nutrients, gases, and metabolites which are favorable to the foetus. Less well understood,however, is the role played by the placenta as an endocine organ, and the physiological significance of placental proteins. Study of the secretions of placental tissue has been hindered by several problems which were not encountered in the classical studies of the pituitary and its target organs; For example, the method of total extirpation and replacement treatment, is denied to investigators of placental endocrinology, Nevertheless, such problems are not a prohibitive barrier to investigation; and indeed, in recent years there has been an increasing interest in this facet of reproductive physiology. 
Brief review on the early investigations of the endocrine placenta

Early events in the study of the placenta as an endocrine gland date back more than 70 years when Bouchacourt in 1902 (Bouchacourt, 1902) treated women with oral doses of "chorinine", an extract of sow placenta, in order to stimulate lactation. In 1905 Halban (Halban,1905) on the basis of clinical observations that ovariectomy did not terminate pregnancy in human, suggested that the placenta may act as an endocrine organ. Moreover, Starling (1905) found that extracts prepared from the rabbit foetus produced mammary growth when injected into virgin females. Hence both concluded that mammary development in pregnancy was controlled by a substance secreted by the placenta. Later in 1913 Aschner (Aschner, 1913) also reported that placental extracts have luteotropic effects when injected into lower animals,

Discovery of human chorionic gonadatropin (hCG)

In the two decades following the publication of Halban's view on endocrine activities of placental extracts, no significant progress in this field was made. The next important landmark in the history of the study of placental endocrinology was the announcement in 1927 by Ascheim and Zondek (Ascheim, 1927) that the urine of pregnant women 
contained a potent gonadotropin capable of producing follicular growth and luteinization in the immature mouse ovary. Subsequent studies by Evans and co-workers (Evans et a1,1933 and 1935) demonstrated that urinary gonadotropins were found in patients with embryonic neoplasia. Their findings lent important support to the concept of placental secretion of a peptide hormone.

Thus, the first placental protein hormone to be recognized and characterized to some degree was human chorionic gonadotropin (hCG). Initially in the $1930^{\prime} \mathrm{s}$, it was called "prolan". Because of its ready availability in copious quantities from urine of pregnant women, it has been studied in terms of its physiological, biological, and immunological properties, A great deal of information is available concerning hCG but its biological role in human pregnancy is yet to be defined clearly. Highly purified hCG is known to be a g1ycoprotein of $36,000-40,000 \mathrm{M} . \mathrm{W}$. con sisting of 2 subunits, alpha and beta. The 1atter is responsible for its hormone specific effects (Bah1,1972;Morgan, 1972). HCG is known to provide interstitial cell stimulating hormone (ISCH) -like activity and perhaps to have a relative$1 y$ smal1 amount of follicle stimulating (FSH)-like activity (A1bert and Derner, 1960; Channing,1970; Flint and Armstrong, 1972). This hormone is present in the maternal circulation long past the time when the ovary contributes significantly to circulating hormonal steroids. Therefore, it has been 
suggested that its role as a gonadotropin is a transitory one. The continued production of hCG beyond the point at which there is need for conceptus to stimulate the ovary to provide for optimum steroid synthesis could simply represent a vestigial function. Still to be investigated. thoroughly is the possibility of an autoregulatory, or at least an autostimulatory role, for the placenta through hCG on its important steroid synthetic function.

\section{Discovery of human placental lactogen (hPL)}

At the time that "prolan" or hCG came to the attention of peproductive physiologists in $1930^{\prime} \mathrm{s}$, Madruzza in 1927 (Madruzza, 1927) reported that when placental homografts were implanted into virgin guinea pigs lactation ensued, suggesting that placentas contain substances other than gonadotropins. Subsequent1y, studies notably by Ehrhart (1936), Coppedge and Segaloff (1951), Gemzell et al (1955), Lyons and coworkers (1955), Ito and Higashi (1961), Fukushima (1961), Kurosaki (1961), al1 described the presence of a prolactinlike and a growth hormone-like substance in placental

extracts, It was not until 1962, when Josimovich and MacLaren published their paper on human placental lactogen, also known as human chorionic sommatomammotropin (hCS), that there was renewed interest in the placenta as an endocrine organ. The discovery of hPL by Josimovich and MacLaren was based 
on the finding that the human placental extracts partially cross-reacted with hGH antiserum in a double diffusion system. There is now a large literature on hPL. Thus in this section, attempts will be made to outline the evidence of placental lactogen production in mamals generally ( selecting few animals as a representative discussion), and to assess the biological activity and possible functions of the hormone. The general term "placental lactogen " here is used to denote a protein hormone secreted by the placenta which is distinct from chorionic gonadotropin (hCG) and which exhibits some of the major effects described by Josimovich and MacLaren (1962).

Comparative assessment of placenta1 lactogen production and effects in three orders of mammals

Order Primates:

$$
\text { Human placental lactogen (hPL) }
$$

Chemistryo

Human placenta1 lactogen (hPL) or human chorionic somatomammotropin (hCS) is a single chain polypeptide with 190 amino acids, has a molecular weight of 21,500 with Noterminal valine and C-terminal phenylalanine held together by 2 disulfide bridges (Friesen,1965; Andrew,1969; Li et a1, 
1971; Sherwood et a 1,1971). Its complete amino acid sequence has been determined (Sherwood et al,1971; Nia11, ètal,1971; Li et $a 1,1971$ ) and shows a remarkable similarity to that of human growth hormone (hGH). Over $80 \%$ of the residue positions are occupied by identical amino acids in the two hormones (Sherwood et a1,1970; Lì et a1,1971; Bew1ey,1971; Nial1 et a 1, 1971) and, if acceptable replacements are also considered, the extent of the homology becomes more than $95 \%$. Marked similarities also become apparent between these hormones and the growth hormones and prolactins of ruminants (Wallis, 1971; Handwerger, 1974; Bewley and Li, 1974). On1y recent1y human prolactin has been isolated and clearly differentiated from hGH (Lewis et a 1,1971; Hwang et a1,1972) and preliminary structural studies (Niall et a1,1972) indicate that it is more closely related to ovine prolactin than to hGH, but nevertheless it is very clear that a.1 these hormones represent closely related group of molecules. The detection of internal homologies, that is repeating areas of similar sequence, within the molecules of hGH, hPL, ovine growth hormone and prolactin has 1 ed to the suggestion that these hormones evolved from a primordial peptide by gene duplication (Bewley and Li, 1974).

Biological effects

Human placental lactogen has minimal prolactin-1ike activity in the pigeon cropsac assay, about $10 \%$ the potency 
of sheep prolactin (Forsyth, 1970; Li, 1972), but a high 1eve1 of activity in stimulating the mammary gland, Various assay systems have been used, including intraductal injection of hormone into the mammary glands of pseudopregnant rabbits (Forsyth,1970) and induction of casein synthesis(Turkington, 1971) or histologically assessed secretion (Forsyth,1971) in midpregnant mouse mammary gland in vitro. In such systems hPL shows from $50-100 \%$ of the activity of sheep prolactin (Forsyth,1971; Turkington,1971; K1einberg et a1,1971). HPL is also luteotropic in mice (Kovacic,1966) and in rats (Josimovich et a 1,1963), although no steroidogenic effect of hPL on the human corpus luteum could be demonstrated when it was given together with human chorionic gonadotropin (hCG) (Stock et al,1971).

Despite the remarkable similarity of $h \mathrm{GH}$ and $\mathrm{hPL}$ in prịmary structure, the two hormones have very different growth promoting effects or potencies, Li (1972) has reported that hPL has $13 \%$ of the activity of hGH in the tibial test, while the results of other authors indicate lower activity of 1ess than 3\% (Josimovich and MacLaren, 1962; Friesen,1965), and it is generally agreed that growth promoting potency of h.PL in man is minimal (McGarry and Beck, 1972). Nevertheless, the hormone has important metabolic effects on protein, carbohydrate, and fat metabolism in various systems (Hartog, 1972):

The possible role of hPL in human is not clear, 
however, Grumbach and coworkers (Grumbach et a1,1968; Grumbach and Kaplan, 1974) have developed the hypothesis that hPL which is secreted into the maternal circulation affects the metabolism of the mother in such a way as to ensure adequate supplies of glucose, amino acids, and minerals for the developing foetus. This concept has recently received support from experiments in which hPL was given to pregnant rats, or to foetuses (Mochizuki et a1,1972). HBL given to the mother increased fetal body weight, total glycogen, and triglycerides, but has no effect when given directly to the foetus,

Thus, although the functions of hPL are not fully understood, the concept is emerging of a hormone which could be of 3-fold importance to the foetus, namely: 1) In assisting the maintenance of pregnancy by a luteotropic effect. 2) In promoting fetal growth by an effect on the metabolism of the mother. 3) In assisting the development of the mammary gland for lactation.

Immunological studies.

HPL cross r reacts immunologica11y with hGH and with monkey growth hormone (mGH) and monkey placental lactogen (mPL) (Josimovich, 1964; Frìesen,1965; Kap1an,1971; Grant et a1,1970; Shome and Friesen,1971; Vinik et a1,1973). An earlier report indicated some immunological cross-reaction between antiserum to hPL and placental extracts from a number 
of species including monkey, rat, dog, pig, horse, sheep, rabbit, and cow (Gudson et a1,1970), suggesting that there is placental lactogen in other non-primate species. However, this has not been confirmed.

An interesting novel effect of $\mathrm{hPL}$ and hCG on $1 \mathrm{ym}$ phocyte transformation in vitro has been reported recently (Contractor, 1973). HPL at concentrations similar to those found in late pregnancy caused a marked inhibition of the reaction. On the basis of this and other evidence the authors raised the possibility that hPL may play a role in blocking maternal immunological responses directed against the foetus. While this undoubtedly is an interesting hypothesis it seems unlikely that this mechanism is the sole reason for the "tolerance" of the foetus by the mother.

Secxetion-

Using immunofluorescence-1abelled antibody techniques, it has been demonstrated that hPL is secreted by the syncytiotrophoblast (Beck, 1967; Sciarra et al,1963; Beck,1970), and has been detected in 12 to 18 day old embryos (Beck,1970). Levels of hPL in the maternal circulation rise progressively until 34 to 36 weeks of pregnancy and then decline slightly (Spe11acy,1972). At term, the concentration is as high as $5 \approx 10 \mathrm{ug} / \mathrm{ml}$ in the mother, however, levels in the foetus are less than $1 \%$ of maternal values, less than $100 \mathrm{ng} / \mathrm{m} 1$ CKap1an and Grumbach, 1965I, There is virtual1y no information 
on the factors which regulate the secretion and synthesis of human placental 1actogen.

\section{Monkey Placental lactogen (mPL)}

The discovery of $\mathrm{mPL}$ was first reported by Kaplan and Grumbach in 1964 who demonstrated that monkey placenta contains a substance that cross-reacts with antiserato hGH and $h P L$. Based on this unique property of $m P L$, $m P L$ has been purified and characterized by several investigators (Shome \& Friesen, 1971; Grant et a1, 1970).

Chemistry-

Monkey placental lactogen (mPL) consists of two components, $\mathrm{mPL}-1$ and $\mathrm{mPL}-2$ of molecular weight 21,000 and 22,500 respective1y, Amino acid compositions of $\mathrm{mPL}-1$ and

mPL-2 are very similar as compared with those of hPL and hGH.

Biological effects

In 1 imited studies on the somatotropic activity of mPL (Shome and Friesen, 1971), mPL appeared to have a greater growth-promoting activity than hPL but less than pituitary growth hormone as shown in Fìgure I. MPL was also found to have a biologic potency of the same order of magnitude as hPL in the mouse vaginal mucification luteotropic assay 


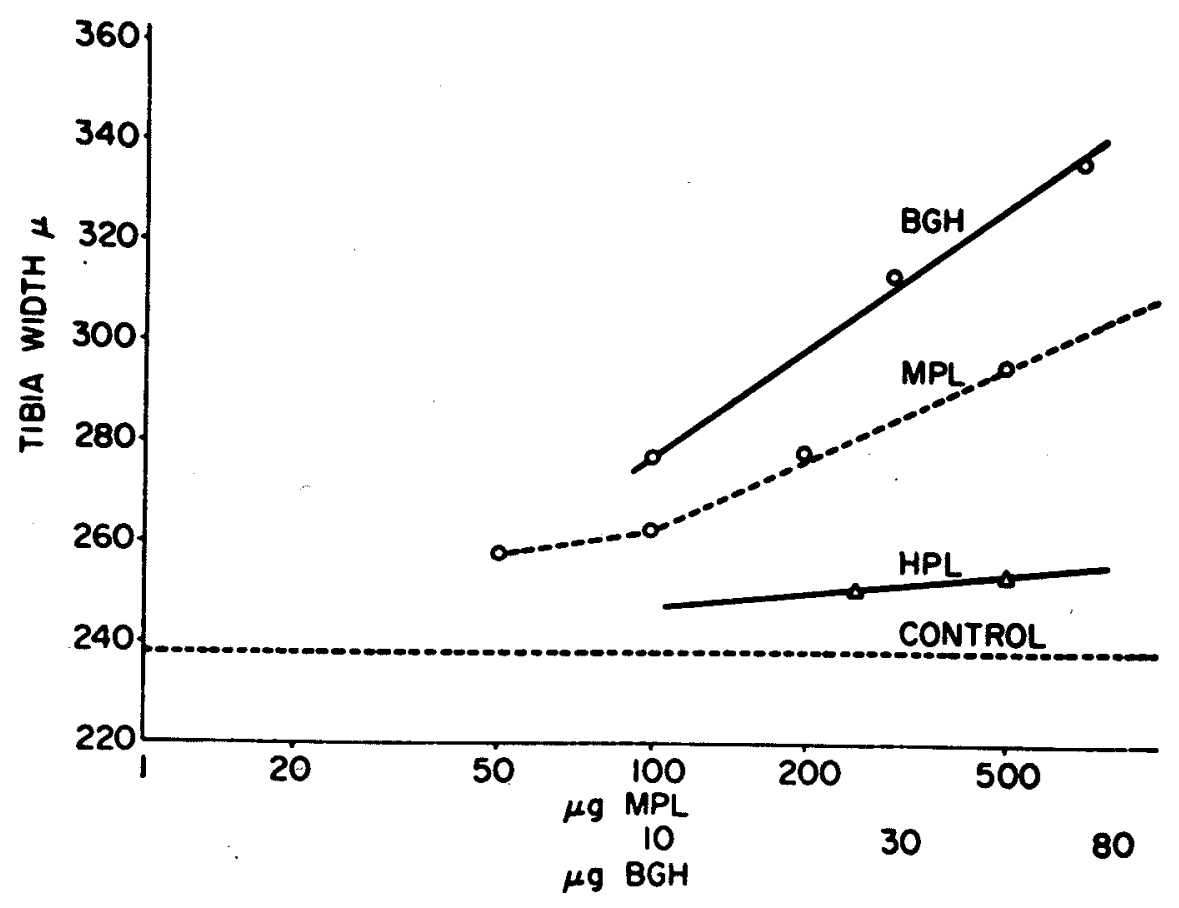

Figure 1. Epiphyseal cartilage width in hypophysectomized rats after administration of $\mathrm{bGH}, \mathrm{mPL}$ or hPL for 4 days. The daily dose administered is indicated in the abscissa which is a 2 cycle $\log$ scale. The units for $\mathrm{mPL}$ and $\mathrm{hPL}$ are 10 fold greater than for bGH. Each dose was tested in 8 rats. The horizontal interrupted 1 ine is the cartilage width of control rats receiving only saline (from Friesen et al,1971). 
(Josimovich, Wilson, and Leff, 1970).

Immunological studies

From the studies on the immunochemistry of mPL, hPL, and hGH, MPL cross-reacts to a greater extent with antisera to hGH than does hPL (Belanger et al,1971). Extracts from a11 monkey species studied cross-reacted equally using a radioimmunoassay for $\mathrm{mPL}$, However, pituitary prolactins do not cross-react in the assay system (Friesen et a1,1971).

\section{Secretion}

The synthesis of mPL has been studied by Friesen (1968), who suggested that both forms of placental lactogen were synthesized in monkey placentas.

The secretion of $\mathrm{mPL}$ and hPL proved very similar; the concentrations of placental lactogen increased throughout pregnancy to reach a mean concentration of $6 \mathrm{ug} / \mathrm{m} 1$, whereas umbilical vein mPL was 1 eșs than $100 \mathrm{ng} / \mathrm{m} 1$. After delivery, materna $1 \mathrm{mPL}$ concentration decreased rapidly with a half-time disappearance rate of $20 \mathrm{~min}$. (Belanger et a 1,1971) as compared with $1 / 21$ ife of $13 \mathrm{~min}$, for $h \mathrm{PL}$, The second $1 / 2$ ife of $\mathrm{mPL}$ is 36 hours as compared with $40 \mathrm{~min}$. for hPL (Friesen et al, 1971). The estimated production rate of $\mathrm{mPL}$ is $0.36 \mathrm{~g} / \mathrm{day}$, which is in contrast to $1.09 \mathrm{~g} / \mathrm{day}$ reported for hPL. The placental concentration of $\mathrm{mPL}$ ( ug/g dry weight) is $10 \%$ that of hPL (Kaplan and Grumbach,1971): 
Experiments of foetoectomy performed by Friesen

et a1 (1971) demonstrated that foetus did not exert any acute control over mPL secretion, but may influence the rate of placental growth and indirectly the production of mPL. Like hPL, there is virtually no information on the factors which regulate the synthesis and secretion of $\mathrm{mPL}$,

\section{Order odentia}

Some of the earliest studies indicating production of a prolactin-1ike hormone by the placenta were done in the mouse (Newton and Beck, 1939; Nandi,1959; Cerruti and Lyons, 1960; Choudary and Greenwald,1969; Komoto and Bern,1970); in rat (Pencharz and Lyons,1931; Selye, Col1ip, and Thompson, 1933; Astwood and Greep,1938; Lyons, 1944; Averi11, Ray, and Lyons, 1950; Ray, Averi11, Lyons, and Johnson,1955; Matthies, $1965,1966,1967,1971$, and 1974), in guinea pig (Pencharz and Lyons,1934; Ne1sons,1935; Amoroso and Finn,1962; Heap and Deanes1y,1966; Heap, Perry, and Rowlands,1967), and in hamster (Talamates, 1973) but in neither species has the hormone been isolated. Of these animals, rat placental lactogen (rPL) or pat chorionic mammotropin ( $r C M$ ) is the one which has been most intensively characterized by classical bioassay : Therefore, in the following discussion, I wish to confine discuss ion to rat placental lactogen, 
Rat Placental lactogen (rPL)

The ability of the rat to maintain the gravid state when hypophysectomized during the second half of pregnancy. was first demonstrated by the work of Pencharz and Lyons (1931) and Selye, Collip, and Thompson (1933). These authors described the twelfth day of pregnancy (day 12 ) as a " critical period "for hypophysectomy in this species because pituitary ablation before day 12 resulted in the termination of pregnancy. Utilizing the deciduoma reaction, Astwood and Greep (1938) demonstrated that progesterone-secreting function of the copora lutea of the pseudopregnant rat could be maintained to the seventeenth day of pseudopregnancy by injection of extracts of rat placenta from eighth to sixteenth day of pregnancy. These authors also demonstrated that deciduoma could be produced in hypophysectomized pseudopregnant rats given extracts of rat placenta as source of this activi ty. Lyons (1944) showed that rat placental extracts are capable of synergizing with ovarian steroids to induce mammary lobulo-alveolar growth and ear1y indications of lactation. Averi11, Ray, and Lyons (1950) assayed rat placental tissue at various stages of pregnancy by implantation into pregnant rats hypophysectomized on day 6. The presence of viable embryos at autopsy on day 12 was considered evidence of the luteotropic activity in the placental tissue, The stage of gestation at which placental extracts proyided the greatest 
effect was day 12, Ray, Averi11, Lyons, and Johnson(1955). demonstrated by means of assay of its various components, that the most potent luteotropic and mammotropic activity was found in the trophoblastic tissue from day 12 placenta. Desjardin and coworkers (1968) demonstrated that removal of the foetus plus foetal placentae on day 12 or 16 of pregnancy reduced the weight of mammary glands to control, nonpregnant levels by day 21 . Removal of the foetus alone on day 16 had no significant effect on mammary weight, DNA, or RNA content on day 21. While removal of the foetus on day 12 did depress al1 these parameters to some extent, considerable mammary development had nevertheless occurred between days 12 and 21. Moreover; the DNA and RNA content of the mammary gland were 30 and $40 \%$ lower, respectively, in pseudopregnant as compared with pregnant rats on day 12 . The placenta, therefore, appears to make some hormonal contribution to mammary development before mid-pregnancy and to provide the major stimulus in the second half of pregnancy, Similarly, Matthies $(1965,1966,1967,1971)$ demonstrated the presence of 1uteotropic and mammotropic factors in foetal placental and materna1 serum of day 12 pregnant rats hypophysectomized and ovariectomized on day 5, Ovarian interstitial tissue, adrenal cortex, and thyroid were reported to be unresponsive to the infection of placental extracts.

Placental involvement in extrauterine weight gain in pregnant rats is also suspected, The nature of the weight 
gain is not fully understood, but water retention is involved (Brooksby and Newtons, 1938; Dewar, 1957), In mice, body weight is unaffected by hypophysectomy at mid-pregnancy (Newton and Beck,1939) and by the destruction of foetuses, but weight loss occurs when placentae are delivered (Brooksby and Newton, 1938), Progesterone maintains body weight in ovariectomized, hysterectomized, pregnant females and, in non-pregnant mice, mimics the weight increase of pregnancy. Thus, progesterone secretion, maintained by the luteotropic effects of placental lactogen, is probably largely responsible for the increased body weight of pregnant mice (Dewars, 1957).

Matthies in 1967 reported that rat placental extracts have minimal effect in pigeon crop-sac bioassay, and showed no growth-promoting activity using tibial epiphyseal cartilage-width bioassay. At the moment, it is difficult to implicate rat placental lactogen as the hormone that mediates the metabolic change occuring in the rat during pregnancy.During pregnancy, there is a decreased carbohydrate tolerance with lack of insulin sensitivity (Knopp et a1,1970), despite increased circulating concentrations of insulin. (Herrera et a 1, 1969) which progresses as pregnancy advances. Thus, rat placental lactogen might mediate some of the metabolic changes of pregnancy:

The data provided by the investigators cited above indicates that the rat placental hormone possesses luteotropic and mammotropic acivities and is present in trophoblastic 
elements of the midpregnant rat placenta and in maternal peripheral blood, The highest concentration of this hormone in maternal serum occurs on the 12 th day, and was thought not to be present thereafter, as judged by the relatively crude bioassay method used. However, following the demonstration of rat placental lactogen using radioreceptorassay method ( see section on NEW DATA ON NON-PRIMATE PLACENTAL LACTOGENS ) Matthies now has confirmed using classical bioassays that rat placental lactogen is found in serum of day 19 pregnant rats,

\section{Order Artiodacty 1 a}

This order is divided into three suborders, the Suiformes, the Tylopoda, and the Ruminantia. Hypophysectomy during pregnancy and corculture experiments have demonstrated that a placental lactogen is secreted by four species in the last suborders, the goat (Cowie et al,1963; Cowie and Tindal, 1271; Butt1e et a1,1272; Forsyth,1972; Forsyth and Butt1e, 1972; Forsyth,1974), cow (Forsyth and Buttle,1972), sheep (Denamur and Martinet,1961; Cowie et a1,1963; Forsyth,1974), and the deer (Forsyth, 1974). Of these animals, only goat placental lactogen is the one which has been most intensively studied and characterized by the classical endocrine methods, and therefore, in the following discussion $I$ will limit it 
to goat placental lactogen.

\section{Goat placenta1 lactogen $\backslash$ (cPE)}

The integrity of the pituitary is essential for the maintenance of pregnancy in some species but not in others. We can place the goat in the former category and the sheep in the latter. In 1963, Cowie and coworkers reported that hypophysectomy: pregnant goats causes abortion at any stage of pregnancy, Ovariectomy at any stage of pregnancy also causes abortion in the goat (Drummond et a 1,1962; Meites et a 1,1951). However, pregnancy after ovariectomy can be maintained in the goat by progesterone administration (Meites et a 1,1951$)$. It is probabletherefore that abortion occurs after hypophysectomy and pituitary stalk section because these operations result in an acute deficiency of luteotropic hormones, which in turn leads to dysfunction of the luteal tissue and a 1ack of progesterone (Cowie et a1,1963). The growth and differentiation of the mammary gland during pregnancy is a response to the action of mamy hormones (Cowie and Tinda1, 1971), one of which is prolactin. This hormone has been considered to exert a major influence as a mammotropin, However, Butt1ë et a1 (1972) and Forsyth(1972) reported that when goat plasmasamples taken during pregnancy were examined for prolactin by a radioimmunoassay and for total lactogenic activity by a rabbit mamary gland organ 
culture assay, high levels of lactogenic activity were detected in the second and last third of pregnancy when the concentration of immunoreactive pituitary prolactin was low or event absent. Thus, this discrepancy in the results of the two assays suggested that the blood of pregnant goats contains a second lactogen of placental origin which does not crossreact immunologically with pituitary prolactin.

Co-culture experiments (Forsyth,1972) demonstrated that this material is secreted by foetal cotyledons, and could be detected in the maternal circulation from the 9 th week ( 64 th day) of gestation until term, However, it is not clear which cells of the placental cotyledons are secreting placental lactogen and also it is not clear at what stage of pregnancy this hormone is first secreted.

As judged by gel filtration experiments, the molecular weight of goat placental lactogen is estimated to be 20,000 (Forsyth and Myers, 1971), which is close to the molecular weight of hPL and mPL. It shows no significant crossreaction with ovine prolactin (Buttle, Forsyth, and Knaggs, 1972). Apart from its ability to stimulate secretion by mouse and rabit mammary gland in vitro, little else is yet known of the properties of goat placental lactogen.

The physiological roles of goat placental lactogen during pregnancy are unknown. However, Cowie (1970) has shown that there is a rapid growth of lobulo-alveolar tissue in the mammary glands of goats between the 70 th and 100 th 
days of pregnancy, so the appearance of this second lactogen coincides with the period of intensive lobulo-aiveolar deve1opment. The latter can be produced in non-pregnant goats by inducing prolactin release by repeated application of the milk stimulus (Cowie, Knaggs, Tindal \& Turvey, 1968), but the maximum development obtained did not approach that occuring in pregnancy, Similarly, some mammogenesis can be obtained in ovariectomized and hypophysectomized goats by the injection of hexoesterol, progesterone, corticotropin, growth hormone and prolactin (Cowie, Tindal G Yokoyamo,1966), but agân the lobulona veolar development did not approach that occuring in pregnancy. Furthermore, the concentration of prolactin (RIA) throughout gestation was low and thus prolactin would not appear to be the major mamotropic hormone responsible for the development of the mamme during pregnan cy. Therefore, the high levels of placental lactogen may largely be responsible for lobulo-alveolar growth in goats. 
SECTION II NEW DATA ON NON PRTMATE PLACENTAL LACTOGENS

Brief introduction of a new assay system radioreceptorassay (RRA).

Until recently, only human and monkey placental lactogen (hPL and mPL) were fairly well defined. Because of the ethical problems of performing experiments on placental lactogen in humans, the identification and characterization of placental lactogens in non-primates is a subject of very active investigation. A great impetus to this research both in our laboratory as we 11 as others has been the development of two radioreceptorassays in the past two years. The one measuring prolactin or lactogen (RRAmPRL) utilizes a rabbit mammary gland receptor (Shiu et a1,1973) while the one for growth hormone-1ike activity employs a rabbit liver receptor (Tsushima \& Friesen, 1973).

The development of receptor assays for peptide hor mones are based on the principle that in order for a hormone (peptide or protein) to exert its biological effects binding of that hormone to its target cell is necessary (Roth, 1973). Thus, specific target ce11 membranes were isolated from animal tissues and used to assay for specific hormones. The advantages of these assays are that they are relatively simple to perform, quite sensitive ( $10 \mathrm{ng} / \mathrm{ml}$ without serum, $50 \mathrm{ng} / \mathrm{ml}$ for serum samples ), and most important1y, they are 
not species specific. The radioreceptorassays (RRA's) can be used to measure placental lactogens derived from many species. Whereas the conventional radioimmunoassay (RIA) is generally species specific, hence RIA has more limited applications. of course, in any determination the RRA can not distinguish pituitary prolactin (PRL) from placental lactogen or pituitary growth hormone (GH) from placental lactogen (PL). Fortunately, however in most species, serum levels of pituitary prolactin or growth hormone during pregnancy are 1 ow as compared to $\mathrm{PL}$ levels. To determine the exact contribution of the pituitary hormone level to total activity it is necessary to employ a specific radioimmunoassay. The difference between total RRA and pituitary hormone (RIA) concentration represents serum concentration of placental lactogen.

Thus, by employing these two novel radioreceptorassays (RRA's), several new placental lactogens have been detected in the past two years (Shiu et a1,1973; Ke11y et al, 1974 a and b; Robertson \& Friesen,1974; Fellows et a1,1974; Handwerger et $a 1,1974)$, In our laboratory, we have identified and quantitated placental lactogen concentrations in the circulation of human, monkey, rat, mice, hamster, guinea pig, cow, goat, and sheep using these assays. However, because rat and sheep placental lactogens have been most intensively characterized by the radioreceptorassays, I wish to restrict my discussion to these two hormones only. 


\section{Rat Placental Lactogen (rPL)}

Chemistryo

Upon purification (Robertson and Friesen,1974), it is found that the molecular weight of rat placental lactogen ( $r P L)$ is approximately 18,000 as determined by ge1 filtration on Sephadex G-100, and 22,000 as determined by electrophoresis sodium dodecyl sulfate (SDS)-acrylamide gels. The isoelectric point of rat placental lactogen is between $\mathrm{pH} 6.5$ and $\mathrm{pH} 7.0$ as determined by isoelectric focusing. Amino acid composition and chemical structure are not known.

Physiology=

Employing radioreceptorassay for prolactin(RRA-PRL), Robertson and Friesen (1974) demonstrated that purified $r P L$ is $41 \%$ as active as ovine prolactin standard (NIH-S-P-10, $25 \mathrm{IU} / \mathrm{mgl}$ but $169 \%$ as active as a human placental 1actogen preparation. In the radioreceptorassay for growth hormone (RRA-GH), purified rat placental lactogen has minimal growth promoting potency as compared with bovine growth hormone,

Secretion

With the receptor assay for prolactin (Shiu et al, 1973), it has been possible to accurately measure serum concentrations of $r P L$ throughout pregnancy. In contrast to the reports of seyeral investigators demonstrating that rat 
chorionic mammotropic activity ( $\mathrm{CCM}$ ) or rat placental lactogen ( $r P L)$ was maximal in serum and in placental extracts at day 12 of gestation using classical bioassay techniques (Astwood and Greep,1938; Matthies, 1974), two peaks of rPL were observed during pregnancy: The highest concentration of rPL occurs on day 12 , reaching a mean level of $1584 \pm 632 \mathrm{ng} / \mathrm{ml}$ (ovine prolactin used as standard), and by day 14 has decined to $180 \pm 24 \mathrm{ng} / \mathrm{ml}$ (Shiu et al, 1973). Further characterization of this secondary peak-activity using gel filtration on Sephadex G-100 (Kel1y et ä1,1973), demonstrated that the molecular weight of $\mathrm{rPL}$ in serum at day 20 was approximately 100,000 M.W. (void volume) and $18,000 \mathrm{M}$, W.. Measurement of prolactin and growth hormone activity by 2 RRA's respectively showed that the material in the void volume $(100,000$ M.W. $)$ is mainly growth hormone-1ike by RRA-GH with very little prolactin-1ike activity by RRA-PRL, In contrast, the 18,000 M.W. material is largely prolactin-like with very little growth hormone-1ike activity by 2 RRAs, Further, the half-time disappearance rates of rPL from day 12 and 19 were also different. RPL from serum at day 19 was rapid (1.2 min.) compared to day 12 ( $19.5 \mathrm{~min}$ ): Although $r$ PL has not been detected in any previous studies at days $17=20$, the positive existence of such a hormone was suggested by studies of Freinkel and colleagues (Knopp et al, 1970), who observed that rats in late pregnancy exhibited insulin resistance and hyperinsulinemia, Whether rPL detected by RRA's is the hormone mediating these changes remains to 
to be proven.

The situation is even more complicated. When rat serum samples during pregnancy are also measured by the radioreceptorassay for growth hormone (RRA-GH) (Ke11y et a1,1974b), on day 12 , the serum $\mathrm{rPL}$ has a ratio of prolactin to growth hormone-1ike activity of $13: 1$, whereas on day 18 the ratio of $\mathrm{PRL} / \mathrm{GH}$ changes to $1: 1$. When placentas were extracted from these two days separate1y,. the ratios of PRL/GH were found to be $110: 1$ and $45: 1$, respectively. Thus, it appears that two possible humoral factors might account for the metabolic changes observed in late pregnancy. However, the possibility of interferrence caused by serum proteins in the radioreceptorassays leading to spurious results cannot be eliminated. Nevertheless, the appearance of double peaks (day 12 and day prior to parturition) of rPL during pregnancy is strikingly different from the secretion pattern of $h P L$ and $m P L$ in human and monkey, respectively. Whether each peak has a different physiological role remains to be defined:

\section{Sheep Placental Lactogen (OPL)}

Chemical, Immunological, and Biological Studies -

Upon gel filtration on Sephadex G-100, the molecular weight of oPL appears to be approximately 22,000 (Ke11y et a1, 1973; Fel1ows et a1,1974; Kel1y et a1;1974a; Chan et a1,1975). 
When tested against oPL antiserum, Fellows and coworkers(1974) reported that partially purified oPL shows partial identity to ovine growth hormone (oGH) but there is no cross-reaction with hPL, hPRL, hGH, or ovine prolactin by ouchterlony diffusion techniques, However, in our laboratory we could not reproduce these results: Handwerger and coworkers (1974) a1so reported that their partially purified oPL preparation is a potent lactogen which stimulates lactation in vivo in the rabbit intraductal assay and casein synthesis in vitro in mouse mammary gland explants, In the radioreceptorassay for prolactin, oPL displaced the ${ }^{125} \mathrm{I}=\mathrm{hGH}$ tracer in a parallel fashion: However, oPL has on 1 y $1 / 6$ as much growth hormone binding activity as prolactin binding activity.

Secretion-

Ovine placental lactogen can be detected in in 1 sma samples using radioreceptorassays for prolactin (Kelly et a1, 1973). By day 60 of gestation and thereafter placental lactogen concentrations increase as pregnancy advances, reaching peak concentrations of 1,000 to $2,000 \mathrm{ng} / \mathrm{m} 1$. on days 95 to 114 of gestation. After the initial peak there is generally a decline in placental lactogen concentration followed by. another peak before parturition, oPL concentrations slowly declined from approximately $1,000 \mathrm{ng} / \mathrm{ml}$ to $500=700 \mathrm{ng} / \mathrm{ml}$. by 12 hours before parturition; they then decreased quite rapidy post-partum. The relative half-time rate of disappea= 
rance of oPL as estimated by ligation of uterine vesse1s on day 140 of pregnancy appears to be less than 20 min.. When both the foetal and maternal cotyledons were extracted in 0.1 M ammonium bicarbonate, the concentration of oPL in extracts was $200 \mathrm{ug}$ per gram wet weight of tissue which is similar to the concentration öf hPL in human placental ex tracts (Friesen, 1965),

By resasaying the serum samples during pregnancy with radioreceptorassay for growth hormone (RRA-GH), Kel1y and cowworker (1974b) reported an interesting observation that the serum concentration of growth hormone-like activity is much lower than prolactin-like activity, the ratio of PRL/GH activity is approximately 3 , or $5: 1$, whereas in placental extracts, the ratio of $\mathrm{PRL} / \mathrm{GH}$ activity is about $1: 1$. With the different ratios of prolactin-like to growth hormonelike activities in serum and in placental extracts in this species, in which the corresponding pituitary growth hormone and prolactin activities do not overlapin the RRA's, the possibility that the placenta secretes two hormones must be considered. However, as shown in the subsequent studies to be reported later, purified opL has ese to activities, namely the somatotropic and lactogenic effects: 
SECTTON TII OBSECTTVES OF THE PRESENT INVESTIGATION

The objectives of this investigation were two fold: (1) to purify and characterize sheep placental lactogen(oPL), and (2) to examine some biological effects of ovine placental lactogen.

This investigation describes:

(a) a procedure for the purification of ovine placental lactogen from sheep placental cotyledons in sufficient quantity and sufficient purity for chemical and biological studies, thus firmly establishing the existence of this hormone in sheep, and

(b) comparing the growth promoting effect of ovine placental lactogen, human placental lactogen, and human pituitary growth hormone in receptor assays. 
SECTION IV: METHODS OF PURTFICATION AND CHARACTERIZATION

MATERIALS AND METHODS

Assays for monitoring hormonal activities - Radioreceptor assays for prolactin or lactogen (RRA-PRL) and for growth hormone (RRA-GH).

Radioreceptorassays for measuring prolactin or lactogen utilized rabbit mammary gland receptors as described by Shiu et al (1973) while the one for measuring growth hormone..or growth hormone-1ike activity employed rabbit liver receptors (Tsushima and Friesen,1973) with slight modification.

1. Method of isolation of specific receptors:

Mammary tissue for RRA-PRL or liver for RRA-GH obtained from mid or late pregnant rabbits was cut into small fragments before being homogenized in 5 volumes of $0.3 \mathrm{M}$ sucrose solution. Homogenization was carried out at $4 \mathrm{C}$ using Polytron PT-10 (Brinkmann) for one minute with the dial set at 7 . The homogenate was filtered twice, first with 4 layers and then through 8 layers of cheesecloth. The filtrate was centrifuged at $780 \times \mathrm{g}$ for $20 \mathrm{~min}$, at $4 \mathrm{C}$, the supernatant was centrifuged at $15,000 \mathrm{~g}$ for $20 \mathrm{~min}$, and the pellet was discarded. The supernatant was again centrifuged at $100,000 \mathrm{~g}$ for 90 min, to obtain the total microsomal pellet which contains most of the broken cell membranes, of the total 
binding activity, $70-80 \%$ was recovered in this fraction, The microsomal pellet was suspended in $0,025 \mathrm{M}$ Tris $-\mathrm{HC} 1, \mathrm{pH} 7.6$ containing $10 \mathrm{mM} \mathrm{CaCl}_{2}$, and kept frozen at $-20 \mathrm{C}$. When required for assay the frozen receptor was thawed, homogenized in a glass homogenizer with $10 \mathrm{mM} \mathrm{CaCl}_{2}$ such that the protein concentration in $0.1 \mathrm{~m} 1$ volume of the suspension contained 100 to $200 \mathrm{ug}$ of protein as determined by the Lowry procedure (Lowry et a1,1951). Membrane suspensions prepared from one rabbit mammary tissue (about 100 grams) will provide sufficient material for as many as 1,000 determinations, whereas 100 grams of liver tissue provides sufficient receptors for $6,000 \mathrm{GH}$ assays,

2. Iodination procedure for hormone preparations ( ovine prolactin (OPRL, NIH-S-P-10) for RRA-PRL and human growth hormone ( hGH, NIH-HS 1648E) for RRA-GH) :

${ }^{125} \mathrm{ImoPRL}$ or ${ }^{125} \mathrm{~T}$ hGH was prepared by the 1actopero xidase method of Thore11 and Johannson (1971), using $1 \mathrm{mCi}$ of $\mathrm{Na}^{125} \mathrm{I}$ (New England Nuclear), 5 ug of oPRL orihgH, 4 ug of lactoperoxidase, 2 ul of $30 \%$ hydrogen peroxide at $1: 1500$ dilution, and 25 u 1 of $0.05 \mathrm{M}$ phosphate buffer, $\mathrm{pH} 7.4$ in a final volume of $106 \mathrm{ul}$.. At the end of one minute chemical reaction time, 1 to $2 \mathrm{ml}$. of $0.025 \mathrm{M}$ Tris-HC1, $\mathrm{pH} 7.6$ was added immediately to the reaction tube after 10 ul of the reaction mixture was taken out for specific activity determination, Unreacted iodide and damaged hormone were separated from intact iodinated hormone by gel filtration on Sephadex G-100 
column ( $1.5 \times 50 \mathrm{~cm})$ using $0.025 \mathrm{M}$ Tris-HC1, pH 7.6 as eluting buffer. The Sephadex G-100 column was pre-treated at once with $1-2 \mathrm{ml}$ of $0,025 \mathrm{M}$ Tris-HCl, $\mathrm{pH} 7.6$ containing $2.5 \%$ bovine serum albumin (BSA) in $w / v$ in order to minimize the loss of iodinated proteins.

In order to determine the specific activity of iodin ated hormone, 10 ul of the reaction mixture was removed and diluted with $1 \mathrm{ml}$, of Tris-HCl buffer, $\mathrm{pH} 7.6$ containing no BSA, Then $0.1 \mathrm{mI}$ of $0.01 \mathrm{M}$ phosphate buffered saline, pH 7.4 containing $2.5 \% \mathrm{BSA}$ and $2 \mathrm{mI}$ of $10 \%$ trichloroacetic acid (TCA) solution were added consecutively to $0.1 \mathrm{ml}$ of the diluted reaction mixture. After 3 hours of incubation at $4 \mathrm{C}$, the total radioactivity of the mixture was determined and then the tube was centrifuged at $780 \mathrm{~g}$ for $20 \mathrm{~min}$. The supernatant was decanted and the precipitate was counted in the LKB autogamma counter. The incorporation of radioactivity into protein is expressed as the TCA precipitable radioactivity over the precount of the TCA reaction mixture as a percentage. The specific activity of the iodinated hormone is defined as the total precipitable counts divided by the amount of protein used for iodination ( $5 \mathrm{ug}$ ). The percentage of incorporation of radioactivity into oPRL or hGH was approximately $55-65 \%$, and its specific activity was $110=130 \mathrm{uCi} / \mathrm{ug}$ of protein.

3. Incubation procedure:

A11 dilutions were made with $0,025 \mathrm{M}$ Tris-HCi buffer, $\mathrm{pH} 7,6$ containing $0,1 \% \mathrm{BSA}$ and $10 \mathrm{mM} \mathrm{CaC1}{ }_{2}$, The assays were 
carried out in glass tubes $(12 \times 75 \mathrm{~cm})$ containing $200 \mathrm{ul}$ of diluent, 100 ul of hormone standard (oPRL or hGH), or 100 ul of known or unknown sample, and $100 \mathrm{ul}$ of ${ }^{125} \mathrm{I-oPRL}$ (approximately $100,000 \mathrm{cpm}$ ) or ${ }^{125} \mathrm{I}-\mathrm{hGH}$ (approximately 80,000 cpm). During the 6 hours incubation period for the lactogenic assay and or 3 hours for growth hormone at room temperature, the tubes were shaken vigoreously for 30 seconds every 30 min. The reaction was terminated by the addition of $3 \mathrm{ml}$ of icecold $0.025 \mathrm{M}$ Tris-HC1 buffer, $\mathrm{pH} 7.6$ containing $0.1 \%$ BSA for Iactogenic assay or $0.025 \mathrm{M}$ sodium acetate buffer, $\mathrm{pH} 5.4$ containing $0.1 \%$ BSA for growth hormone assay. Under these conditions, the hormonal receptors were sedimented by centrifugation at $780 \mathrm{~g}$ for $20 \mathrm{~min}$, at $4 \mathrm{C}$. The supernatant was decanted and the membrane bound ${ }^{125} \mathrm{I} \rightarrow \mathrm{OPRL}$ or ${ }^{125} \mathrm{I}-\mathrm{hGH}$ in the precipitate was counted in the LKB autogamma counter.

\section{Starting materials}

Two possible sources of raw material for ovine placenta1 lactogen purification have been examined: (1) sheep placental cotyledons removed at the time of surgery were kindly provided by Dr, H, Robertson, Reproductive Physiology, Animal Research Institute, Ottawa, Canada, and Dr. V Chernick, Faculty of Medicine, Dept, of Pediatrics, University of Man., Winnipeg, Canada. These tissues were immediately frozen and stored at $\rightarrow 20 \mathrm{C}$ with or without separating maternal and foetal cotyledons, (2) Sheep placental cotyledons (foeta1) 
obtained within 1 or 2 hours after parturition were stored frozen at $=20 \mathrm{C}$. These tissues were kindly provided by Dr. H. Robertson, Reproductive Physiology, Animal Research Institute, Ottawa, Canada; and Dr. N.E. Stanger, Faculty of Agriculture, Dept. of Animal Science, University of Manitoba, Winnipeg, Canada.

\section{Hormone preparations}

Fuman growth hormone (NIH-HS 1648E), ovine prolactin (NIH-PaS-10), bovine growth hormone (NIH-BG B1003A), and al1 other hormone preparations were kindly süpplied by the Endocrine Study Section of the National Institutes of Health, U, S,A ,

\section{Protein measurement}

Protein concentrations of the fractions collected during purification were estimated by measuring the absorbance at $278 \mathrm{nin}$, making the assumption that one unit of absorbance was equivalent to protein concentration of $1 \mathrm{mg} / \mathrm{ml}$. For more accurate determinations, the protein content of the original crude extract and of the pools containing oPL at different stages of purification were estimated by the method of Lowry (Lowry et a1,1951) using bovine serum albumin (BSA) as standard, The final purified product was weighed after lyophilization, and its protein content per unit weight was determined by spectrofluorometer (Aminco-Bowman), using ovine prolactin 
(NIH-P-S-10) as standard; excitation was at $278 \mathrm{~nm}$ and emission at $350 \mathrm{~nm}$.

Concentration of volume by u1trafiltration

A11 concentration procedures were carried out at 4 C in an Amicon Diaflo cell of various capacity $(10,60$, 450 , and $2,000 \mathrm{~m} 1 \ldots)$. The size of ce11 used depended on the initial volume required to concentrate and the final volume which was desired, UM-10 membrane filters were used in all concentration steps.

Purification procedures

A11 steps were carried out at 4 C unless otherwise specified.

1. Extraction-

Placental tissues which wereobtained at the time of surgery were immediately frozen at -20 C without separating maternal and foetal cotyledons. At the time of extraction, 1.2 kilograms of placental cotyledons ( 56-65 days gestation) were homogenized with a Polytron PT-10 (Brinkmann) homogenizer at maximum speed for 30-60 seconds in $0.1 \mathrm{M}$ ammonium bicarbon ate solution, adjusted to $\mathrm{pH} 9.5$ with $1 \mathrm{~N}$ ammonium hydroxide, using a ratio of buffer to tissue of $5: 1(\mathrm{v} / \mathrm{w})$. The homgenate was stirred overnight and then centrifaged at $30,000 \mathrm{~g}$ for 30 minutes. The pel1et was discarded. 
2. Ammonium sulfate precipitation-

To the supernatant was added slowly ammonium sulfate

to a final concentration of $40 \%$ saturated solution. After allowing the precipitate to settle overnight, the mixture was centrifuged at $30,000 \mathrm{~g}$ for $20 \mathrm{~min}$, the precipitate was discarded. To the supernatant was added slowly additional ammonium sulfate to achieve a $75 \%$ saturated solution, After stirring the solution for an hour, the precipitate was allowed to settle overnight and subsequently collected by centrifugation.

3. Dialysis

The precipiate was dissolved with $0.1 \mathrm{M}$ ammonium bicarbonate solution (a11 precipitate dissolved at this time) and dialyzed against running tap water for 48 hours, then dialyzed against distilled water for 48 hours. After dialysis, the solution. was centrifuged at $100,000 \mathrm{~g}$ for $90 \mathrm{~min}$ to remove visibie particles.

4. Diethylaminoethy1 (DEAE) anion exchange chromatography-

To the supernatant, solid ammonium bicarbonate was added to make a $0.05 \mathrm{M}$ solution, $\mathrm{pH} 7.8$. The $0.05 \mathrm{M}$ supernatant was applied to a column $(40 \times 60 \mathrm{~cm})$ of diethylaminoethyl cellulose. (Whatman DE-32) previously equilibrated with $0.05 \mathrm{M}$ ammonium bicarbonate, $\mathrm{pH}$ 7.8. After the column was washed with an addtional volume ( 5 liters ) of starting buffer, the concentration of ammonium bicarbonate was increased stepwise from 0.05 to 0.1 , and $0.2 \mathrm{M}$, Final1y, the column was washed 
with $0.5 \mathrm{M} \mathrm{NaCl}$ in $0.2 \mathrm{M}$ bicarbonate buffer. The active fractions were collected, pooled, and concentrated to $50 \mathrm{~m} 1$ by ultrafiltration using $U M=10$ membrane.

5. Ge1 filtration-

The concentrated material was applied to a sephadex G-100 (Pharmacia, Uppsala, Sweden) column $(4.2 \times 104 \mathrm{~cm}$ ) which was equilibrated with $0.01 \mathrm{M}$ ammonium acetate,pH5.0. Fractions ( $10 \mathrm{~m} 1 /$ fraction) were collected in a LKB fraction collector. 6. Carboxymethy focliulose: (CMC) cation exchange chromatography-

Appropriate fractions from Sephadex G-100 column were pooled and applied to a column $(1.8 \times 18 \mathrm{~cm})$ of carboxymethyl-cellulose (Whatman $\mathrm{CM}-2 \hat{3}$ ) which was also equilibrated with $0.01 \mathrm{M}$ ammonium acetate buffer, $\mathrm{pH}$ 5.0. After washing the column with $300 \mathrm{~m} 1$ of starting buffer, a stepwise elution with $\mathrm{NaCl}$ at $0.01,0.05,0.1,0.15$, and $0.2 \mathrm{M}$ was carried out in the presence of $0.01 \mathrm{M}$ ammonium acetate, $\mathrm{pH} 5.0$. The column was finally eluted with $0.5 \mathrm{M} \mathrm{NaCl}$. The fractions containing oPL were pooled and then concentrated to a volume of $3 \mathrm{ml}$. 7. Ge1 filtration-

Final1y, the concentrated material was applied to a Sephadex G-100 column (1.4 X $94 \mathrm{~cm})$ which was equilibrated with $0,1 \mathrm{M}$ ammonium bicarbonate, $\mathrm{pH} 8,7$. The active fractions were pooled, concentrated to a volume of $1,5 \mathrm{ml}$, and then 1 yophilized, 


\section{Characterization procedures}

1. Chemica 1:

(a) Analytical gel electrophoresise

Polyacrylamide gel electrophoresis was carried out as described by Davis (1964) and Reisfeld et al (1962) with slight modification. In alkaline acrylamide gel electrophoresis, a 7.2\% acrylamide and $\mathrm{pH} 8.8-9.0$ were used, whereas under acidic condition;, 9.0\% acrylamide and pH 4.3-4.5 were used, In both conditions, duplicate samples were run-one gel was stained with dye while the other was cut serially and the individual segments were eluted in 1 to $2 \mathrm{~m} 1$ of $0.1 \mathrm{M}$ Tris-HC1, pH 7.6 containing $0.1 \%$. BSA at 4 C for 24 hours with shaking (Fisher Rotator). The eluants subsequently were analyzed by the two radioreceptorassays. For the alkaline polyacrylamide gel, the staining was performed by placing the ge 1 in $1 \%$ Amido B1ack dye (in 7\% acetic acid) for 1 or 2 hours. The stained gel was removed from the staining solution and placed in a test tube with $7 \%$ acetic acid to destain until distinct bands were seen. For the acid gel polyacrylamide gel, the same procedure was employed except 1\% Basic Fuchsin dye was used instead of Amido Black.

(b) Analytical gel isoelectrichocusing electrophoresis Analytical thin layer polyacrylamide gel isoelectric 
focusing was performed using a LKB 2117 multiphor apparatus. Focusing was achieved using a pH range 3.5 to 9.5 with a $6 \%(w / v)$ concentration of acrylamide and a cross-1inking of $2.5 \%$. In the final preparation of purified oPL, duplicate samples were run, one gel was stained with $0.1 \%$ Coomassie Brillant Blue R-250 containing $3.26 \%$ sulphosalicylic acid and $10.86 \%$ of trichloroacetic acid (TCA), while the other was cut serial1y and the individual segments were eluted in 1 to $2 \mathrm{ml}$, of $0,1 \mathrm{M}$ Tris $\mathrm{HCl}, \mathrm{pH} 7.6$ containing $0.1 \%$ BSA (w/v) for 24 hours at $4 \mathrm{C}$. Subsequent $1 \mathrm{y}$ the eluants were analyzed by the 2 RRA's:

The staining procedure was carried out at $22 \mathrm{C}$ for 2-3 hours, and then destained for $36-48$ hours in a solution containing water, ethano 1 , and acetic acid in a ratio of $8: 3: 1$ respective1y.

One additional blank gel run at the same time was divided serially and the individual segments were eluted with distilled water for 24 hours at $4 \mathrm{C}$ with shaking (Fisher Rotator). The pH of the eluant was determined by pH electrode (Fìsher, Acumet, Mode1 420).

(c) Preparative isoelectrichocusing =

The technique used was essentially that recommended in the 8100 Ampholine instruction manual. Separations were obtained using an isoelectriéfocusing column of $110 \mathrm{~m} 1$ capacity (LKB Ins, Broma, Sweden) and carrier ampholytes in the 
range of $\mathrm{pH} 3,5$ - 10 obtained from the same source, Gradients were routinely run with the cathode in the upper electrode position. Gradients were prepared in an LKB 8121 gradient mixer and loaded at $1-2 \mathrm{~m} 1$ per minute with a peristaltic pump (LKB, 12000 Broma, Sweden). Electrofocusing was allowed to proceed until a constant current was achieved $(20-24$ hours).; The gradient was displaced by the addition of water to the top of the column and $2 \mathrm{ml}$ fractions were collected with the flow rate of $2 \mathrm{~m} 1 / \mathrm{min}$. . Protein concentrations were monitored by absorbance at $278 \mathrm{~nm}$, pH of the fractions were measured by $\mathrm{pH}$ electrode (Fisher, Accomet, Model 420), and the oPL activity was determined by the 2 RRA's.

(d) Molecular weight estimation-

The molecular weight of oPL was estimated by ge1 filtration on a Sephadex G-100 column $(2.5 \times 75 \mathrm{~cm})$. The column was equilibrated at room temperature with $0.01 \mathrm{M}$ Tris HC1 containing $0.1 \% \mathrm{BSA}$ and $0,1 \mathrm{M} \mathrm{NaC1}$ at $\mathrm{pH} 7,6$ and was calibrated with ${ }^{125} \mathrm{~T}-\mathrm{hGH}$ as a marker protein. The hGH was labelled with ${ }^{125} \mathrm{I}$ using the enzymatic method described by Thore11 and Johannson (1971).

\section{Immunological:}

(1) Immunization procedures:

Anti-sera to oPL were raised in New Zealand white rabbits (female, $2-3 \mathrm{~kg}$ ) obtained from Canadian Breeding 
Farm \& Laboratory, Canada, using Freund 's complete adjuvant, Four rabbits were injected subcutaneously once a week for the first 3 weeks with $200 \mathrm{ug}$ of oPL each in $0.5 \mathrm{ml}$ of $0.1 \mathrm{M}$ ammonium bicarbonate mixed with an equal volume of complete Freund"s adjuvant. Thereafter, the animals were injected at 3 week intervals with 50 ug of oPL per anima1. The animals : were bled after the third injection and the serum was tested for antibodies to oPL.

(2) Todination of oPL:

${ }^{125} \mathrm{I}$-OPL was prepared by the chloramine $\mathrm{T}$ method of Greenwood, Hunter, and Glover (1962), using $1 \mathrm{mCi}$ of $\mathrm{Na}^{125} \mathrm{I}$ (New England Nuclear), 5 ug of purified oPL, 100 ug of ch1oramine $\mathrm{T}, 250 \mathrm{ug}$ of sodium metabisulphite, $1 \mathrm{mg}$ of potassium iodide, and 250 ul of $0.05 \mathrm{M}$ phosphate buffer, $\mathrm{pH} 7.4$ in a final volume of $300 \mathrm{ul}$. Unreacted iodide and damaged hormone were separated from intact ${ }^{125} \mathrm{I}-\mathrm{OPL}$ by gel filtration on a Sephadex Gr100 column (1.8 X $45 \mathrm{~cm})$ using $0.01 \mathrm{M}$ phosphate buffered saline (PBS), pH 7.4, containing 2.5\% BSA (w/v). The percentage of incorporation of radioactivity into oPL was $55-65 \%$. The specific activity of the oPL tracer was

$110-130 \mathrm{uCi} / \mathrm{ug}$ of protein.

(3) Tests for integrity of ${ }^{125} \mathrm{I}$-OPL:

Fractions eluted from the Sephadex G-100 column were tested for specific binding on rabbit liver receptor assay. The fractions which had the highest specific binding were used in subsequent immunoassays, The specific binding assay 
was performed according to the method described by Tsushima G Friesen (1973) except that ${ }^{125}$ I -oPL was used as tracer, and oPL was used as cold hormone. The specific binding is defined as the difference in radioactivity bound between the tube containing no "cold" hormone and that with excess hormone $(2.0 \mathrm{ug} / \mathrm{ml}$.$) .$

(4) Radioimmunoassay procedures:

A double antibody radioimmunoassay. (Beck et al, 1965) was used. Al1 dilutions were made in $0.01 \mathrm{M} \mathrm{PBS,} \mathrm{pH} 7.4 \mathrm{con}-$ taining $2.5 \%$ BSA.

During the assay, approximately $30,000 \mathrm{cpm}$ of ${ }^{125} \mathrm{I}-$ oPL in $0.1 \mathrm{~m} 1$. of oPL standard or assay sample, and $0.5 \mathrm{~m} 1$ of $0.01 \mathrm{M}$ PBS, pH 7.4 containing 2,5\% BSA. After 72 hours incubation at $4 \mathrm{C}$, sheep anti-rabbit gamma globulin serum $(1: 50$ dilution) in $0,1 \mathrm{ml}$ was added to the incubation medium, and a further excess of normal rabbit serum ( $1: 30$ dilution) in $0.1 \mathrm{ml}$ was added. After another 24 hours incubation period in the cold, the precipitates formed were centrifuged at $780 \mathrm{~g}$ for $15 \mathrm{~min}$, and the supernatants were decanted. The precipitates were counted in a LKB gamma counter (Mode1 8000). To test the specificity of the assay, hormone preparations from pituitary, placenta, or pituitary and placental extracts were serially diluted with $0.01 \mathrm{M}$ PBS, $\mathrm{pH} 7.4$ containing $2.5 \%$ BSA and added to the assay mixture instead of oPL stand$\operatorname{ards}$ 
3. Blologica1:

(a) Bioassay of growth promoting activity-

Female Sprague-Dawley rats were obtained from

Canadian Breeding Farm \& Laboratory Ltd, Montreal, Canada.

A11 rats were hypophysectomized at 2 weeks of age and kept in rooms under closely regulated conditions of temperature and humidity before and during the experiments, At the end of a 4 weeks acclimatization period, animals exhibiting inappropriate weight gain were discarded, Purified oPL or bovine growth hormone were prepared for injection using equal volumes of chilled saline $(0,9 \% \mathrm{NaCl})$ and $0.05 \mathrm{M}$ ammonium bicarbonate, $\mathrm{pH} 7.8$. If necessary, diluted $\mathrm{NaOH}(0.01 \mathrm{~N})$ was added to dissolve the hormone preparations but the final pH was never greater than 9,5. The solutions containing sal-: ine, oPL or bGH were administered in $0.5 \mathrm{~m} 1$ subcutaneously daily for a period of 9 days using 10 hypophysectomized rats at each dose. The animals were weighed daily prior to the injection. The weight gain of individual rats was calculated and final results were expressed as the mean for each treated group. The potency estimates of oPL using bGH $(0.9 \mathrm{U} / \mathrm{mg})$ as standard were calculated according to the method of Pugsley (1946). At the end of the experiment, all rats were killed and the sella turcica of each rat was inspected for completeness of hypophysectomy. 
(b) Lactogenic bioassaye

The lactogenic property of oPL was assessed by its ability to stimulate ${ }^{3} \mathrm{H}$-casein synthesis in rabbit mammary explants maintained in organ culture. The procedures employed were similar to those of Juergens et al (1965) for mouse tissue with slight modification.

$$
\text { Virgin New Zealand white rabbit }(2-3 \mathrm{~kg} \cdot) \text { was made }
$$
pseudopregnant by a single intravenous injection of $100 \mathrm{U}$ hCG. 12 days later, mammary glands were removed under aseptic conditions and cut into explants about $1 \mathrm{mg}$ each. Four explants were placed on a siliconized lens paper which was floated on $1 \mathrm{ml}$ of culture medium in a Falcon culture dish. The culture medium was Medium 199 (Gibco) which was supplemented with insulin and hydrocortisone, $10 \mathrm{ug} / \mathrm{m} 1 \mathrm{each}$, peniciliin and streptomycin at concentration $\mathrm{s}$ of $50 \mathrm{ug} / \mathrm{m} 1$, and HEPES buffer (10 mM). The dishes were placed in a plastic box ( $35 \mathrm{X}$ $25 \times 15 \mathrm{~cm})$ and exposed to $95 \%$ air $-5 \% \mathrm{CO}_{2}$ sufficient to maintain the pH at about 7.4 , after which the system was closed and incubated at $37 \mathrm{C}$ for 72 hours. At the end of 72 hours, ex plants were transferred into new medium which contained either ovine prolactin (NIH-P-S-10) or a highly purified preparation of oPL at a final concentration of $1 \mathrm{ug} / \mathrm{m} 1$. At the end of an additional 24 hours incubation, ${ }^{3} \mathrm{H}-1$ eucine was added to the medium such that one m1. of medium contains 5 uCi of ${ }^{3} \mathrm{H}-1$ eucine: Incubation in the presence of radioisotope was carried on for an additional 4 hours. 
Casein assay - At the end of 4 hours incubation, the explants from each dish were weighed and homogenized in $7 \mathrm{ml}$, of solution with the following composition: KC1,0,15M; sodium phosphate $\left(\mathrm{NaH}_{2} \mathrm{PO}_{4}\right), 0.004 \mathrm{M}$; imidazole, 0.01M; Hammarston bovine casein (Nutritional Biochemica1s), $5 \mathrm{mg}$. The final $\mathrm{pH}$ was 6.7. The homogenate was centrifuged at $100,000 \mathrm{~g}$ for $60 \mathrm{~min} .5 \mathrm{ml}$ of the supernatant fluid was made $0.01 \mathrm{M}$ with respect to $\mathrm{CaCl}_{2}$, and $50 \mathrm{ug}$ of crystalline rennin (Sigma) was added, followed by incubation with shaking at $37 \mathrm{C}$ for 30 min.. This procedure resulted in the precipitation of casein. After centrifugation at $780 \mathrm{~g}$ for $10 \mathrm{~min}$. at room temperature, the precipitate was washed twice with the homogenizing solution (without casein) made $0,01 \mathrm{M}$ with respect to $\mathrm{CaCl}_{2}$. The pellet was then heated in $5 \%$ TCA at $95 \mathrm{C}$ for 15 min.. After cooling, the suspension was centrifuged at $780 \mathrm{~g}$ for $10 \mathrm{~min}$, at $4 \mathrm{C}$, washed twice with cold TCA, and three times with absolute alcoholnether $(3: 1, v / v)$ at room temperature. The pellet was dissolved in 0.5 inl protosol. After the addition of $0.1 \mathrm{ml}$ distilled water, the dissolved pellet was counted in toluenescintillation counter (Isocap/ 300, Nuclear Chicago).

The results are expressed as cpm/mg wet weight of explants.Using this procedure isotopically labeled phosphoproteins (casein) in the $100,000 \mathrm{~g}$ supernatant fraction are precipitated along with the carrier bovine casein by calcium ions and rennin. 


\section{Receptor assays:}

(a) Displacement curve of oPL in the radioreceptorassay for prolactin (RRA-PRL) and for growth hormone (RRA-GH) using rabbit mammary and liver respective1y-

A highly purified oPL preparation was accurately weighed and dissolved in $0.1 \mathrm{M}$ ammonium bicarbonate, $\mathrm{pH} 8,7$, Serial dilutions of oPL were made in $0.025 \mathrm{M}$ Tris-HC1, pH 7.6 containing $0.1 \%$ BSA. The radioreceptorassay for prolactin (RRA-PRL) was performed according to the method of Shiu et a1 (1973) as described previously, The radioreceptorassay for growth hormone was performed according to the method of Tsushima $\&$ Friesen (1973) as described previously except that 125 I $-\mathrm{bGH}$ and $\mathrm{bGH}$ were used as tracer and standard respectively. ${ }^{125} \mathrm{I}-\mathrm{bGH}$ was prepared by the lactoperoxidase enzymatic method described by Thorel1 and Johannson (1971) with slight modification. During iodination, the pH of $0.05 \mathrm{M}$ phosphate buffer added in the reaction mixture is $\mathrm{pH} 4.2$ instead of pH 7,4,5 ug of lactoperoxidase, 10 ul of $30 \%$ hydrogen peroxide $(1: 1,50.0$ dilution), and reaction periods of 20 min. were used. The percentage of radioactivity incorporated was $55-60$, and the specific activity was $110-130 \mathrm{uCi} / \mathrm{ug}$ of protein.

(b) Displacement curve of oPL in the radioreceptorassay for growth hormone (RRA-GH) using human liver tissueHuman livers obtained at autopsy and stored frozen at -20 c were kindly provided by the Health Science Center, 
Dept, of Pathology. Human liver receptors were prepared according to the method of Tsushima E Friesen (1973) with modifications described by Carr et a1 (1975). A 15,000g pel1et was used as receptor source instead of the $100,000 \mathrm{~g}$ microsomal pel1et. ${ }^{125} \mathrm{I}-\mathrm{hGH}$ and $\mathrm{hGH}$ were used as tracer and standard respective1y. 
SECTION $V:$ RESULTS

Radioreceptorassays for prolactin (RRA-PRE) and for growth hormone (RRA-GH) using rabbit mammary tissue and liver

respective1y:

The sensitivity of both radioreceptorassays (RRA-PRL and RRA-GH) employed to monitor the hormonal activities is about $10 \mathrm{ng} / \mathrm{m} 1$ ( $1 \mathrm{ng}$ ) as shown in Figure 2 , a and b. In the RRA-PRL, ovine prolactin as well as prolactin of other species, human growth hormone, and primate placental lactogens inhibited the binding of ${ }^{125}$ I -oPRL to rabbit mammary tissue prolactin receptors, whereas other polypeptide hormones did not inhibit the binding of ${ }^{125}$-opRL. Only human growth hormone but not non-primate pituitary growth hormones competed for the prolactin binding sites. In addition, sheep placental extract inhibited the binding of ${ }^{125} \mathrm{I}$-oPRL in a parallel manner as shown in Figure 2 a. In the RRA $\mathrm{GH}$, hGH, growth hormone preparations from other species, and primate placental lactogens infibited the binding of ${ }^{125} \mathrm{I}-\mathrm{hGH}$ to rabbit 1 iver membrane GH-receptor sites in a parallel manner, whereas other hormone preparations do not inhibit the binding of ${ }^{125}$ I-hGH. Again, sheep placental extract displaced ${ }^{125}$ I-hGH in a parallel manner with the standard as shown in Figure $2 \mathrm{~b}$.

Purification: 


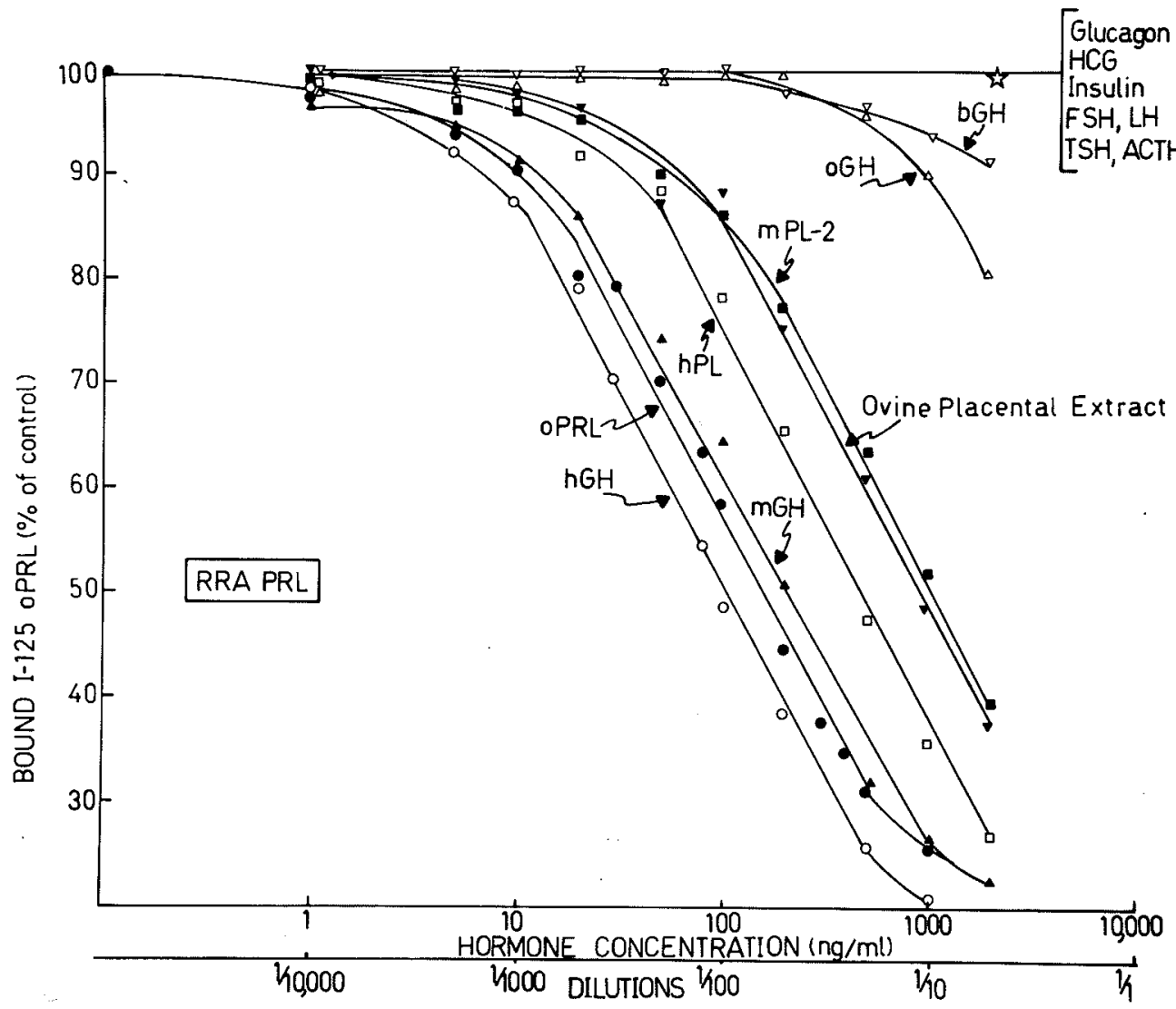

Figure 2a. Radioreceptorassay for prolactin using particulate fraction derived from rabbit mammary glands. The sensitivity and specificity of the binding of the assay is illustrated (from Shiu et a1,1973), 


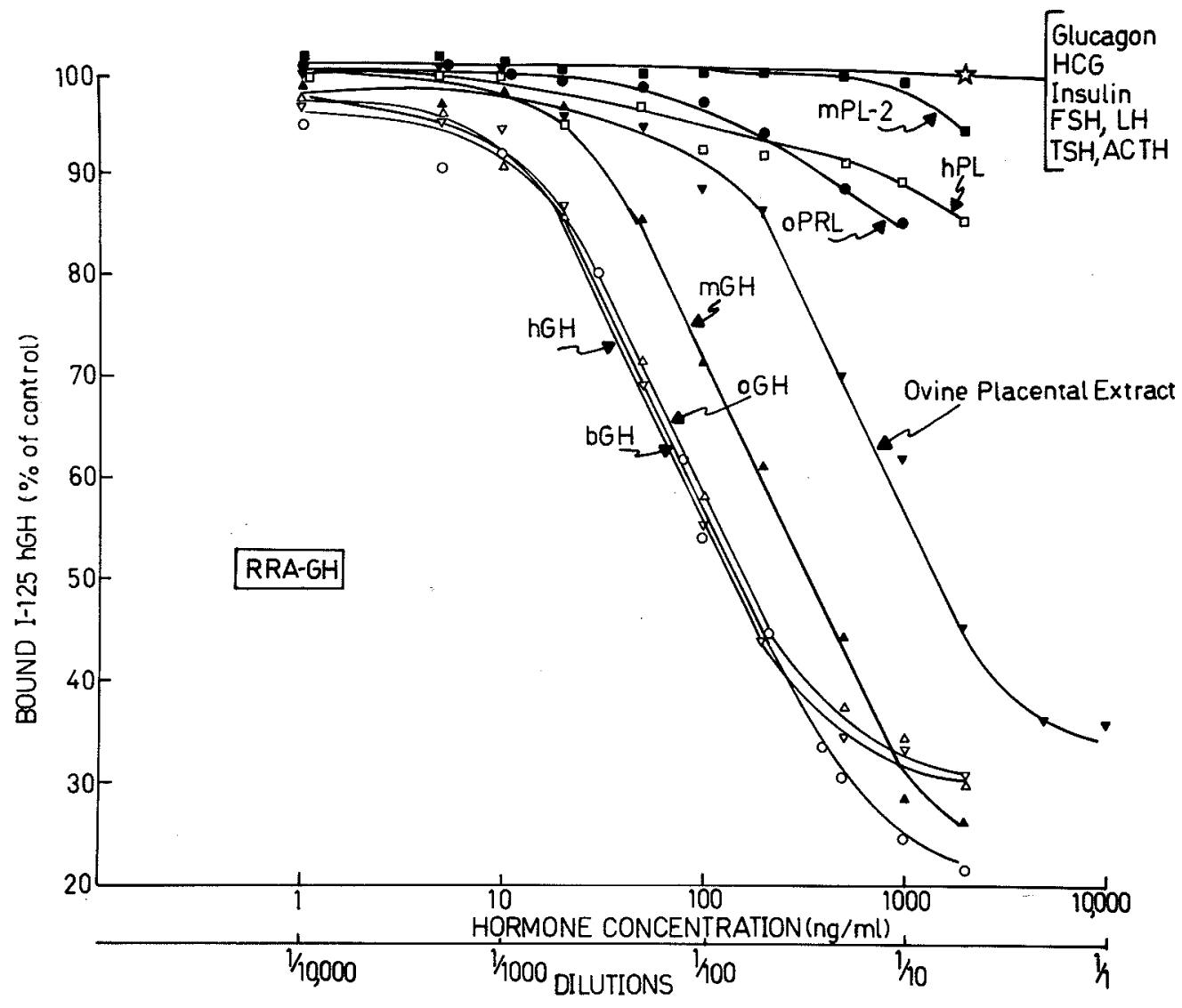

Figure 2b. Radioreceptorassay for growth hormone using particulate fractions derived from rabbit liver. The sensitivity and specificity of binding of the assay is illustrated (from Tsushima and Friesen,1973) 
OPL concentration in placental tissues at different gestation-

al periods.

Figure 3 shows the oPL content of the different starting materials that we have examined. The placental cotyledons at 74 days of gestation and afterward appear to have maximal concentration of oPL. Fresh placental cotyledons obtained at surgery and stored frozen at $-20 \mathrm{C}$ were a far richer source of oPL than placental cotyledons obtained after delivery: Although oPL concentration in placental tissues obtained after parturition is low, its content is still sufficiently high ( 32 ug of RRA-PRL and 22 ug of RRA-GH per gram of wet tissue) to make it a useful alternative when fresh placentalissues ( 74 days to 145 days of gestation) are not readily available.

Extraction of oPL from frozen placental cotyledons

Several conditions were tested to determine the best procedure to use in the initial extraction of oPL from frozen placental cotyledons, As shown in Table $I$, by far the greatest amount of oPL was extracted at $\mathrm{pH} 9.5$. Acidic solutions were much less effective in solubilizing oPL. Attempts to recover oPL by re-extraction of the acidic precipitate in $0.1 \mathrm{M}$ ammonium bicarbonate, $\mathrm{pH} 9.5$ were unsucessful, less than $1 \%$ of oPL could be recovered. Thus, it appears important that the primary extraction should be carried out at an alkaline pH at $4 \mathrm{C}$, 


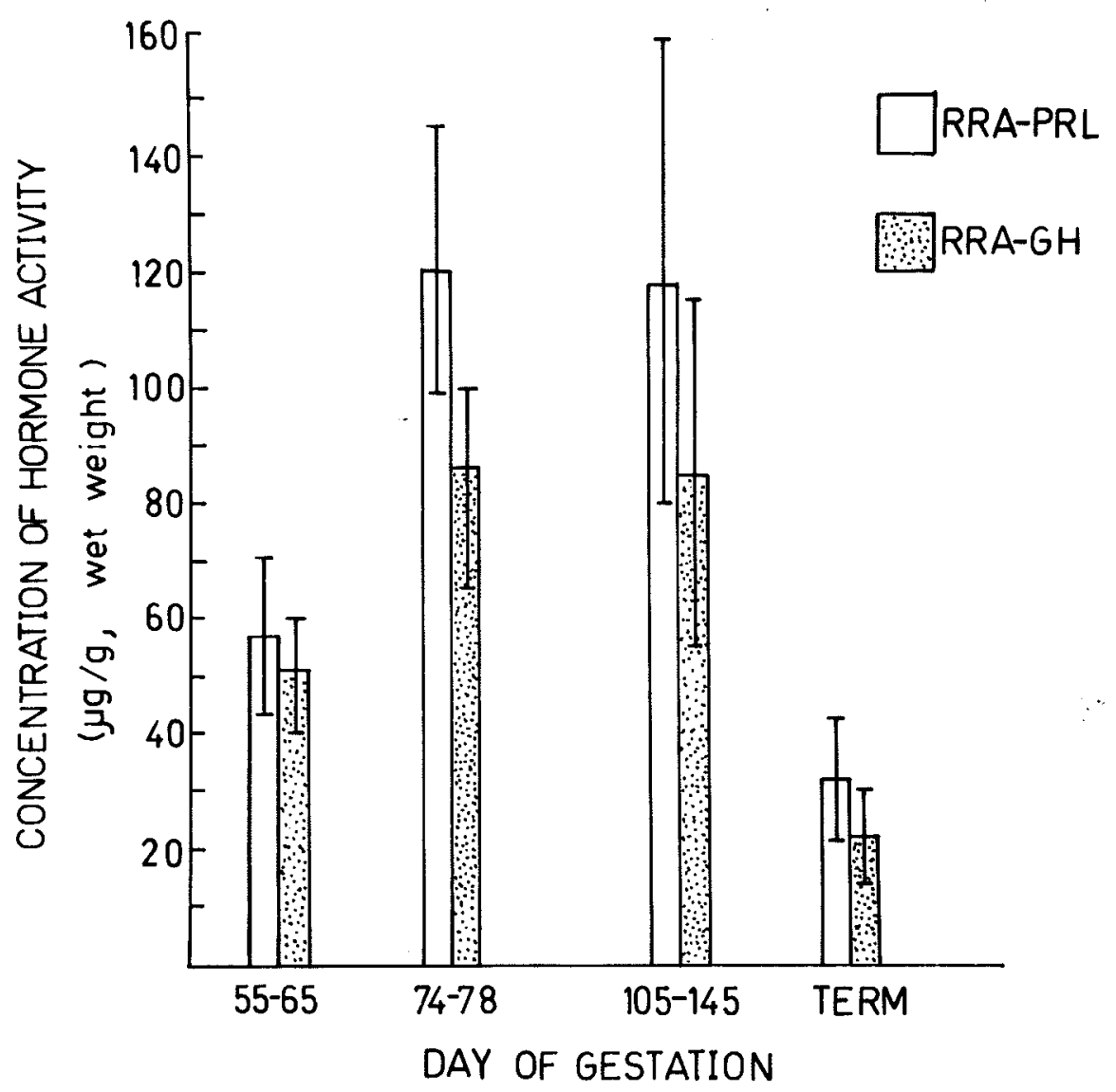

Figure 3. OPL concentration in p1acental tissues at different gestational periods.Placental cotyledons were homogenized in 5 volume of $0.1 \mathrm{M} \mathrm{NH}_{4} \mathrm{HCO}_{3}$ buffer, $\mathrm{pH} 9.5$ and stirred overnight at $4 \mathrm{C}$. 


\section{EXTRACTION OF OPL FROM FROZEN PLACENTAL COTYLEDONS}

Placental cotyledons were homogenized in 5 volumes of extracting fluid and stirred overnight at $4 \mathrm{C}$.

\begin{tabular}{|c|c|c|c|}
\hline EXTRACTING FLUID & $\mathrm{pH}$ & $\begin{array}{l}\text { RRA }=\text { PRL } \\
(\mathrm{ug} / \mathrm{g} \text { wet weight) }\end{array}$ & $\begin{array}{l}\text { RRA-GH } \\
\text { (ug/g wet tissue) }\end{array}$ \\
\hline $0.1 \mathrm{~N} \mathrm{NaOH} *$ & 10.5 & 50 & 45 \\
\hline $0.1 \mathrm{M} \mathrm{NH} \mathrm{NHCO}_{3}+1 \mathrm{M} \mathrm{NH} 4 \mathrm{HH}^{0 \mathrm{H}}$ & 9.5 & 90 & 75 \\
\hline $0,1 \mathrm{M} \mathrm{NH}_{4} \mathrm{HCO}_{3}+1 \mathrm{M} \mathrm{NH}_{4} \mathrm{OH}$ & 8.7 & 80 & 68 \\
\hline $0.1 \mathrm{M} \operatorname{Tris}-\mathrm{HC} I$ & 7.4 & 47 & 30 \\
\hline $0.1 \mathrm{M}$ Ammonium acetate & 6.8 & 2 & 1.5 \\
\hline $0.1 \mathrm{M}$ Ammonium acetate + acetic acid** & 5.0 & $<0.1$ & $<0.1$ \\
\hline $0,1 \mathrm{~N}$ Acetic acid & 3.0 & $<0.1$ & $<0.1$ \\
\hline
\end{tabular}

$* \mathrm{pH}$ lowered to 10.5 with $5 \mathrm{~N} \mathrm{HCl} ; * * \mathrm{pH}$ lowered to 5.0 with $1 \mathrm{~N}$ acetic aicd. 
Fractionation of oPL from crudelextracts

after the primary extraction, several fractionation methods were tested to determine the best procedure to use for separating oPL from other proteins present in the crude extract. As shown in Figure 4, it appears that fractional precipitation with organic solvents, such as ethanol(Fig.4a) and acetone (Figure 4 b) were not effective due to the $10 \mathrm{ss}$ of oPL activity during precipitation. Fractional precipitation by lowering the $\mathrm{pH}$ of the extract (Fig, 4 c) was also not very effective, since the loss of oPL activity also was high. The best fractional precipitation method for oPL appears to be ammonium sulfate precipitation, as shown in Figure $4 \mathrm{~d}$. Fractions obtained between 40 and 75 percent saturation of ammonium sulfate contain about 60 to $80 \%$ of the original. oPL activity but on 1 y $15-25 \%$ of the original protein.

Diethylaminoethy1 (DEAE) -ce11u1ose anion exchange chromatography

Figure 5 shows the elution pattern when the dialyzed material after ammonium sulfate precipitation was subjected to DEAE ion exchange chromatography, Most of the oPL was unabsorbed by the column. With increasing ammonium bicarbonate concentrations very little additional hormone was eluted. 

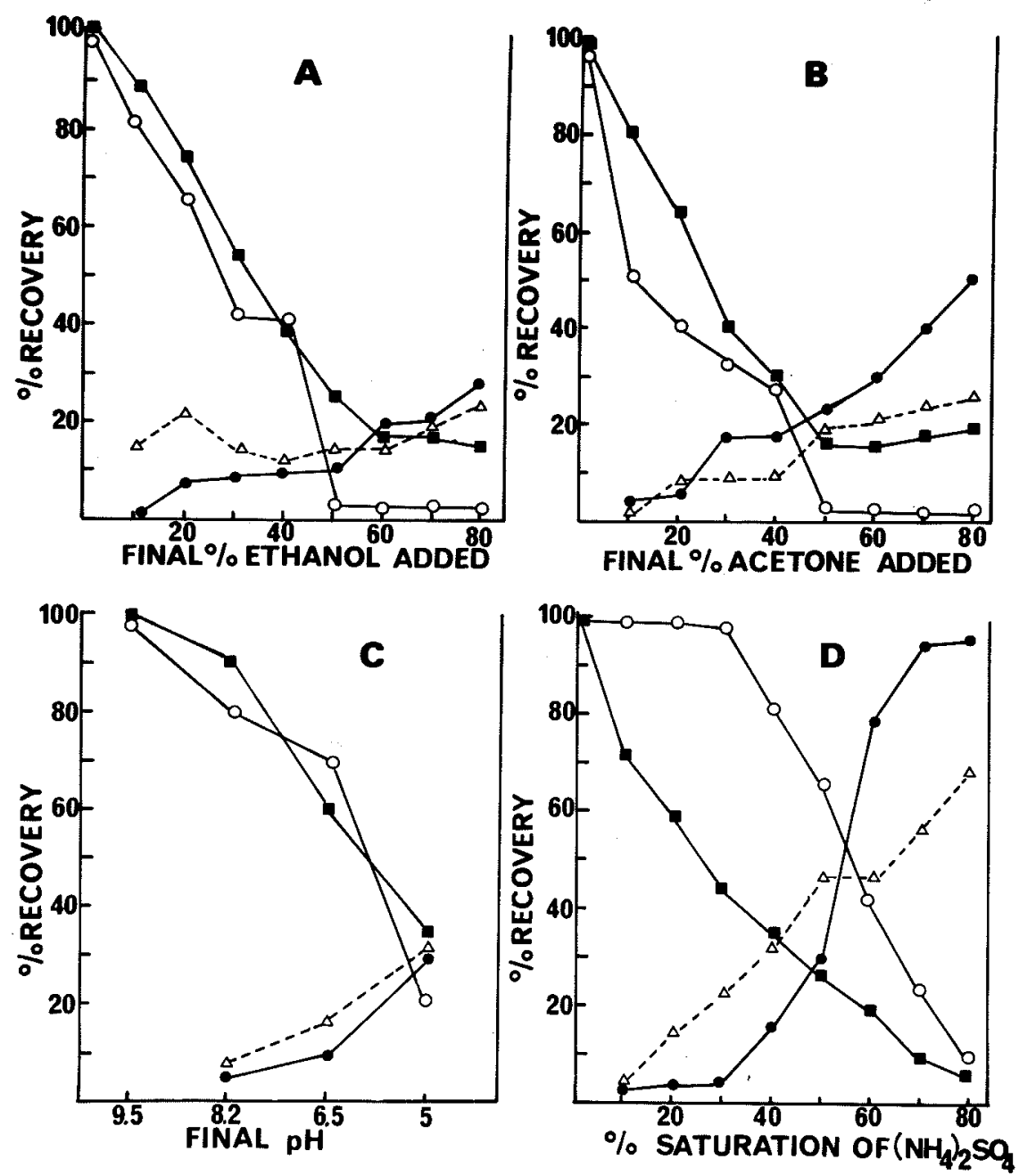

Figure 4. Fractionation of oPL from crude extract. (A)Ethanol...
(B) Acetone,
(C) pH with $1 \mathrm{~N}$ acetic acid. And
(D) Ammonium

sulfate precipitation. \% recovery of protein by Lowry $\rightarrow-$

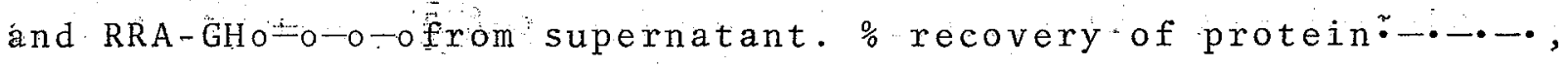
and RRA-GHA-A-A-Arom precipitate (solubie protein). Similar pattern of RRA-PRL was obtained (not shown). 


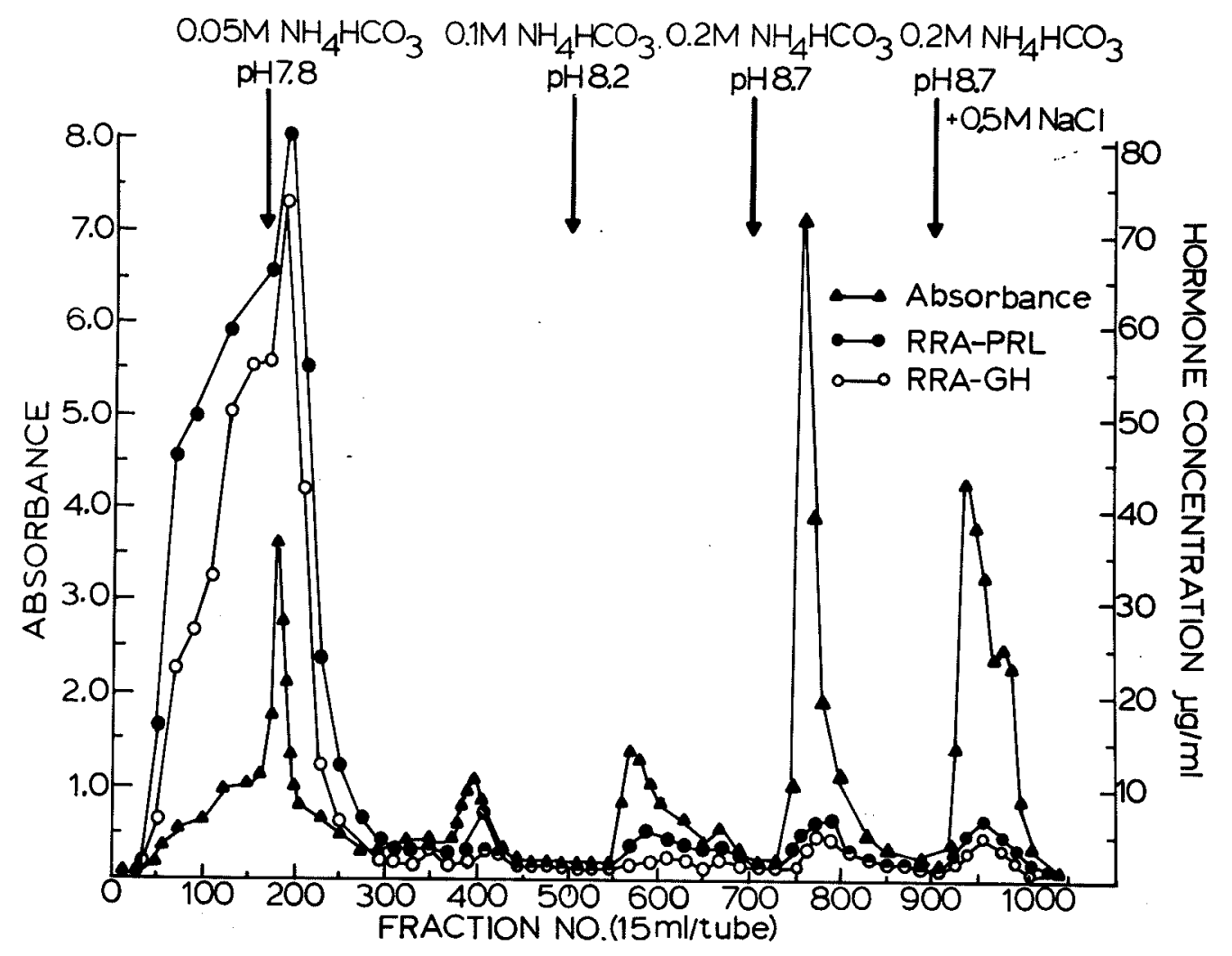

Figure 5, Diethylaminoethyl (DEAE)-cellulose chromatography of oPL rich fraction, the ammonium sulfate precipitate obtained between $40-75 \%$ saturation. The DEAE -cellulose (Whatman $\mathrm{DE}-32) \operatorname{column}(60 \times 40 \mathrm{~cm})$ was equilibrated with $0.05 \mathrm{M}$ ammonium bicarbonate, pH 7,8 , 
Ge1 filtration

Figure 6 shows the distribution of protein and oPL after gel filtration on Sephadex G-100 of the active fractions obtained from the DEAE column, Most of the oPL emerged in fractions with an elution volume of $1,9-2,4$ times that of the void volume:

Carboxymethyl (CM) ce11ulose cation exchange ehromatography The fractions from the Sephadex G-100 gel filtration were pooled and applied to a CMacellulose ion exchange column for additional purification, as shown in Figure 7. Most of the oPL was eluted in the presence of $0.2 \mathrm{M} \mathrm{NaCl}$, although a smal1 additional peak eluted with 0,5M NaCl. However, analysis upon polyacrylamide ge1 electrophoresis, indicated that this fraction did not differ from the major peak eluted with $0.2 \mathrm{M} \mathrm{NaCl}$.

\section{Column chromatography}

The fractions containing oPL from CMC-chromatography were pooled, concentrated and further purified by gel filt - : ration on Sephadex G-100, as shown in Figure 8. Most proteins including oPL eluted at $1,9=2,4$ times the void volume,

A summary of the purification procedure and the recovery of oPL appears in Table II. 


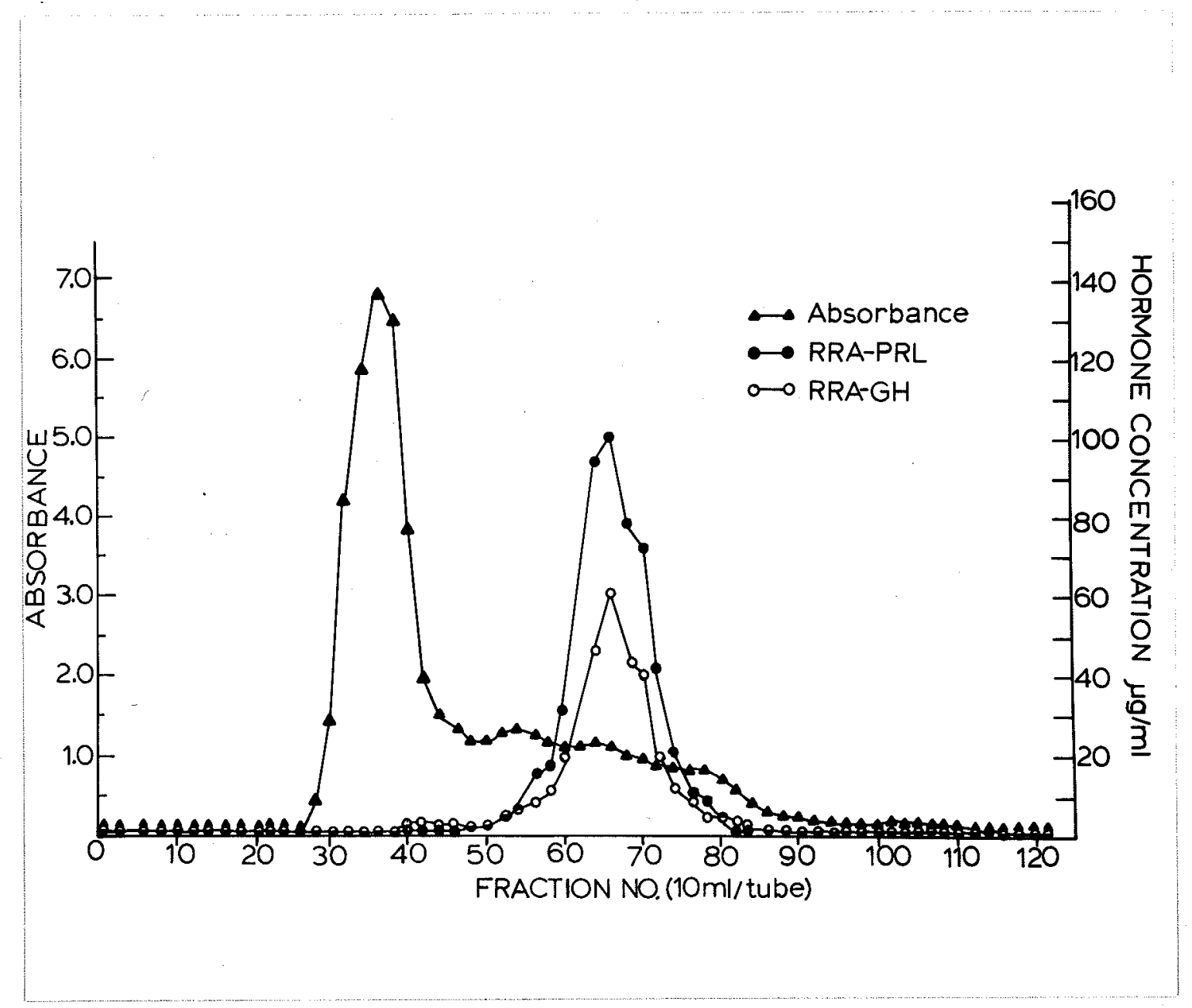

Figure 6. Gel filtration of the oPL rich fractions obtained from DEAE-cellulose column in Figure 5 on a Sephadex $G-100$ column (104 X $4.2 \mathrm{~cm})$ using $0.01 \mathrm{M}$ ammonium acetate, $\mathrm{pH} 5.0$ as buffer. 


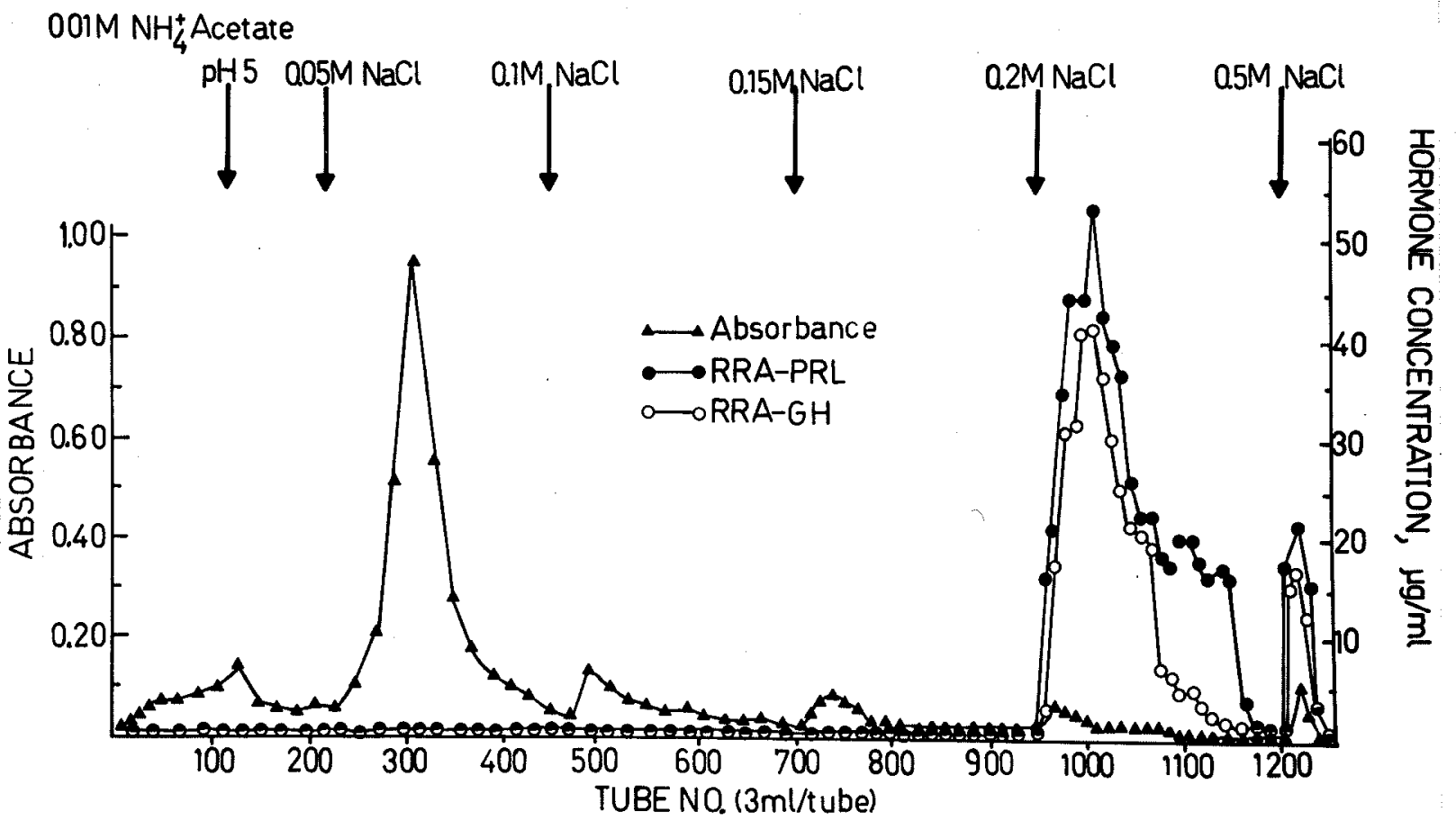

Figure 7, CM-cellulose chromatography of the oPL rich fractions from the Sephadex G-100 column in figure 6 (fractions \#56-80). The CM-cellulose (Whatman CM-23) column(18X1.8cm) previously equilibrated with $0.01 \mathrm{M}$ ammonium acetate buffer, pH 5.0 . 


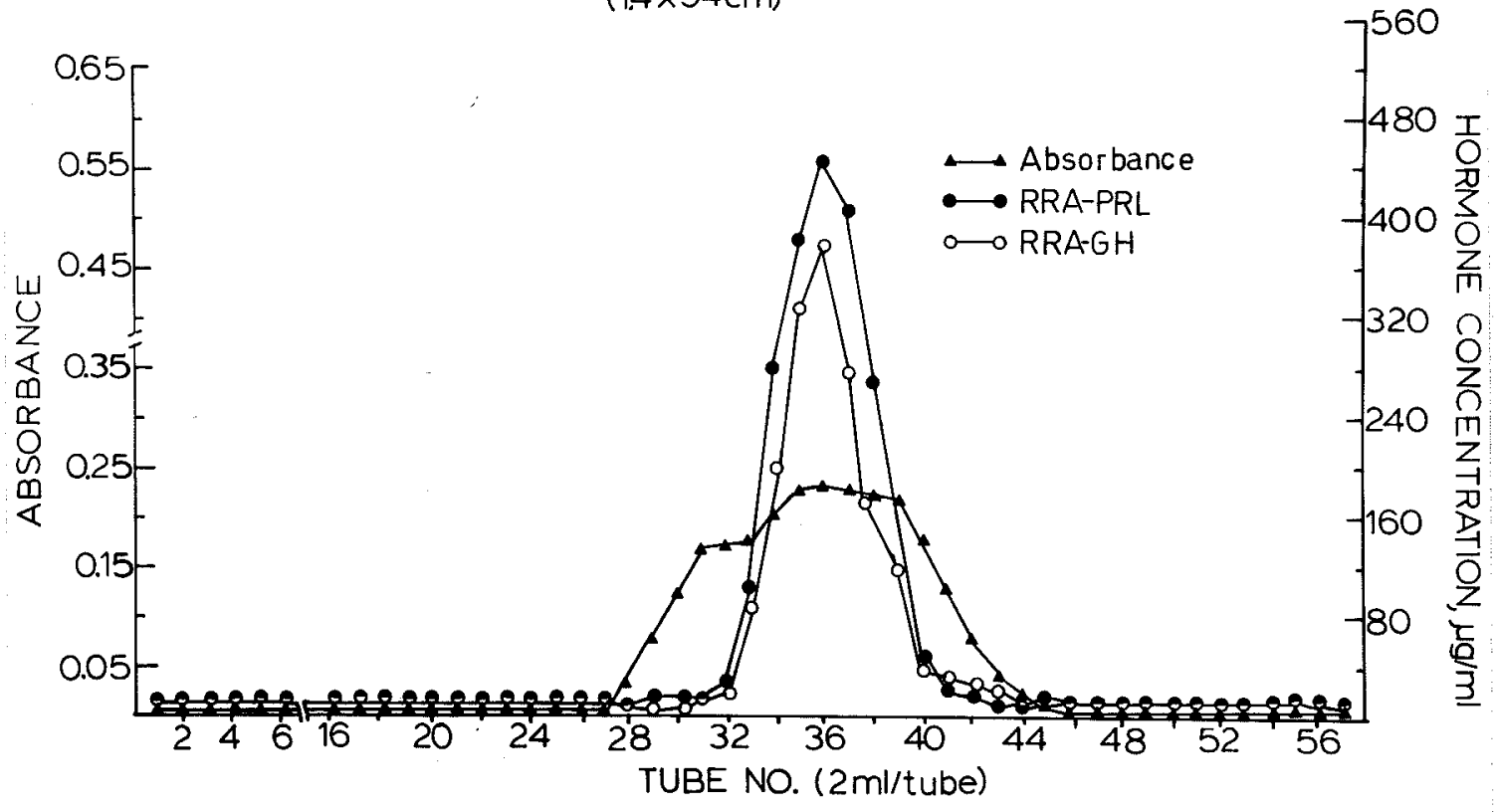

Figure 8, Ge1 filtration on Sephadex G-100 column (94X1.4 cm) of fractions from the CM-cellulose column in Figure 7. The Sephadex G-100 column was equilibrated with $0,1 \mathrm{M}$ ammonium bicarbonate, $\mathrm{pH} 8.7$. 
TABLE II

TABLE OF PURIFICATION

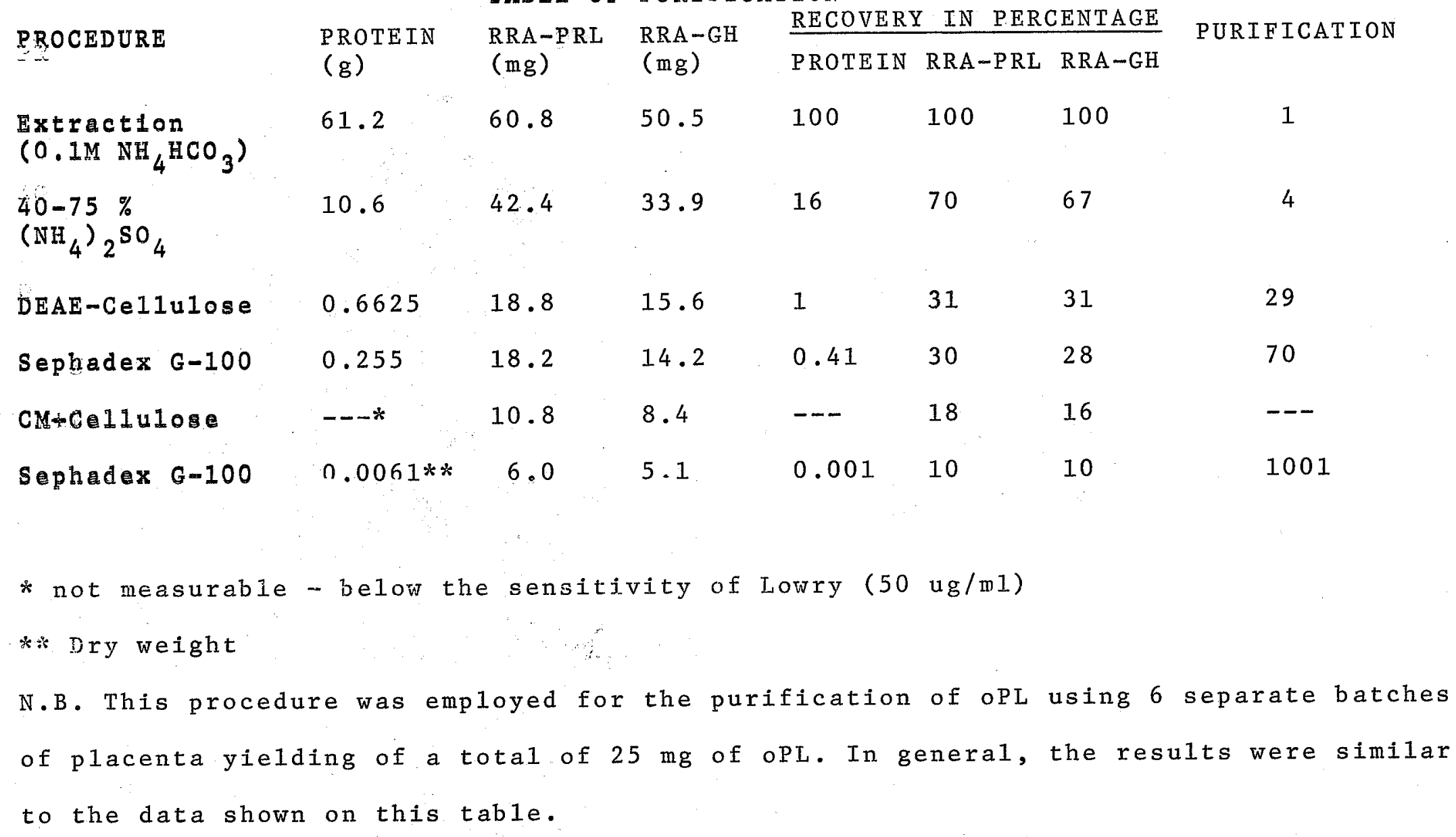


Characterization:

Analytical polyacrylamide gel electrophoresis

Figure 9 shows the protein pattern of the most highly purified oPL preparation upon electrophoresis run under alkaline $(\mathrm{pH} 8,8-9,0)$ and acidic $(\mathrm{pH} 4,3-4,5)$ conditions, Under the alkaline conditions, ovine pituitary growth hormone and prolactin were also run at the same time for the purpose of comparing their relative mobility ( $\left.R_{f}\right)$. The $R_{f}$ values observed were $0,18,0.27$, and 0.6 for oPL, oGH, and oPRL respectively. In the most highly purified preparation of oPL, 3 bands are still evident, When individual gel segments were eluted and assayed for oPL by 2 RRA's, only the middle band was active. Furthermore, when the purified oPL was subjected to polyacrylamide gel electrophoresis at an acid pH, 3 bands again were visible. Once more only the middle band was positive for oPL when eluted segments were assayed as shown in Figure 10 .

\section{Analytical gel isoelectric-focusing}

The protein pattern upon gel ìsoelectric focusing at each of the steps of the purification is shown in Fig.11. The highly purified preparation of oPL displayed a number of bands when analyzed by this very sensitive technique. When the eluted segments were assayed as shown in Figure 12 by the 2 RRAS, oPL activity was found to coincide with the 


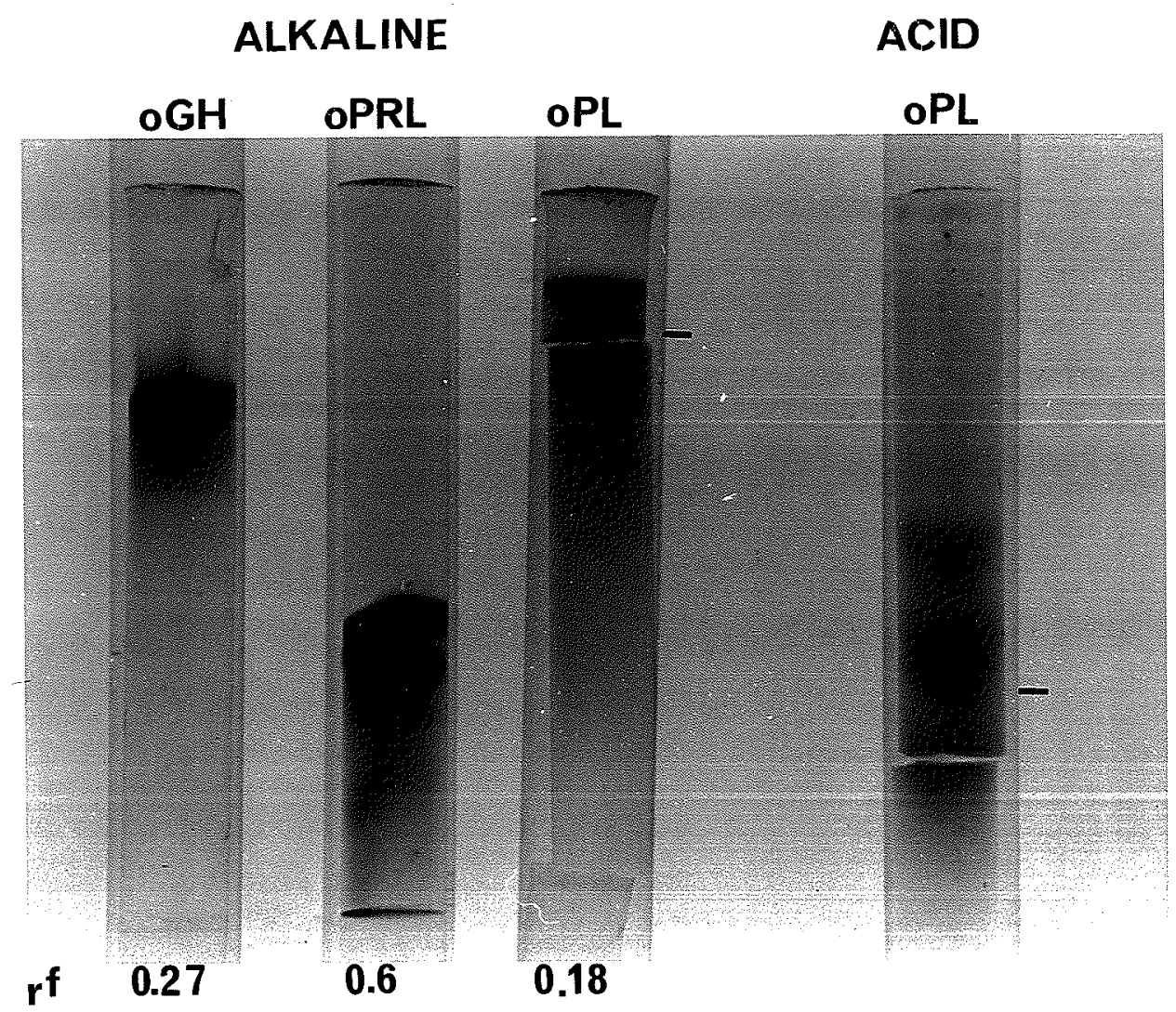

Figure 9. Polyacrylamide gel electrophoresis pattern of oPL. The first three gels represent oGH,oPRL, and oPL run upon alkaline condition;at $\mathrm{pH} 8,8-9.0$. The $\mathrm{R}_{f}$ for these 3 hormones are $0.27,0.6$ and 0,18 respective1y. The fourth ge1 represents oPL run under acidic condition at $\mathrm{pH} 4.3-4.5$. The dot beside the two oPL gels indicates the position where the oPL activity is detected by the 2 RRA's, 

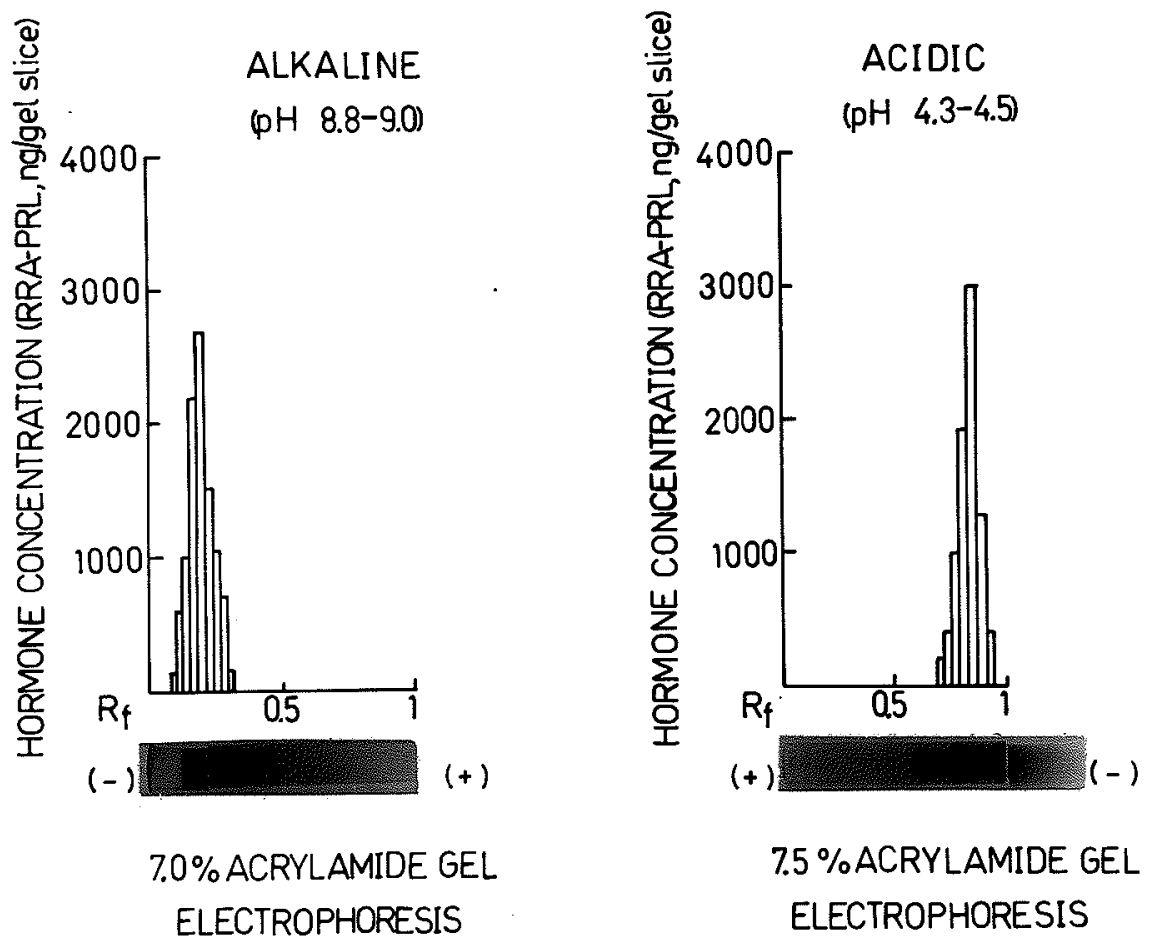

Figure 10. Pattern of oPL activity eluted from polyacrylamide ge1 electrophoresis, one ge1 each run under alkaline or acidic condition was segmented at $1 \mathrm{~mm}$ intervals and eluted with 2 m1. of $0.1 M$ Tris - HC 1 buffer, $\mathrm{pH} 7.6$ containing $0.1 \%$ BSA. Gel eluants were assayed and the distribution of oPL(shown) was measured by RRA-PRL, Similar pattern was obtained (not shown) by RRA-GH. 


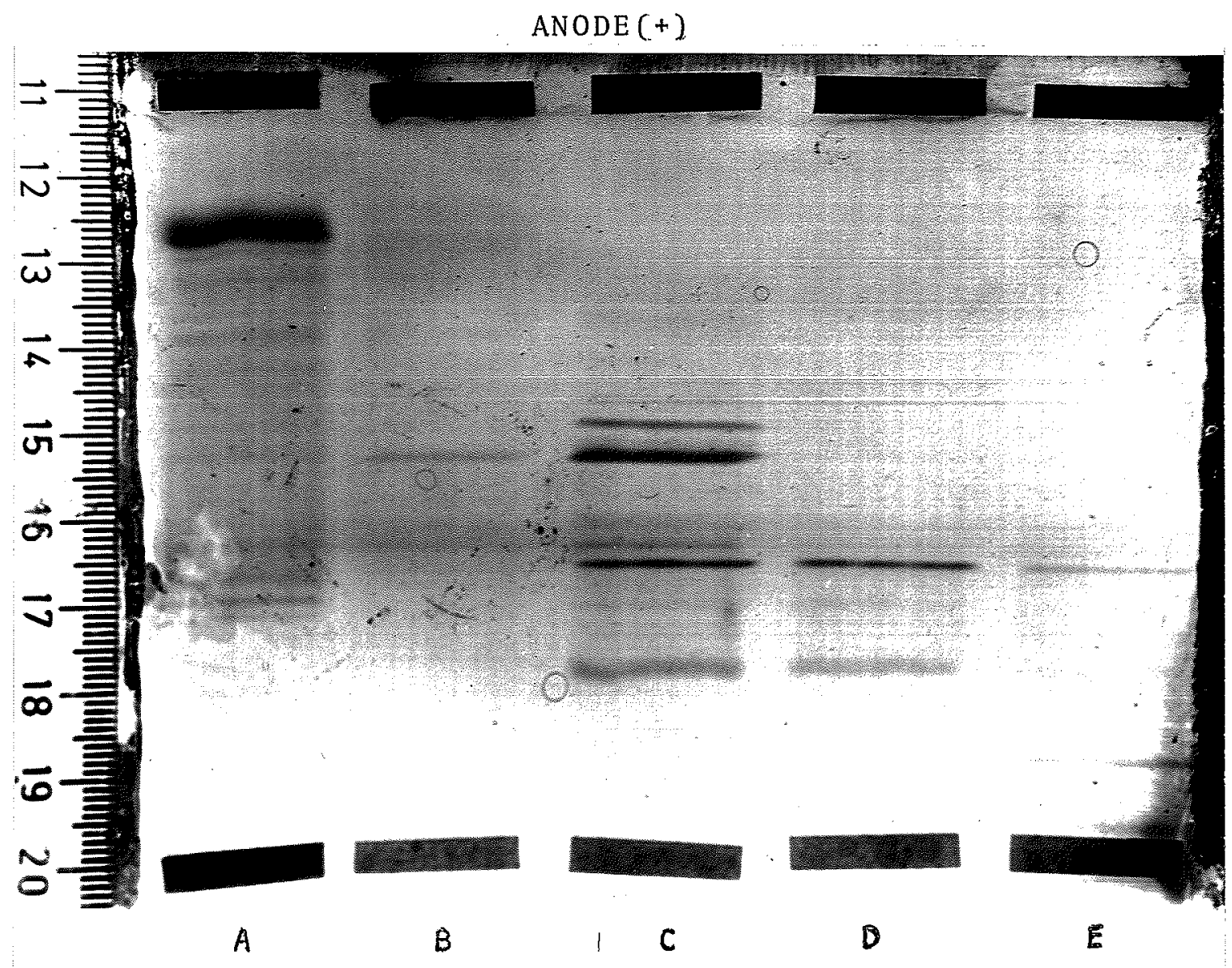

Figure 11. Analytical polyacrylamide gel isoelectric focusing pattern of oPL.The five gels in channels A to E are the fractions obtained during different stages of purification. (A) crude extract, 65 ug dry weight.(B) fraction obtained after Sephadex G $\rightarrow 100$ chromatography, 50 ug dry weight. (C) fraction obtained after DEAE-cellulose chromatography, 66 ug dry weight. (D) 2 wug and (E) 26 ug are fractions of different batches which were obtained after CM-ce11ulose and Sephadex G-100 chromatography. Fraction $E$ was used for analysis and characterization of oPL. The anode was placed on the top of the gel, while the cathode was placed near the bottom of the gel. 


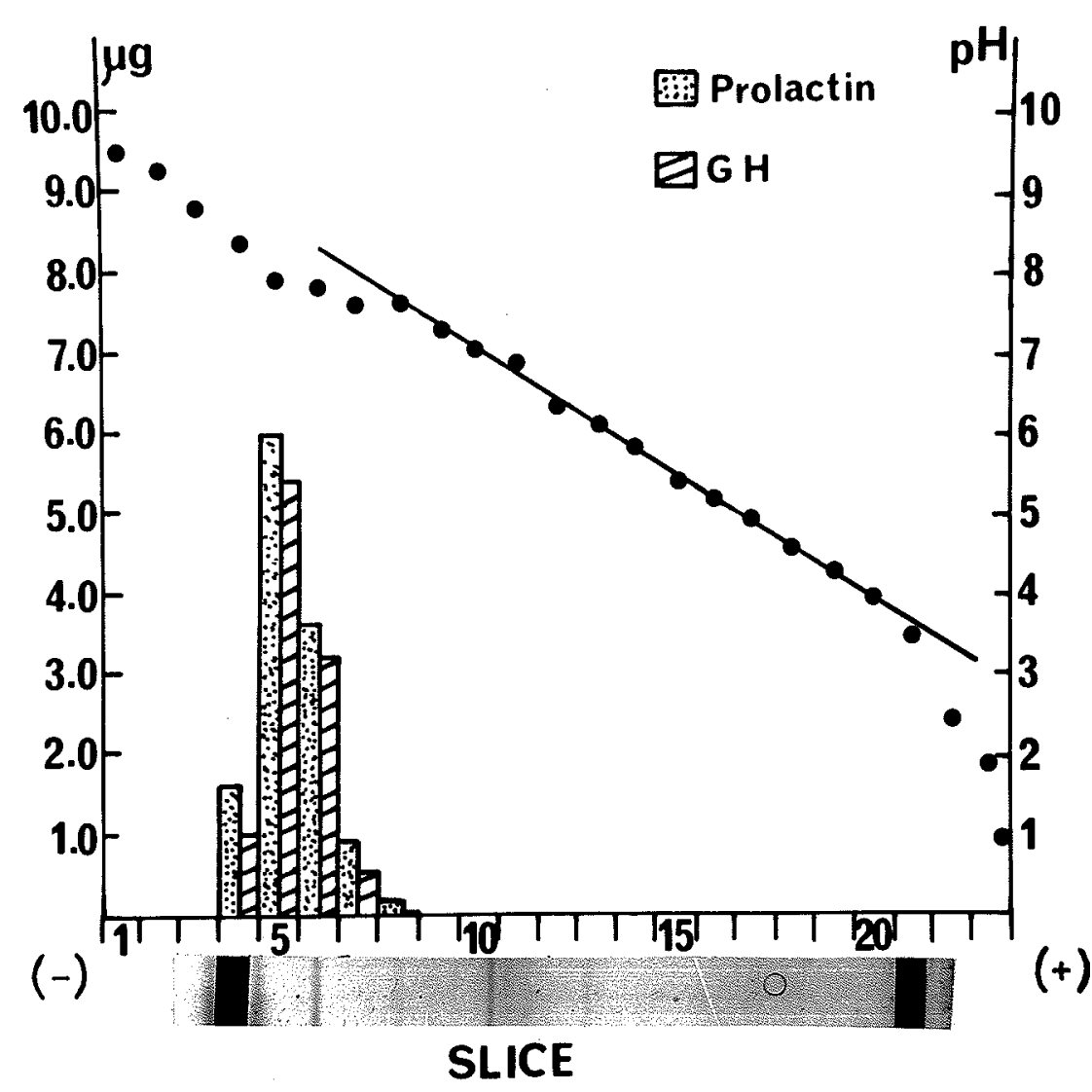

Figure 12. Pattern of oPL activity eluted from polyacrylamide gel isoelectric focusing. The cathode was placed near segment \#4, while the anode was placed on segment 21 . Gel eluants were assayed, and the distribution of oPL activity was determined by the 2 RRA's, The concentration of prolactinlike and growth hormone-like activities were measured by the RRA-PRL and RRA-GH respectively; These 2 activities were indicated in the same gel segment, 
2 bands near the cathode. In addition, when serial dilutions of the eluates from these segments were made, the response curves observed in the 2 RRA's showed complete parallelism to that of ovine prolactin and hGH standard. However, the band which was situated nearest the cathode (paper filter) possesses the highest oPL activity, suggesting that the oPL activity detected corresponding to the other band may be due to incomplete isoelectric focusing.

\section{Preparative isoelectric focusing}

Figure 13 shows that when the partially purified oPL was subjected to preparative isoelectric focusing, several regions of UV absorbing material were present but oPL was concentrated in the pH region $8.5-9.0$,

\section{Molecular weightestimation}

Figure 14 shows that when purified oPL was applied to a Sephadex G-100 column together with ${ }^{125} \mathrm{I}-\mathrm{hGH}$, oPL emerged in the same fractions as ${ }^{125} \mathrm{I}-\mathrm{hGH}$, suggesting that the mole cular weights of oPL and hGH are very similar $20,000-22,000$ M.W. .

Radiolmmunoassay fox bPL

Figure 15 shows the sensitivity and specificity of the radioimmunoassay for oPL using a double antibody technique, sheep pituitary growth hormone and prolactin do not 


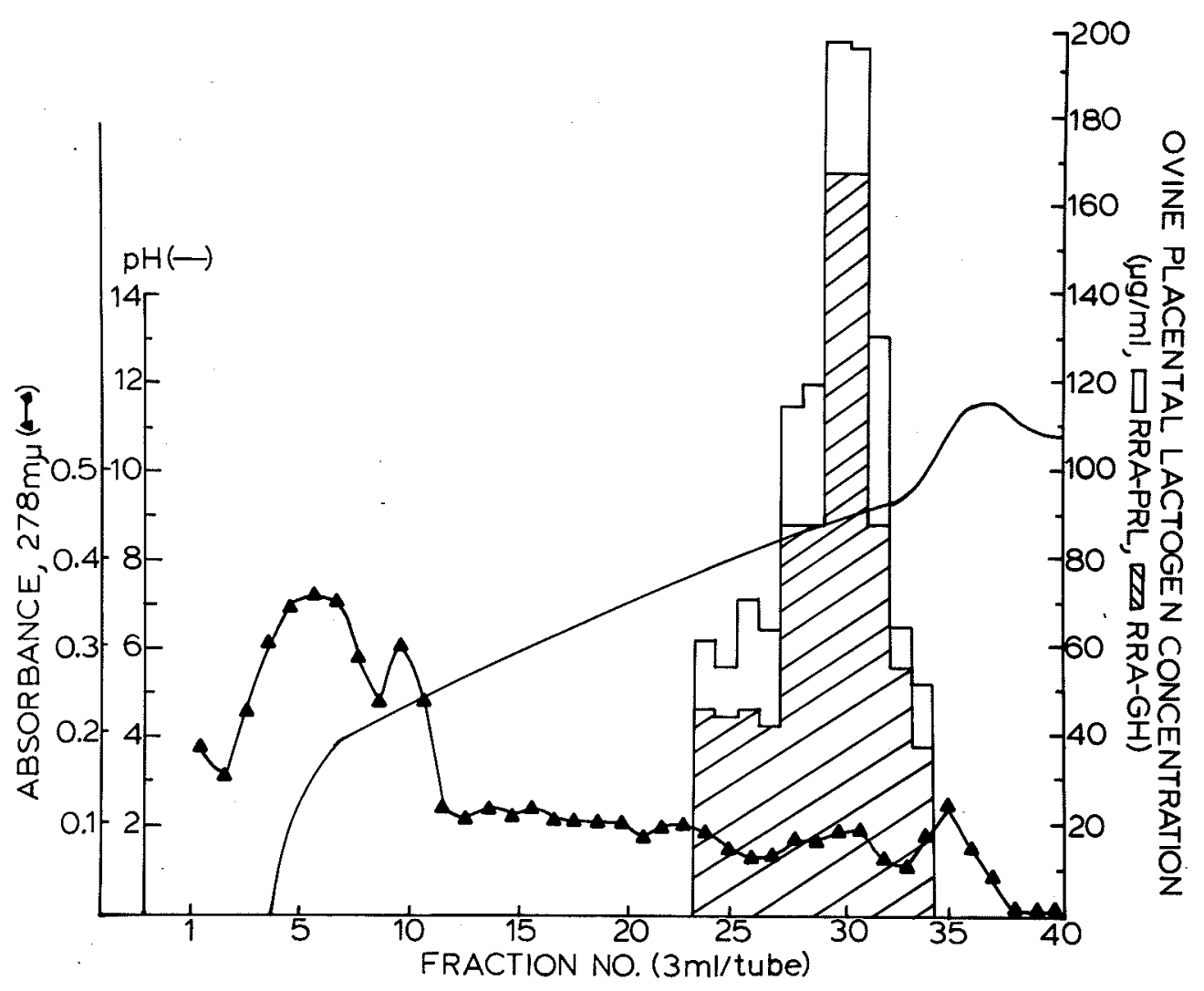

Figure 13. The elution profile of oPL after isoelectricfocusing. Isoelectric focusing was performed in a sucrose gradient containing $1 \%$ carrier ampholytes in the pH $3-10$ range. 


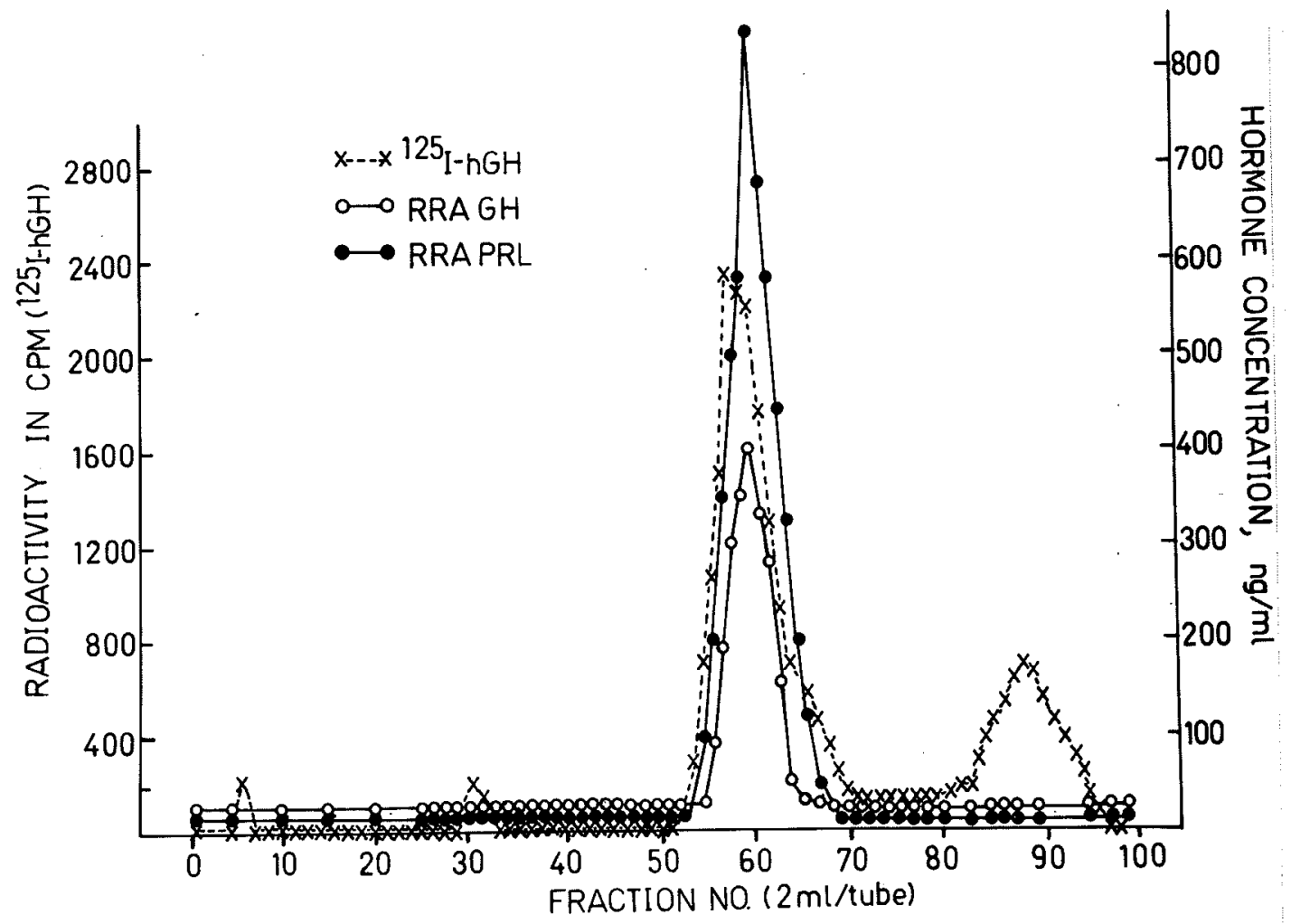

Figure 14. Molecular weight determination of oPL by gel filtration on Sephadex G-100. Sephadex G-100 column $(75 \times 2.5 \mathrm{~cm})$ was equilibrated at room temperature with $0.01 \mathrm{M}$ Tris-HCl containing $0,1 \% \mathrm{BSA}$ and $0.1 \mathrm{M} \mathrm{NaCl}$ at $\mathrm{pH} 7.6$ and was calibrated with ${ }^{125} \mathrm{I}-\mathrm{hGH}$ as a marker protein. 


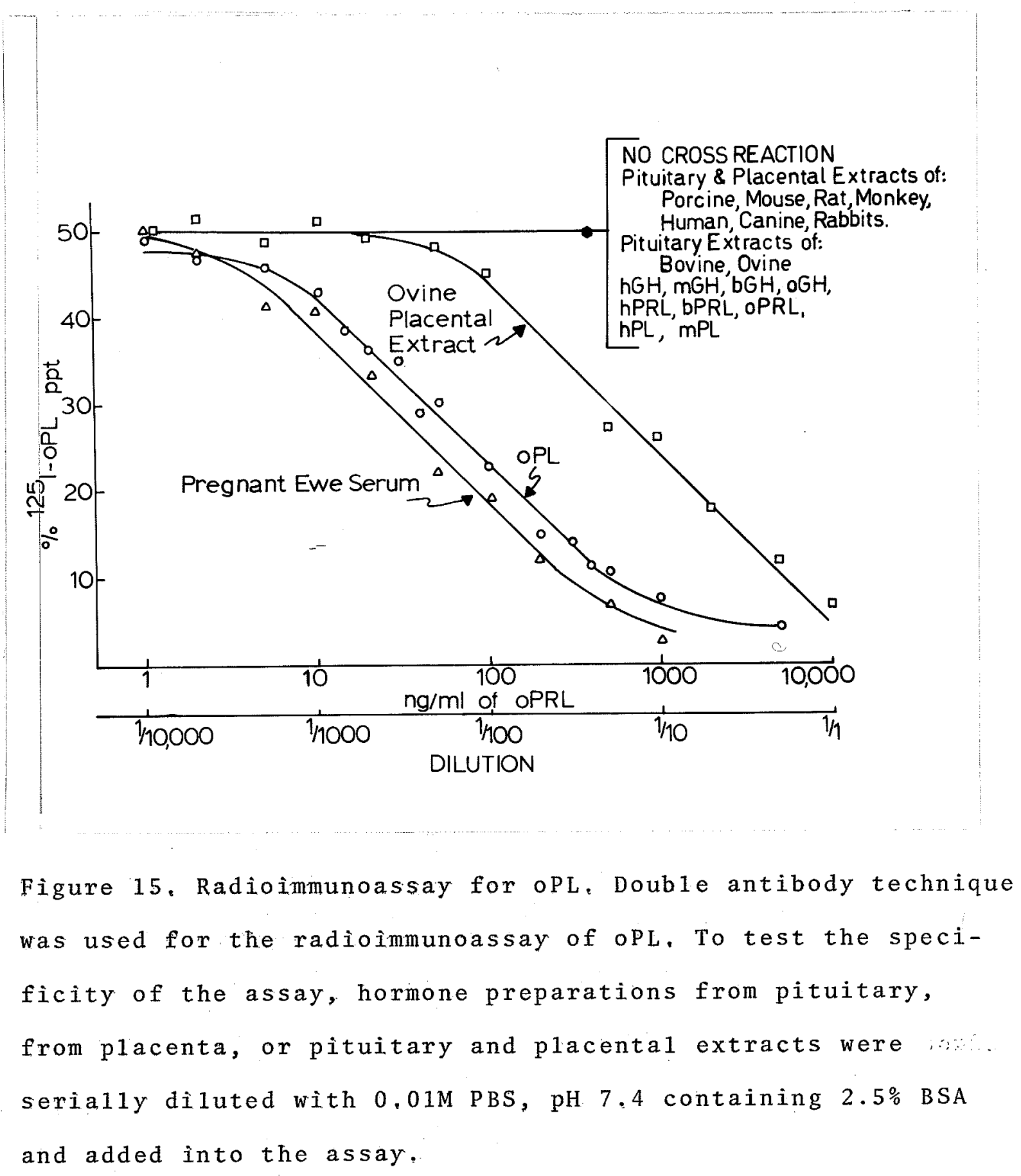


crossmeact with antisera to oPL, Similar $1 y$, several other hormone preparations from other species either of pituitary origin or placental origin, showed no cross-reaction at all. The only samples which do crossureact in the assay are sheep placental extract and pregnant sheep serum ( $129-131$ days gestation). These results indicate that oPL is immunologically different from sheep pituitary GH or PRL and also from any other hormone preparation tested.

\section{Bioassay of growth promoting activity}

Figure 16 shows the results of the bioassay for growth promoting activity of purified oPL, Purified oPL is 1.5 times more potent than bGH standard $(0.9 \mathrm{U} / \mathrm{mg})$. The relative growth promoting potency of oPL is calculated to be $1.3 \mathrm{U} / \mathrm{mg}$ with $95 \%$ confidence 1 imits of $0.9-1.6 \mathrm{U} / \mathrm{mg}$.

\section{Lactogente bioassay}

Figure 17 shows the results of the bioassay for lactogenic activity of purified oPL, Purified oPL is equipotent with the ovine prolactin standard (NIH-P-S-10,26IU/mg), adding further evidence that oPL is a very potent lactogenic as we11 as growth promoting hormone.

Displacement curke of opt In the radioreceptorassay for prolacein (RRA ERLI) and for growth hormone (RRA-GH) using rabititissue receptors: 


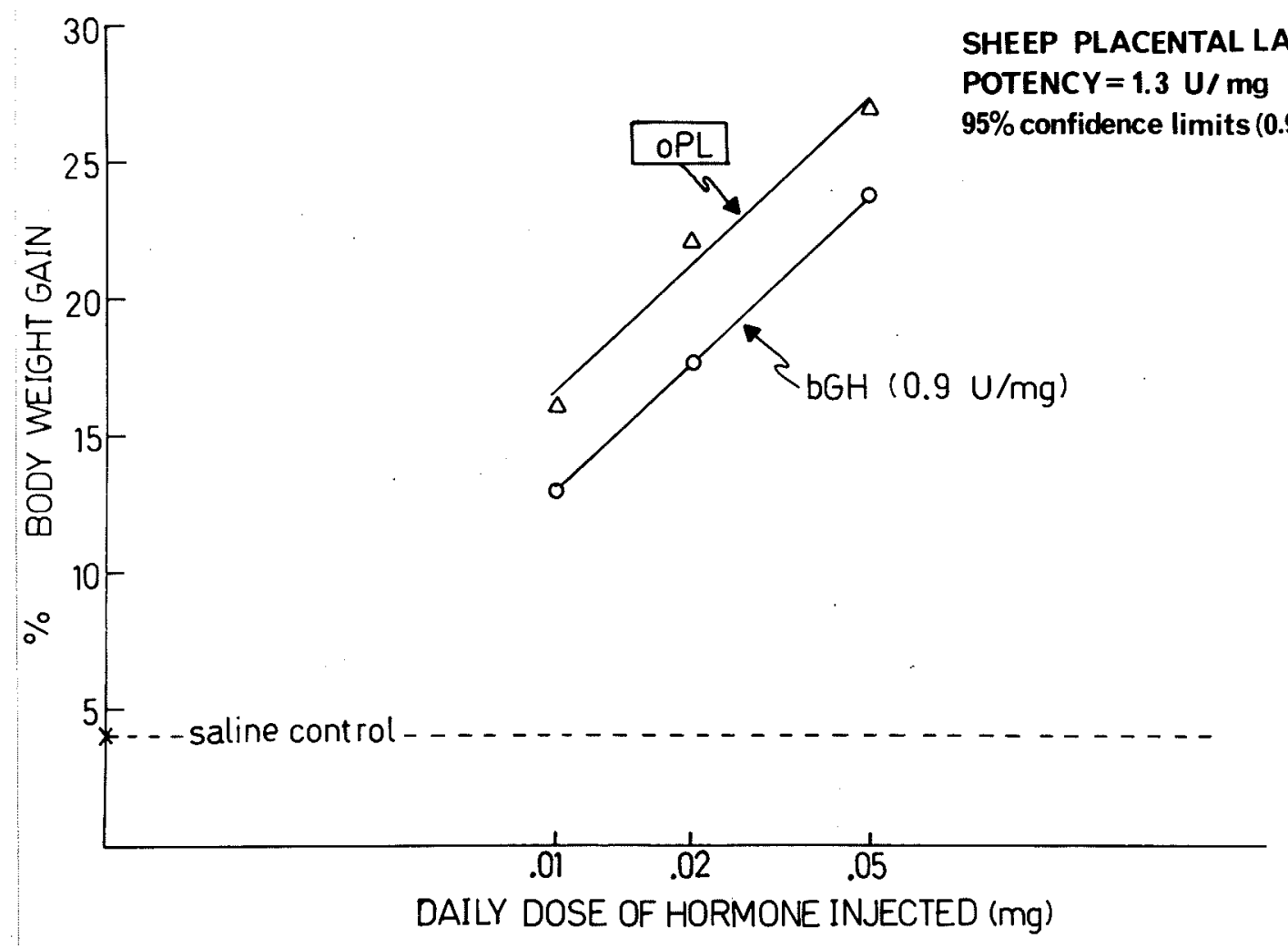

Figure 16. Bioassay of growth promoting activity of oPL. 10 hypophysectomized rats were used at each dose. Bovine growth hormone $(0.9 \mathrm{U} / \mathrm{mg})$ was used as standard, and saline was used as control group. 


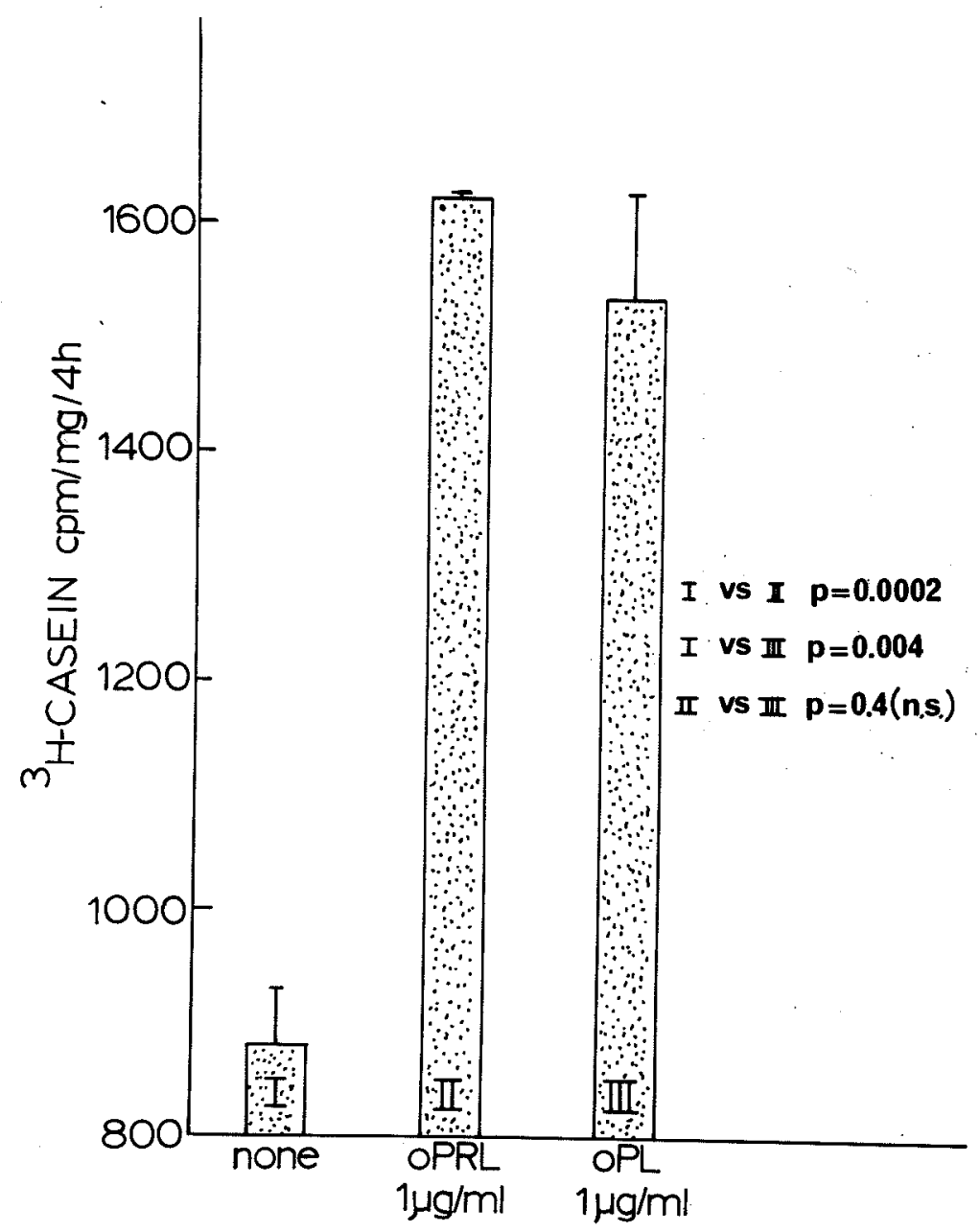

Figure 17. Bioassay of lactogenic activity using organ coculture of rabbit mammary explants. Results are expressed as cpm/mg wet weight of explants. Each group contains of 3 dishes, Each dish contains of 4 explants, ovine prolactin was used as standard, and saline was used as control. 
When the highly purified oPL preparation was assayed in both RRA's (Figure 18), oPL inhibited the binding of either ${ }^{125} \mathrm{I}$-oPRL (Fig, $18 \mathrm{a}$ ) or ${ }^{125} \mathrm{I}-\mathrm{bGH}$ (Fig, 18b) in a paral1e1 manner to the hormone standards used (oPRL for RRA$P R L$ and $b G H$ for RRA-GH respectively). When the ratio of prolactin to growth hormone activity of oPL was compared with that found for $h \mathrm{GH}$ and $h \mathrm{PL}$ by the two radioreceptorassays, it was apparent that oPL has a ratio of $2: 1$, whereas the ratio of $h \mathrm{GH}$ is $1: 1$ and of $h P L$ is $100: 1$.

Displacement curve of oPL in the radioreceptorassay for growth hormone (RRA-GH) using human liver tissue

In human liver receptor assays, oPL was able to displace ${ }^{125}$ I - hGH from its binding sites as effectively as hGH (Figure 19), whereas hormone preparations from other species showed no competition for binding sites, Only primate pituitary growth hormone and ovine placental lactogen compete for binding sites in the assay. Admittedly hPL showed very minimal crossereaction in the assay in keeping with its weak growth promoting effect. 


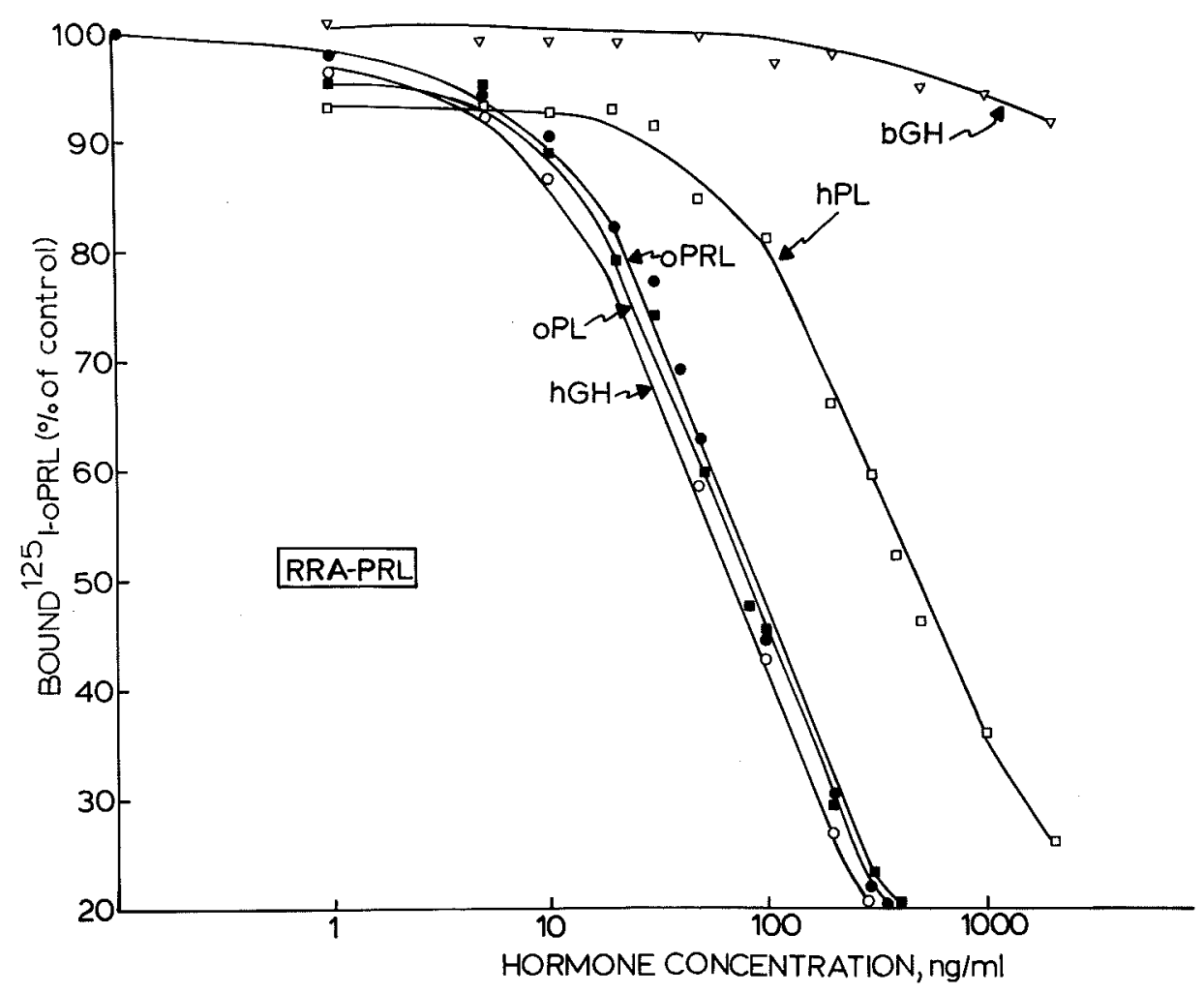

Figure 18a. Displacement curve for a highly purified preparation of oPL, hGH, hPL, oPRL and bGH in the radioreceptorassay for prolactin (RRA-PRL) using rabbit mammary gland.Rabbit mammary receptors were incubated with ${ }^{125} \mathrm{I-OPRL}$ in the pre-s sence of increasing concentration of "cold" hormone. The ordinate represents the ${ }^{125}$ I-oPRL bound to prolactin binding sites, In the absence of any added hormone the amount bound is taken to be $100 \%$ In the presence of oPRL, oPL,hGH, and hPL, the \% of ${ }^{125}$ TropRL bound is decreased. The abscissa represents the concentration of hormone added to the assay tube. 


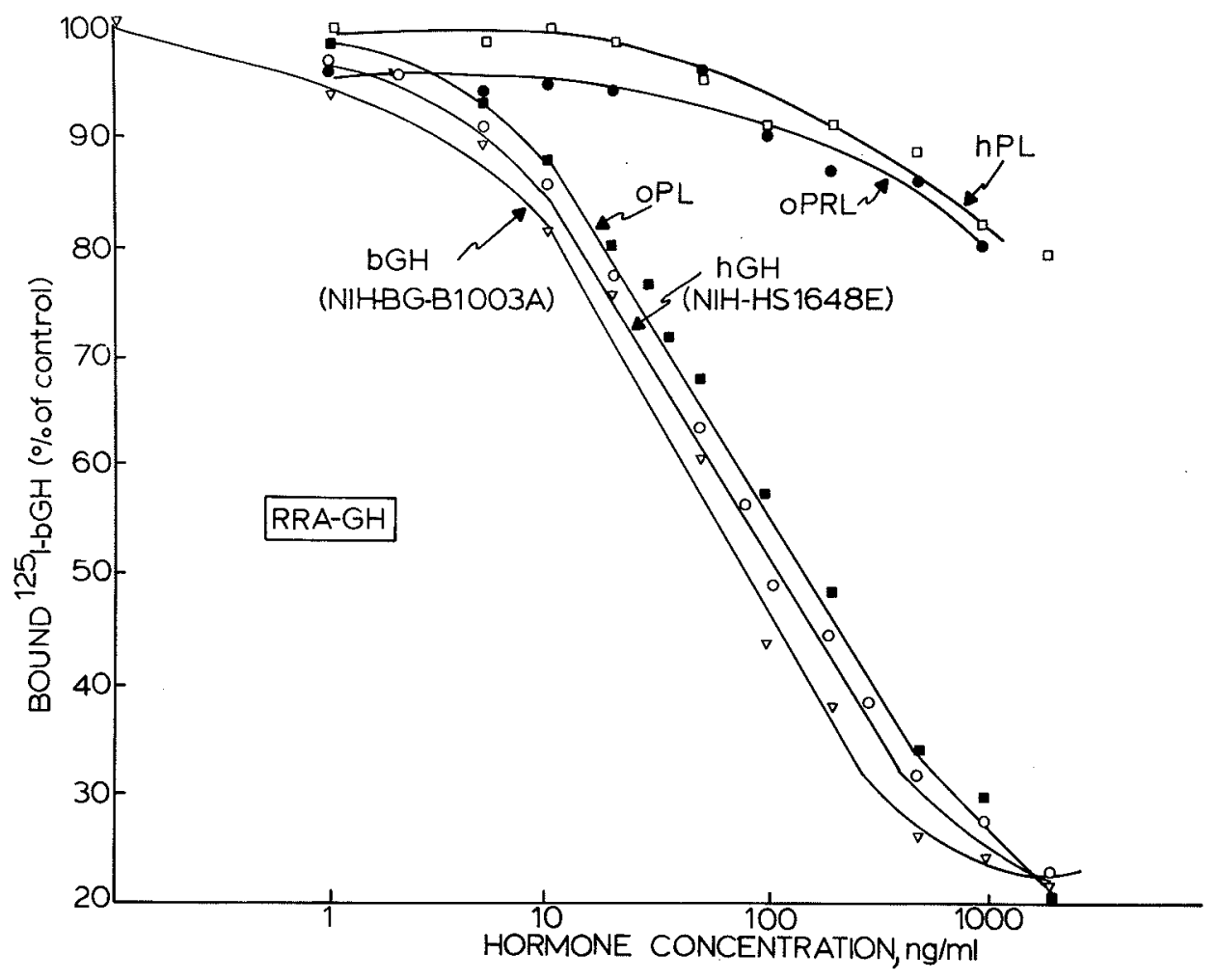

Figure 18b, Displacement curve for a highly purified preparation of oPL, hGH, hPL, oPRL and bGH in the radioreceptorassay for growth hormone (RRA-GH) using rabbit 1iver.Rabbit liver membranes were incubated with ${ }^{125}$ I-bGH in the presence of increasing concentrations of $b G H, o P L, h G H, o P R L$ and $h P L$, The ordinate represents the displacement of ${ }^{125} \mathrm{I-bGH}$ bound to growth hormone binding sites in the absence and presence of $b G H, O P L, h G H$, oPRL and $h P L$. The amount of ${ }^{125} \mathrm{I}-\mathrm{bGH}$ bound in the absence of "cold" hormone is taken to be $100 \%$. The abscissa represents the concentration of "cold" hormone added: 


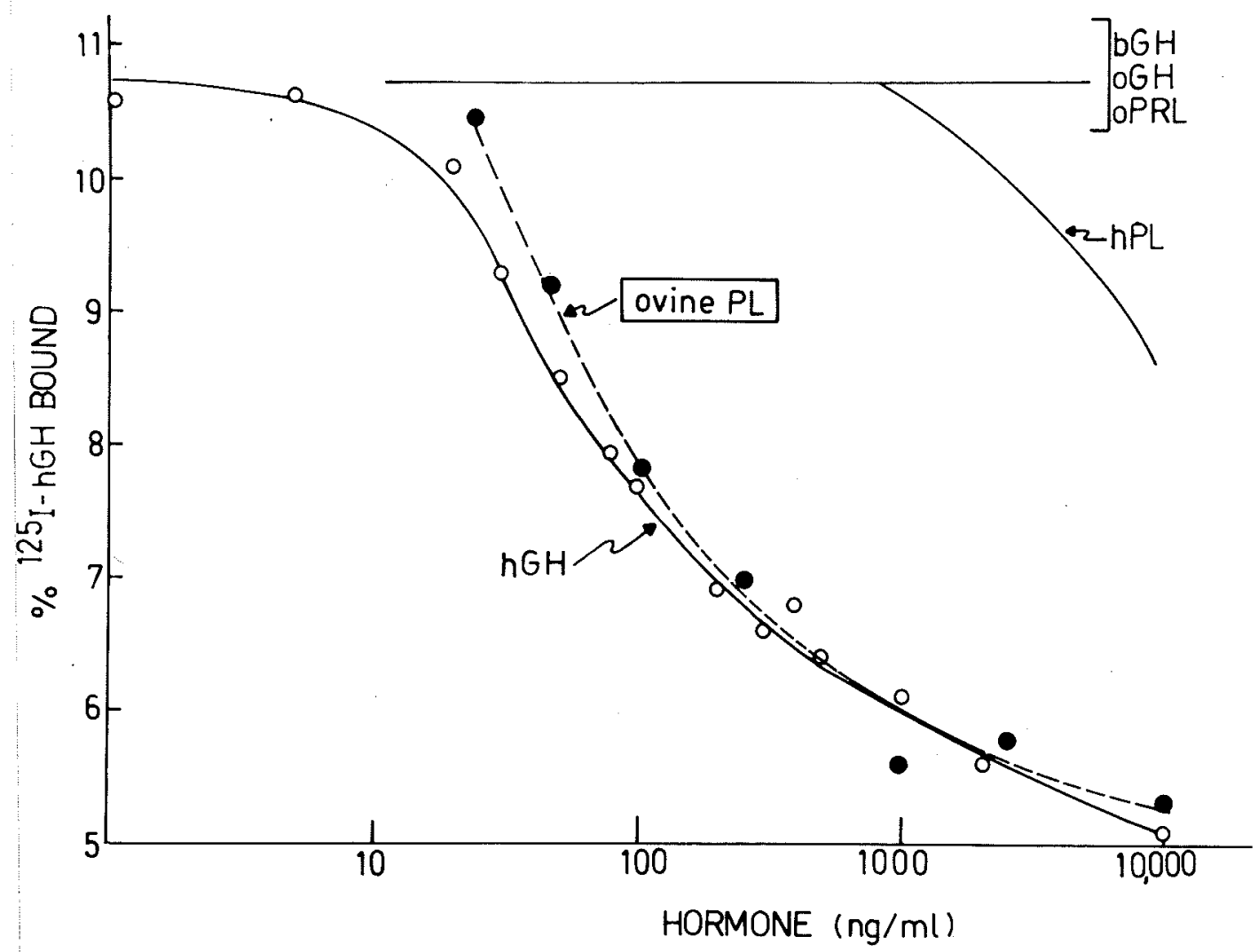

Figure 19, Radioreceptorassay for growth hormone (RRA-GH) using human liver. The specificity of the assay is shown. The ordinate indicates the $\%$ of ${ }^{125} \mathrm{I}-\mathrm{hGH}$ bound to the human liver growth hormone binding sites in the absence or presence of "cold" hormone added to the assay tube. 
SECTION VT: DISCUSSTON

The main reasons for the previous failure to purify ovine placental lactogen are two fold: namely, the lack of immunological reaction of ovine placental lactogen (OPL) with antiserum to $h P L, m P L$, or other pituitary hormone preparations; and secondly, the absence of a simple, inexpensive, and specific assay for monitoring ovine placental lactogen. With the development of radioreceptorassays for prolactin (RRA-PRL) by Shiu et al(1973) and for growth hormone (RRA-GH) by Tsushima and Friesen (1973), which are relatively simple, inexpensive, and specific for prolactin-like and growth hormone-like respectivély, it became possible to detect and quantitate oPL activity in the circulation of the pregnant ewe and also in placental extracts. By using these 2 RRA's as assay tools, we and others (Fe11ows et al, 1974) have been able to purify ovine placental lactogen from sheep placental cotyledons.

It appears that placental cotyledons of 74 days gestation or more contain more oPL than placental tissues which are obtained after parturition. The placental lactogen content remains stable when placentas are stored at $-20 \mathrm{C}$, but after one year we found that oPL content progressively decreased, Thus, frozen placental tissue of 74 days gestation or more which is stored for less than one year provides the best tissue sounce for oPL purification, Since the collection 
of placental tissues of 74 days gestation or more is usually limited in quantity, placental tissues obtained after parturition provides a promising alternative source of oPL.

\section{A) Extraction and Purification}

In our initial attempts to purify oPL from frozen placental cotyledons, we encountered a number of difficulties which will be discussed:

1. Preliminary extraction- One major problem which was encountered with the initial alkaline extract was that it was turbid and viscous and could not readily be cleared by centrifugation or filtration. The viscosity of early-term placental extracts ( $54-65$ days) was greater as compared with extracts obtained near term (130-145 days) or placental extracts obtained postpartum. The nature of the factors contributing to the viscosity is not clear, but mucous substances, such as mucin, mucopolysaccharides, are suspected. When this thick extract was directly chromatographed on Sephadex G-100, resolution was poor unless small batches of placental cotyledons were used, 2. Ammonium sulfate precipitation-Fractional precipitation with ammonium sulfate $(40-75 \%$ saturation) proved to be a valuable step in the purification of oPL. However, one problem associated with this procedure is the solubility rate of ammonium sulfate salt when added to the extract. Ammonium sulfate dissolves very slowly in extracts, causing a relative- 
1y large percentage of oPL $(25-40 \%)$ to precipitate in $40 \%$ saturated ammonium sulfate.

3. Anion exchange chromatography (Whatman DE-32) - At this stage, 10 - $20 \mathrm{~g}$ of protein was applied to a large DEAEce1lulose column $(40 \times 60 \mathrm{~cm})$. For unknown reasons, $40-60 \%$ of oPL was lost in this step presumably because of irreversible adsorption in the column.

4. Cation exchange chromatography. (Whatman CM-23)-One major problem associated with CMncellulose column chromatography is the amount of oPL recovered. In our experience, the percentage of oPL $10 \mathrm{ss}$ in this procedure varied between $40-60 \%$. The nature of this loss is not clear.

\section{B) Analysis and Characterization}

1. Analytical polyacrylamide gel electrophoresis- In alkaline polyacrylamide gel electrophoresis $(\mathrm{pH} 8.8 \times 9,0)$, three stained bands were seen which were not we11 separated. The distance between each band being approximately 2 segments is $0.2-0.3 \mathrm{~cm}$ apart. When the gel was divided into segments, and when the segments were eluted and oPL activity determined by the 2 RRA's, some overlap in activity of the middle band was noted. Fortunately, in acidic polyacrylamide ge1 electrophoresis (pH 4.34.5), the three stained bands were more clearly separated by at 1east 3,4 segments. The presence of oPL was detected in eluants from segments which corresoponded to the middle 
stained band, Thus, the data from acid gel support the view that the middle band in the alkaline gel corresponds to oPL. Another question raised by the polyacrylamide gel electrophoresis is the relationship of the intensity of the stained band and the amount of protein. In practice, we assume that the intensity of the stained band is proportional to the amount of protein present and is similar for al1 proteins, but whether this is always the case for every protein is questionable. Therefore, the exact purity of our highly purified oPL preparation is unknown. But if we assume that the 3 bands stain equally one might estimate that the oPL preparation is approximate 1 y $30 \%$ pure.

2. Analytical gel isoelectric focusing-One of the problems associated with this sensitive technique is the determination of the time which is required to set up a steady-state grad: ient, In our experience, the exact time is very difficult to determine, In the present studies, we employed cytochrome C as an indicator and assumed that a steady state gradient was set up when cytochrome $C$ passed over the anode. Whether this was the time that a steadynstate was set up or not, remains uncertain.

3. Estimation of molecular weight by gel filtration- The reliability of the gel filtration technique as a means of estimating molecular weight in many instances is question. able: The presence of aromatic amino acid residues in proteins can result in the retardation of proteins on the gel filtra 
tion column, resulting in an erroneous estimate of the true molecular weight.

4. Immunological relationships - In our radioimmunoassay for oPL, the only samples which crossireacted with oPL antisera were serum from pregnant sheep and sheep placental extracts, whereas pituitary $G H$ and $P R L$, exhibited no cross-reaction. However, Handwerger et a1 (1974) demonstrated their oPL antisera cross-reacted with ovine growth hormone (oGH) on ouchterlony plates. Thus, a question is raised whether Handwerger's oPL preparation is the same as ours, Although our oPL preparation did not crossmreact with ovine pituitary $G H$ and $P R L$ in a radioimmunoassay system, it is possible that some antisera to oPL may cross-react with oGH or oPRL. Thus, further studies will be necessary to define the immunological relationship between oPL and $O G H$; OPRL, and other hormone preparations.

5. Bioassay of growth promoting activity - Bioassay of growth promoting activity using body weight gain in hypophysectomized rats is adequate. However, it is not completely specific, since the factors contributing to the weight gain have not been defined. Therefore, in order to establish the specific growth promoting property of oPL, other bioassays for growth hormone, such as tibial assay (Geschwind and Li, 1955) wil1 be performed,

6. Bioassay of lactogenic activity $=$ Although the mammotropic assay using organ conculture of rabbit mammary explants 
provides evidence that oPL is lactogenic, in order to assess the proliferative action of oPL, the local pigeon crop-sac assay would be preferred, Preliminary results obtained from Dr, C, Nicoll, University of California, Berkely, demonstrated that the highly purified preparation of oPL in the pigeon crop-sac assay exhibited minimal activity(approximately $10 \%$ ), was non-paralle1. to oPRL. standard(NIH-P-S-10,26 IỤ/mg) used. Lactogenic activity also has been assessed by Handwerger's group. They demonstrated that oPL not only stimulated 1actation in vivo in the rabbit intraductal assay but also stimul- . ated casein synthesis in vitro in mouse mammary gland ex-: plants.

7. Displacement curve of oPL in the radioreceptorassay for growth hormone (RRA-GH) using rabbit tissue- In this assay, we employed ${ }^{125} \mathrm{I}-\mathrm{bGH}$ and $\mathrm{bGH}$ as tracer and standard respectively, The reason that we did this is that bGH exhibits only somatotropic and no lactogenic activity, whereas hGH produces both activities in the receptor assays (Shiu et a1,1973 and Tsushima \&.Friesen, 1973). Therefore, using ${ }^{125} \mathrm{I}-\mathrm{bGH}$ and bGH as tracer and standard respectively, we more confidently predicted that oPL has growth hormone activity, 8. Radioreceptorassay for growth hormone (RRA-GH) using human liver- It is especially interesting that in the radioreceptorassays for prolactin and for growth hormone(RRA-PRL and RRAGG) using rabbit tissues, only hGH and oPL have the property of crossnreacting in both assay systems, Moreover 
oPL binds to human 1 iver receptors as we 11 as hGH whereas hPL binds only $1 / 100$ as we11. On the basis of these observations, we think it is reasonable to suggest that ovine placental lactogen because it binds so effectively to human receptors, is 1 ike $1 y$ to promote the somatotropic effects triggered by the binding of growth hormone to its receptors. It has already been demonstrated that in the human lymphocyte, non-primate growth hormones do not bind to this target tissue (Roth,1973), suggesting that the species specificity of growth hormones is evident at the level of the tissue receptors. If this is the case, then it is quite possible that sheep placental lactogen would prove to be an effective therapeutic agent in promoting growth not only in non-primates which already has been demonstrated in hypophysectomized rats but possiblyalso in primates as we 11 . If this were to be the case, this would represent a finding which has important therapeutic applications.

In conclusion, during our purification and analytical steps, we failed to separate prolactin and growth hormone activity, in the oPL preparation suggesting this hormone has two intrinsic biological effects. Evidence from electrophoretic and immunological studies make it clear that the protein hormone we have isolated is not ovine pituitary prolactin or growth hormone. Additional evidence that ovine placental 1actogen is distinctive is that oPL is active in both 
radioreceptorassays (RRA-PRL and RRA-GH), whereas ovine pituitary prolactin and growth hormone each is active in only one radioreceptorassay: oPRL in RRA-PRL and oGH in RRAGH, Furthermore, oPL binds to human liver receptors for growth hormone whereas other non-primate growth hormones do not. This fact suggests that oPL may have important clinical implications in the treatment of human growth hormonedeficient patients. 
Comparative data on placental lactogens

Only three placental lactogens, namely hPL, mPL, and oPL have been characterized to some degree. Therefore, in the following discussion, I have summarized some data relating to these 3 hormones,

1. Chemistry

TABLE III

\begin{tabular}{|c|c|c|c|c|}
\hline & $\mathrm{hPL}$ & $\mathrm{mPL}-1$ & $\mathrm{mPL}-2$ & oPL \\
\hline Mol, wt. 1 & $21,000 *$ & $21,000 * *$ & $22,000 * *$ & $20,000-22,000$ \\
\hline A.A. Comp. ${ }^{2}$ & $190 *$ & $183-185 * *$ & $185 * *$ & \\
\hline $\mathrm{R}_{\mathrm{f}}(\mathrm{pH} 8.8-9.0)^{3}$ & $0.72 * *$ & $0.52 * *$ & $0.52 * *$ & 0.18 \\
\hline $\mathrm{PI}^{4}$ & & & & 8.8 \\
\hline
\end{tabular}

Mo1, wt. ${ }^{1}$ - molecular weight

A.A. Comp. ${ }^{2}$ - amino acid composition

$\mathrm{R}_{f}^{3}$ - electrophoretic mobility

pI $I^{4}$ - Isoelectric point

* from Sherwood et al,1971

** from Friesen et a1, 1971

The molecular weight of placental lactogen from different species (Ke11y et a1,1974b), rat, goat, sheep, human, monkey, all are similar $\left(20,000=22,000 \mathrm{M}, \mathrm{W}_{\text {, }}\right)$ as 
judged by gel filtration studies, whereas the molecular weight of bovine placental lactogen appears to be 45,000 M.W. and guinea pig is $60,000 \mathrm{M}, \mathrm{W}$..

\section{Secretion}

TABLE IV

\begin{tabular}{|c|c|c|c|}
\hline & hPL & $\mathrm{mPL}$ & oPL \\
\hline $\begin{array}{l}\text { 1. Earliest period } \\
\text { detected (day) } \\
\text { (a) Maternal blood } \\
\text { (b) Plac. Tissue }\end{array}$ & $\begin{array}{l}30 \\
18 *\end{array}$ & $\begin{array}{l}40 \\
?\end{array}$ & $\begin{array}{l}60 * * \\
31 * * * 1\end{array}$ \\
\hline $\begin{array}{l}\text { 2. Maternal conc, at } \\
\text { term }\end{array}$ & $3-10 \mathrm{ug} / \mathrm{m} 1$ & $3-7 \mathrm{ug} / \mathrm{m} 1$ & $0.5-1.5 \mathrm{ug} / \mathrm{m} 1 * *$ \\
\hline $\begin{array}{l}\text { 3. Foetal conc. at } \\
\because \text { term }\end{array}$ & $<100 \mathrm{ng} / \mathrm{m} 1$ & $<100 \mathrm{ng} / \mathrm{m} 1$ & $?$ \\
\hline $4 \cdot \mathrm{T}_{1 / 2} \underset{\text { phase }}{\text { phase } 2}$ & $\begin{array}{l}12 \text { min. } \\
75 \text { min. }\end{array}$ & $\begin{array}{l}20 \text { min } \\
36 \text { hours }\end{array}$ & $\begin{array}{l}15-20 \mathrm{~min} . * * \\
?\end{array}$ \\
\hline 5. Production rate/day & $1 \mathrm{~g}$ & $0.3 \mathrm{~g}$ & $0.95 \mathrm{~g} * * *^{2}$ \\
\hline $\begin{array}{l}\text { 6. Placental content } \\
\text { (mg/g wet weight) } \\
\text { Average plac, wt. }\end{array}$ & $\begin{array}{l}0.3 \\
500 \mathrm{~g}\end{array}$ & $\begin{array}{l}0.07 \\
150, \mathrm{~g}\end{array}$ & $\begin{array}{l}0.1 * * * \\
400 \mathrm{~g} * * *\end{array}$ \\
\hline $\begin{array}{l}\text { 7. Plac, tissue pool } \\
\text { turnover/day }\end{array}$ & 6 & 20 & $4 * * * 3$ \\
\hline
\end{tabular}

Table re-drawn from Friesen et a1,1971 except that:

* - Beck, 1970

**-Ke11y et a1, 1974a

$* * *$ my own studies 
$* * *^{1}$ - The earliest placental tissue that $I$ have studied is the 25 days of gestation (maternal caruncles or maternal attachment sites). No oPL activity detected in this early stage of pregnancy. When foetal placental tissue of 31 days of gestation was examined, oPL activity was detected but in the maternal tissue of same animal, very minimal amounts of oPL were detected. The oPL content in maternal tissues is about $1 / 3$ that of foetal tissues. Thus, oPL is probably secreted into the maternal secretion by the foetal placental cotyledons after the attachment of the embryo to the uterus at day 30 . $* * *^{2}$ - The production rate per day of oPL is calculated from the first $t_{1 / 2}$ of $15 \mathrm{~min}$ assuming an extracel1ular volume of $191 \ldots$ $* * *^{4}$ - The placental tissue pool turnover/day of sheep is calculated on the basis that the placental content of oPL is $0.1 \mathrm{ug} / \mathrm{g}$ wet weight, production rate/day is $0.15 \mathrm{~g}$. and the placental tissue weight of $400 \%$. 
3. Biological effects

TABLE V

hPL

$\mathrm{mPL}$

OPL

1. Lactogenic effect*

(a) Pigeon crop-sac assay ductal assay

(c) Casein synthesis

$10 \% 1$

$10 \%^{9}$

$50-100 \% \frac{2}{2}$

positive 10
$90-100 \%$

2. Somatotropic effect**

(a) Body weight assay

(b) Tibial assay

$50-100 \% 2$

(c) Uptake of radioactive sulfate by: rib

cartillage

$\operatorname{less}_{13 \%} 3 \%^{3} \quad$ positive ${ }^{1.3} \mathrm{U} / \mathrm{mg}^{* * * 11}$ positive 4

3. Luteotropic effect

(Vaginal mucification

1uteotropic assay)

positive ${ }^{5}$ positive $e^{8}$

4.Diabetogenic effect

(Lipolytic effect)

positive ${ }^{6}$

* - using ovine prolactin as standard

** using hGH as standard

***- using bGH as standard

1. Li, 1972

2. Tủkington, 1971; K1einberg and Frankz, 1971

3. Josimovich and MacLaren, 1962; Friesen, 1965

4- Kaplan et a1,1964; Breuer,1969; Murakawa,1968

5- Josimovich and Astwood, 1964; Kovacic, 1966; HenzI and Serge, 1970 
6.Friesen,1965; Turt1e et a1,1966; Rìggi,1966;Genazzáni et ä1,1969

7. Shome and Frìesen, 1971

8 - Josimovich et al, 1970

9 - Private communication with Dr, C, Nicoll, University of California, Berkeley, U.S.A.

$10-$ Handwerger et a 1,1974

11 -our own results

It appears that oPL has more prolactin-like activity in rabbit mammary assay and in the body weight gain assay than hPL and mPL. Whether oPL also has the luteotropic and diabetogenic effects remains to be demonstrated.

4. Immunologica1 relationship

TABLE VI

\begin{tabular}{llll}
\hline & hPL & mPL & oPL \\
\hline 1. Antiserum to hPL & $+*$ & $+*$ & $-* * *$ \\
2. Antiserum to mPL & $+* *$ & $+* *$ & $-* * *$ \\
3. Antiserum to oPL & $*^{* * *}$ & $-* * *$ & $+* * *$ \\
\hline
\end{tabular}

* - From Josimovich. 宅 Brande,1964; Kaplan G Grumbach,1964; Friesen,1965a; Grant et a1,1970. 
** from Shome and Friesen,1971; Vinik et a1,1973

*** - from my own studies

It appears that oPL has different antigenic sites than hPL and mPL which is one of the reasons accounting for the past failure to detect ovine placental lactogen. Whether antisera to oPL raised in animals other than rabbits behave the same way remains to be demonstrated.

5. Secretion pattern

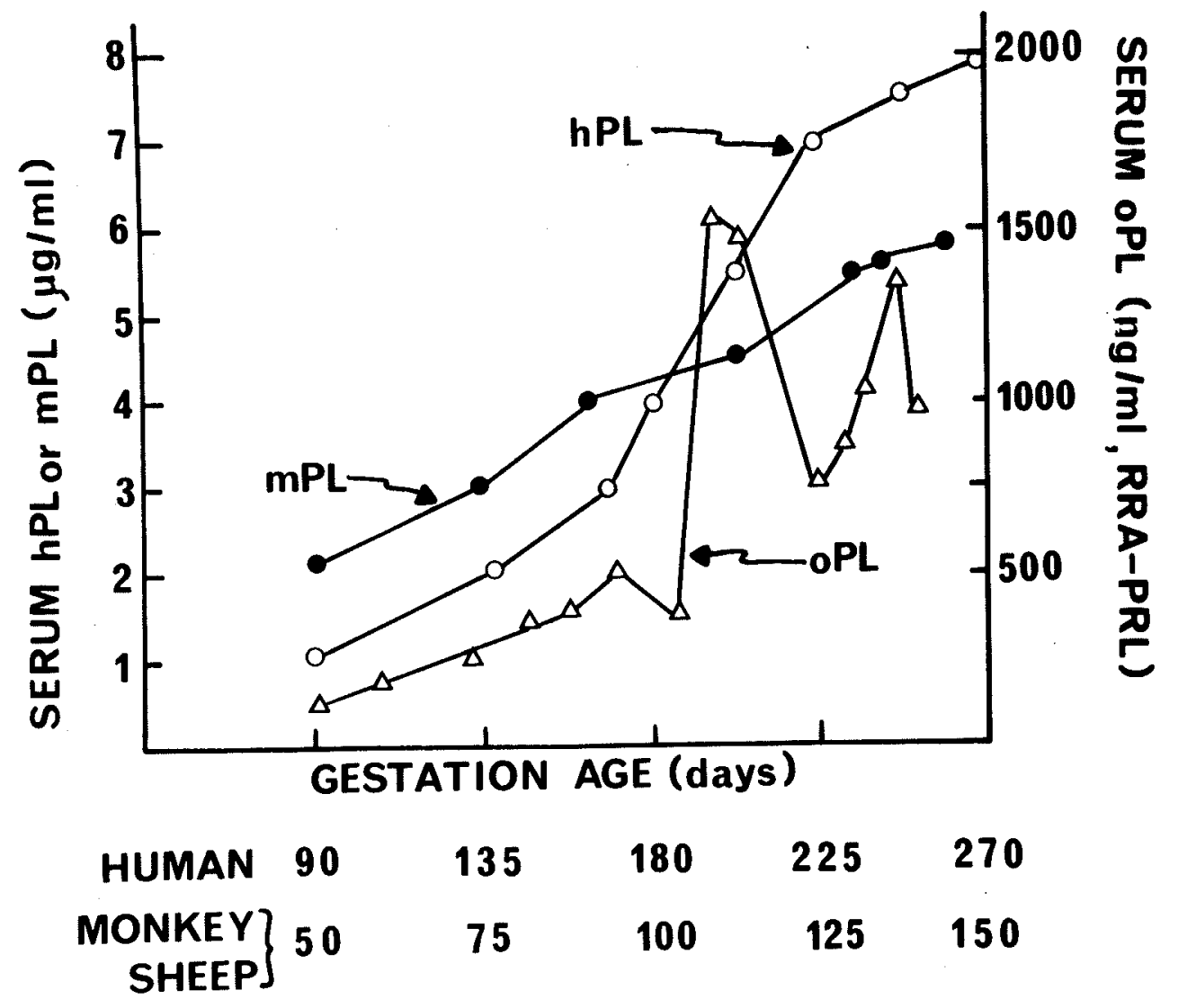

Figure 20. The secretion patterns of $h P L, m P L$ and oPL during pregnancy. The concentrations of hPL and mPL were measured by radioimmunoassays(Friesen et a 1,1971), oPL by RRA-PRL (Ke11y et a1,1974a) 
It is interesting that oPL secretion is different from $h P L$ and $m P L$ in that two peaks of activity are present during pregnancy. Whether each peak of activity plays a different physiological role in sheep remains unknown.Studies by Kelly et al (1974b) showed that the secreted growth hormone activity measured by RRA-GH is also very similar to prolactin activity measured by RRA-BRL. However, the ratio of $\mathrm{PRL/GH}$ is $3: 1$ or $5: 1$, whereas the ratio of $\mathrm{PRL} / \mathrm{GH}$ in the extract and the highly purified oPL preparation is about $1: 1$ measured by the 2 RRA's. The reasons for the high ratio of PRL/GH in serum samples remain unclear.

It is also interesting that the concentrations of prolactin and growth hormone-like activity of serum samples of pregnant monkeys assayed by the 2 RRA's are as high as $50 \mathrm{ug} / \mathrm{ml}$ (ratio of $\mathrm{PRL} / \mathrm{GH}$ is $1: 1$ ) at term. Whereas by radioimmunoassay for $\mathrm{mPL}$, the concentrations reach levels of only $3-7 \mathrm{ug} / \mathrm{m} 1$. Thus, whether the activities measured by the 2 RRA's are different from mPL measured by RIA also remain unclear. Furthermore, when monkey placentas were extracted and the extract measured by the 2 RRA's, a significantly higher $G H$ and $P R L-1 i k e$ activities were detected, at a concentration of $100 \mathrm{ug} / \mathrm{g}$ of wet weight, whereas by RIA for $\mathrm{mPL}$, the content is only $70 \mathrm{ug} / \mathrm{g}$ of wet tissue. However, no significant differences in concentrations of hPL were measured in either the serum or placental extracts. 
In conclusion, $O P L$ is immunologically and chemically different from $h P L$ and $\mathrm{mPL}$, except that the molecular weight is similar with each other. Biologically, oPL is more potent than hPL and $\mathrm{mPL}$ in both lactogenic and somatotropic effects. Furthermore, the secretion pattern of oPL is a1so different from that of hPL and mPL. Whether the amino acid composition and the amino acid sequence of oPL, $h P L$, and $m P L$ are also different or similar remains unclear.

Possible role of oPL in the sheep

The role of ovine placental lactogen in sheep at present is unknown. Therefore, in the following discussion, we are simply speculating about any possible effects.

1) Mammotropic effect-

Since oPL has a potent prolactin-1ike effect as demonstrated in the rabbit, it is possible that oPL may stimulate mammary gland development in sheep during pregnancy in preparation for lactation. Evidence to suggest that oPL might be involved in mammary development in the sheep is derived from the data obtained from experiments by Denamur and Martinet (1961). Hypophysectomy of pregnant sheep after 50 days of gestation did not affect the normal course of pregnancy. Although the mammary gland was not so well developed as in intact controls, nevertheless some development did occur and a transient lactation took place: From these 
experiments, it is suggested that during pregnancy, the p1acenta is able to secrete a prolactin-like substance (OPL ?) which stimulates mammary development in preparation for 1actation.

2) Somatotropic (metabolic) effect-

It is not known whether ovine placental lactogen has any similar metabolic effects in the sheep as hPL does in women. Nevertheless, it appears that in ruminants, as in women, glucose utilization by maternal tissue is reduced in pregnancy (Lindsay, 1971), glucose is the major energy source for the foetus (Leat,1971), and that foetal sheep plasma glucose level and glucose uptake bear a linear relationship with maternal arterial glucose concentration (Battaglia and Meschia, 1972). Therefore, the role of oPL during gestation can best be considered in terms of a placentomaternal unit in which a polypeptide hormone secreted by foetal tissues cour most recent studies indicate that in fact oPL is secreted by the foetal placental cotyledons) exerts its major metabolic effect on the pregnant ewe to ensure the nutritional demand of the foetus.

Evidence supporting the above hypothesis is obtained from the fact that sheep pituitary growth hormone (materna1) secretion during the late gestational period is not elevated (Basset, Thorburn and Wallace,1970), maternal plasma glucose level is slightly depressed (Reid and Hink,1962 a and b), and the substrate requirements by the conceptus progressive1y 
increase, thus leading to the notion that oPL may act as the "growth hormone" of pregnancy. Whether the growth hormonelike effect of oPL (as demonstrated in lower animals) would lead to an impaired glucose uptake directly in the pregnant ewe or stimulate free fatty acid (FFA) release with a resultant decrease of effective insulin remains unknown. If, oPL stimulates FFA release and exerts a contra-insulin action, then the increased ketones induced by the metabolism of FFA in the mother provide an important energy source for the foetus. As a consequence of decreased effective insulin, increased muscle proteolysis and ketone formation may be enhanced, since it is well documented that during pregnancy in the sheep muscle proteolysis and ketone formation are enhanced by restricted feeding (Beaton,1961). Thus, decreased glucose utilization and enhanced maternal gluconeogenesis induced by oPL would ensure a steady supply of glucase for the foetus.

In short, we propose that oPL might act as the "growth hormone" of pregnancy in the sheep. OPL might induce a constant tonic effect on maternal metabolism by mobilizing FFA release from adipose tissues for gluconeogenesis in the maternal liver which ensures for the foetus a steady source of various fuels, of which glucose is the principal one. Insulin is a fluctuating modifier of the effect of oPL on the maternal organism. Feasting increases effective insulin and restores maternal substrates, whereas fasting results 
in a decreased effective insulin and induces primary catabo1ic effects and gluconeogenesis of oPL to ensure an adequate supply of metabolic nutrients for the foetus.

3) Luteotropic effect

Evidence to suggest that the embryo secretes a luteotropin, possibly oPL, ìs derived from data obtained from the following experiments done by several investigators. When hypophysectomy was performed in the pregnant sheep on day 2 or day 10 gestation, the corpus luteum disappeared by day 20 and the embryo was absorbed (Denamur, Martinet and Short,1966; Denamur, Torres, Kann and Short, 1972). Furthermore, when hypophysectomy was performed on day 10 of pregnancy and the embryo maintained by daily injections of progesterone (Foote,Gooch, Pope and Casida,1957; Moore and Rowson,1959; Bindon,1971), the corpus luteum sti11 regressed completely by day 20. Thus, pituitary hormones appeared to be essential for converting the corpus luteum of the cycle into one of pregnancy. Although we cannot rule out the possibility that the conceptus may begin to secrete some luteotroic substance (oPL?), at this stage its contribution is like$1 y$ to be negligible.

When an embryo is introduced into the uterus on day 12-13 of the estrus cycle, the corpus luteum is transformed into a corpus luteum of pregnancy, and the life-span of the corpus luteum is extended 5-10 days longer, whereas when the embryo is removed before day 12 of gestation, corpus 
1uteum regressed more rapidly within 2-3 days (Moore \&.Rowson, $1966 \mathrm{a}, \mathrm{b}, \mathrm{c}, \mathrm{d})$. When hypophysectomy was carried out on day 30 of gestation and after the embryo had been implanted (Amoroso, 1952;Bjorkman, 1965; Davies and Wimsatt, 1966;Boshier, 1969), the corpus luteum regressed more slowly, although the conceptus eventual1y aborted. However, when hypophysectomy was performed on day 60 of gestation, the weight of the corpus luteum examined 12 days later; remained at $75 \%$ of the control value, and abortion did not occur. There was no evidence that the secretory activity of the corpus luteum increased during the first fifty days of pregnancy (Edgar and Ronaldson,1958; Short and Moore,1959; Basset, Oxborrow, Smith and Thorburn,1969; Fly11ing 1970), but the corpus luteum is necessary for the maintenance of pregnancy during the first fifty days of gestation (Denamur and Martinet, 1955). Thus, these findings indicate that the embryo is essential for the maintenance of the corpus luteum of pregnancy after day 12 , but the nature of the luteotropic stimulus secreted by the embryo is unknown. The function of the embryo is to extend the life span of corpus Iuteum rather than to stimulate the secretory activity of the gland.

It is interesting that the time at which the conceptus acquires its luteotropic property coincides with the time when progesterone levels begin to increase (Harrison and Heap, 1968; Basset et a1,1968). One convincing piece of evidence suggesting that the luteotropic hormone may be oPL derives from the fact that the increase in serum progesterone 
and oPL during pregnancy parallel each other (Kelly et al, 1974)! However, whether oPL actually stimulates progesterone secretion requires direct experimental evidence.

In conclusion, the physiological roles of oPL in the sheep remain unknown, but three possible effects may be mentioned: namely, the stimulation of mammary gland growth, adaptation of metabolic processes during pregnancy, and luteotropic effects.

Possible experiments to demonstrate the biological effects of oPL in sheep

1) Mammotropic effect-

The mammotropic effect of oPL may be demonstrated by local adminstration of oPL to pseudopregnant sheep. The methodology will be similar to that described by Bradley and Clarke (1956). One might also examine the effect of oPL on casein synthesis by sheep mammary explants according to the method described by Juergens et al (1965). Furthermore, if the availability of oPL permitted, oPL may be administered into hypophysectomized non-pregnant ewes to observe the effects on mammary development.

2) Metabolic effect.

The metabolic effect of opL may be demonstrated using in vitro systems. The effect of oPL on lipolysis and 
incorporation of amino acid could be studied using the method described by Friesen (1965), Turt1e et al(1966), Riggi(1966), Genazzani et al (1969), except that sheep tissues are used instead of those from rat or rabbit.

Furthermore, oPL measurement in sheep serum during varying physiological conditions, such as restricted feeding during pregnancy or starvation, may provide insight into a possible role of oPL.

3) Luteotropic effect-

The luteotropic effect of oPL in the sheep may be demonstrated by several means. First, binding studies of ${ }^{125} \mathrm{I}$ oPL on the sheep corpus luteum could provide evidence to indicate that oPL has an effect on the corpus 1uteum.Second$1 y$, by measuring progesterone levels of plasma in the ovarian vein after infusion of oPL into the ovarian artery of the hysterectomized sheep , the direct relationship of $O P L$ and progesterone levels could be assessed. And finally, by chronic infusion of $O P L$ into hypophysectomized, and hysterectomized pregnant sheep and measuring the relationship among the levels of progesterone,. OPL, and the maintenance of the pregnant corpus luteum, we could assess the significance of oPL in maintaining the corpus luteum. 
In summary, we have been successful in partially purifying ovine piacental lactogen ( $O P L$ ) and have demonstrated that it has potent growth promoting and mammotropic effects in lower animals. OPL appears to be structural1y related to human growth hormone because it binds effectively to lactogenic as well as somatotropic binding sites in target tissue in animals and even more importantly in human tissues. Hence, its steric conformation must be very closely related to that of hGH. As a result it is possible that oPL may have growth promoting activity in humans. 
SECTION VIII : BIBLIOGRAPHY

Albert, A, and I. Derner(1966) J C1in Endocrinol Metab 20, 1225

Amoroso,E.C. (1952) In Marsha11's Physiology of Reproduction. 3 rd edition. Ed, A.S. Parks, Longmars Green, London.

Amoroso, E.C. and C.A. Finn (1962) in Zuckerman, S. (ed)., The Ovary, Vol. 1, Academic Press, New York, p451

Andrews, P. (1969) Biochem. J 111,799

Ascheim, S, and B. Zondek (1928)K1in Wochenschur Z, 1404

Aschner, B.(1913) Arch Gynaeko1 99, 534

Astwood,E.B. and R.0.Greep (1938) Proc Soc Exp Biol Med $\underline{38}$, 713

Averil1,S.C.,E.W.Ray, and W.R. Lyons(1950) Proc Soc Exp Bio1 Med 75,3

Bah1,0.P., Car1sen, R.B,, Be11isario, R. and N. Swaminathan (1972) Biochem Biophys Res Communications 48,416

Bassett,J.M., Oxborrow,T.J.,Smith,I.D., and G.D. Thorburn (1969) J Endocr $\underline{48}, 251$

Battaglia,F.C. and C. Meschia(1972) in Foetal and Neonatal Physiology. Proc of Sir Joseph Barcroft Centenry symposium. Cambridge University Press,p382

Beaton, G,H.(1961) Fed Proc (20) 1 pt 2, 196

Beck,J.S, and A.R.Currie (1967) Vitamins Hormones 25, 89

Beck,J.S. (1970) N Eng1 J:Med 283,189

Belanger, C.,B. Shome,H.G.Friesen, and R.E. Myers(1971) J C1in Invest $\underline{50}, 2660$

Bewley,T.A. and C.H.Li (1971) Experientia 27,1368

Bewley,T.A. and C,H.Li (1974) in Lactogenic Hormones,Foetal Nutrition, and Lactation, vol.2, (ed) Josimovich, J.B., M.Reynolds, and E. Cobo, John Wiley and Son, New York, U.S.A. p 297

Bindon, B.M.(1971) J Reprod Fert 24,146 
Bjorkman,N. (1965) J Anat $\underline{98,283}$

Boshier,D.D. (1969) J Reprod Fert 19,51

Bouchacourt,M,L.(1902) CR.Soc Bio1,Paris 54,132

Bradley,T,R: and P.M. Clarke (1956) J.Endocr 14,28

Breuer,C.B. (1969) Endocrinology 85,989

Brooksby,J.B, and W.H. Newton (1938) J Physiol 92,136

Buttle,H.L.,I.A. Forsyth and G.S. Knaggs(1972) J Endocr $\underline{53}$, 483

Carr,D. and H.G. Friesen (1975) Manuscript in preparation

Cerruti,R.A. and W.R. Lyons (1960) Endocrinology 69,884

Channing, C.P. (1970) Recent Prog Horm Res 26,589

Choudary,J,B. and G.S. Greenwald (1969) Anat Rec 163, 339

Contractor,S.F, and Davies,H.(1973) Nature New Biol 234,384

Coppedge, R.L. and A.Segaloff (1951) J.C1in Endocr 11,465

Cowie, A.T., Danie1, P.M., Prichard,M., and J.S. Tindal(1963) $\mathrm{J}$ Endoc $\mathrm{r} \underline{31}, 157$

Cowie,A.T., Tindal,J.S., and A. Yokoyama (1966) J Endocr $\underline{34}$, 185

Cowie, A.T., G.S. Knaggs, J.S.Tinda1, and H. Turyey (1968) Ibid 40,243

Cowie,A.T.(1970) In Lactation p123-140. Ed.I.P.Falconeo, London: Butterworth

Cowie, A.J. and J.S, Tindal (1971)

Davies, B.J.(1964) Ann N Y Acad Science 121,404

Davies,J, and W,A. Wimsatt (1966) Acta Anat $\underline{65,182}$

Denamur, R, and J. Martinet-(1955) C R Soc Biol 149,2105

Denamur, R. and Martinet,J.(1961) Ann Endocr,Paris 22,755

Denamur,R., Torres, S,W, G. Kann, and R.U. Short (1973) in The Endocrinology of Pregnancy and Parturition, edited by C.G. Pierrepoint,p 2 
Desjardins, C., M.J. Paape, and.H.A. Tucker (1968) Endocrino$\log y \underline{83}, 903$

Dewar,A.D.(1957) J Endocr 15,216

Drummond-Robinson,G., and S.A.Asde11.(1926) J Physio1 61,608

Edgar,D.G, and J.W. Ronaldson(1958) J Endocr 16,378

Ehrhardt, K, (1936) Munch Med Wschr 83, 1196

Evans, H.M., M.E.Simpson, R.R. Austin, and R.S.Furguson(1933) Proc Soc Exp Biol Med 31, 21

Evans, H.M., and M.E. Simpson (1935) Anat Rec 61,supp1

Fe11ows, R.E., Hurley,T., Maurer,W., and Handwerger, S. (1974) Proc of 56 th Meting of the Endocrine Society, Atlanta, GA, Abstract no. 116

Flint,A.D.F., and P.T. Armstrong (1972) in Gonadotropins, edited by B.B. Saxena, CG Binding, HM Gandy. New Yórk, Wiley-Interscience, p 269

Flyl1ing,p.(1970) Acta Endocr 65,273

Foote,W,D, Gooch,L,D., Pope,A.L, and L.E. Casida (1957) $J$ Anim Science 16,986

Forsyth, I, A, (1970) J Endocr 46, iv - v

Forsyth,I.A. and R.P. Myers(1971) J Endocr 51,157

Forsyth, I.A. (1972) in Wolstenholme, G.E.W, and J. Knight (eds) Lactogenic Hormones, Churchil1-Livingstone, London, p151

Forsyth, I.A, and H.L. Buttle (1972) in Fourth International Congress of Endocrinology. Abstracts of Short Communications, Exerpta Medica, Amsterdam,p106

Forsyth, I.A. (1974) in Lactogenic Hormones, Foetal Nutrition and Lactation, vol.2, (ed) Josimovich, J.B., M. Reynolds, and E. Cobo, John Wiley and Son, $N$, U.S.A. p 49

Friesen, H.G.(1965a) Endocrinology $\underline{76}, 369$

Friesen,H,G: (1965b) Nature 208,1214

Friesen,H,G, B, Shome, C.Belanger, P.Hwang, H. Guyda, and R.Myers(1971) Exerpta Medica INternational Congress Series no.244, Growth and Growth hormone,p224 
Fukushima,M., Tohoku,(1961) J Exp Med 74,161

Genazzoni,A,R., M.L. Aubert, M.Casoli, P. Fiarretti and J.P. Fe1ber (1969) Lancet $\underline{2}, 1385$

Gemze11,C.A,, Diczfalusy,E, and Tihìnger,G,(1955) J Clin Endocr 15,537

Greenwood,F.D., Hunter,W.M. and J. Glover (1963) Biochem J 89 , 114

Grant,D.B.,S.L.Kaplan, and M.M. Grumbach(1970) Acta Endocr 63, 736

Gudson,J.P., Leake,N,H., van Dyke,A.H. and W. Atkins (1970) Am J Obst and Gynec 104,441

Grumbach,M.M., S.L.Kaplan, J.J. Sciarra, and I.M. Burr(1968) Ann N. Y Acad Scì 148,501

Halban,J.(1905) Arch Gynaek 75,353

Handwerger,S., Maurer,w., Hurley, T., Barrett, J.and R.E.Fel1ows (1974) Proc of 56th Meeting of the Endocrine Society, Atlanta,GA, Abstract no. 117

Handwerger, S, and L.M. Sherwood (1974) in Lactogenic Hormones, Foetal Nutrition, and Lactation, vol. 2, ed.

Josimovich, J.B.,M.Reynolds, and E. Cobo, John Wiley \& Son, New York, U.S.A. p 33

Hartog, M:(1972) C1in Endocr 1,209

Harrison, F.A. and R.B. Heap (1968) J Physiol 196,43

Heap, R.B, and R, Deanes 1 y (1966) J Endocr $\underline{34,417}$

Heap, R.B. and Deanes1y R.(1964) J Endocr $30, i-i i i$

HenzI,M.R, and E.J. Serge (1970) Contraception $\underline{1}, 315$

Herrera,E,, R.H, Knopp, and N. Freinke1 (1969) J C1in Invest $\underline{48}, 2260$

Hwang,P., H, Guyda, and H.Friesen (1972) J Biol Chem 247,1955

Ito, Y, and K. Higashi (1961)Endocr Japon 8,279

Josimovich,J,B, and MacLaren,J,A, Endocrinology $\underline{71}, 209,1962$

Josimovich,J,B, , B,L. Atwood, and D.A. Goss(1963) Endocrinology $\underline{73}, 410$ 
Josimovich, J, B. and B.L. Brande (1964) Trans N Y Acad Sci 27 , 61

Josimovich,J.B, and B,L, Atwood (1964) Am J Obstet Gynecol $\underline{88}, 867$

Juergens,W.G., F.E. Stockdale,Y.J, Topper and J.J. E1ias(1965) Proc Natl Acad Science 54,629

Kaplan,S.L. and M.M. Grumbach (1964) J C1in Endocrol Metab $\underline{24}, 80$

Kaplan,S,L, and M.M, Grumbach (1965) Science 147,751

Kaplan,S.L. and M.M. Grumbach (1974) in Lactogenic Hormones, Foetal Nutrition and Lactation, vol. 2, ed. Josimovich,J.B., M. Reynolds, and E.Cobo, John Wiley \& Son, New York, U.S.A. p183

Ke11y,P.A., H.A. Robertson and H.G.Friesen(1974a) Nature 248 , 435

Ke11y,P.A., T. Tsushima, R.C. Shiu and H.G. Friesen (1974b) Manuscript in preparation.

Kleinberg, D.L. and A.G. Frantz(1971) J Clin Invest 50,1557

Knopp,R.H., H.J. Ruder, E.Herrera, and N. Frienke1 (1970) Endocrinology $\underline{65}, 352$

Kohmoto,K, and H.A. Bern (1970) J Endocr 49,29

Kovacic, N.(1966) J Endocr $\underline{35}, \mathrm{xxv}$

Kurosaka,M.(1961) Tohoku J Exp Med $\underline{74,161}$

Leat, R.A.F, (1971) Proc Nutri Soc 30,236

Lewis, U,J., R,N, P, Singh, and B.K. Seavey (1971) Biochem Biophys Res Commun $\underline{44}, 1169$

Li,C,H, Dixon,J,S., and D. Chung (1971) Science 173,56

Li,C.H. (1962) Proc Amer Phil Soc 116,365

Li, C.H. (1972) in Wolstenholme, G.E.W., and J.Knight (eds), Lactogenic Hormones, Churchill-Livingston, London, $\mathrm{p} 7$

Lindsay,D.B. (1971) Proc Nutri Soc 30,272

Lowry, O.H., N.J. Rosebrough, A.L, Farr, R.J, Randa11(1955)

$J$ Biol Chem 193,265 
Lyons,W.R. (1944) Anat Rec $\underline{88,446}$

Lyons,W.R., R.E. Johnson,R.D. Cole and C.H, Li. (1955) in Smith, R.W., O.H. Gaebler, and C.N. Long (eds), The Hypophyseal Growth Hormone, Nature and Actions, McGraw-Hi11. New York,p461

Madruzza,G. (1927) Riv Ital Ginec 6 , 113

Matthies,D,L. (1965) Anat Rec 151,583

Matthies,D.L.(1966). Anat Rec 154, 384

Matthies,D.L.(1967) Anat Rec 159,55

Matthies, D.L.(1974) in Lactogenic Hormones, Foetal Nutrition, and Lactation, vol.2, (ed) Josimovich, J.B., M. Reynold, and E.Cobo. John Wiley and Son, New York, U.S.A. p 297

Meites,J,(1961) in Milk: the mammary gland and its secretion, chap.8, pp 321-367. Eds. S.K. Kon and A.T. Cowie. New York and London: Academic Press

McGarry, E.E. and J.C.Beck(1972) in Wolstenholme,G.E.W., and J.Knight (eds), Lactogenic Hormones, Churchil1Livingstone, London, p 361

Mochizuki,M,,H, Morikawa, Y. Yamada, and S. Tojo(1972) in Fourth International Congress of Endocrinology. Abstracts of Short Communications, Exerpta Medica, Amersterdam, p 14

Moore, N.W., and L,E.A. Rowson(1959) Nature 184,1410

Moore, R.M., and L.E.A. Rowson(1966a) J Reprod Fert 11,307

Moore,R.M., and L.E.A. Rowson (1966b) J Reprod Fert 12,539

Moore,R,M., and L.E.A. Rowson (1966c) J Endocr 34,233

Moore, R.M. and L,E.A. Rowson (1966d) J Endocr 34,497

Morgan, F.J., Kammerman, S., and R.E. Canfield (1972)

In Gonadotropins, edited by BB Saxena, CG Beling,

HM Ganday. New York, Wiley-Interscience, p 211

Murakawa, S, and M.S. Raben (1968) Endocrinology $\underline{83}, 645$

Nandi,S.(1959). University of California Publications in Zoology 65,1

Nelson,W.0.(1935) Proc Soc Exp Biol Med 33,222 
Newton, M.H, and N.Beck (1939) J Endocr vol. 1 p 65

Nia11,H.D. (1971) Nature 230,90

Nia11,H.D, , Hogan,M.L, , Saver, R, , Rosenblum, I.Y, and F.C. Greenwood (1971) Proc Nat Acad Sci USA $\underline{68}, 866$

Pencharz, R.I. and J.A, Long (1933) Am J Anat 53, 1

Pencharz, R.I. and W.R. Lyons (1934) Proc Soc Exp Biol Med $\underline{31}, 1131$

Pugsiey, L, J. (1946) Endocrinology $\underline{39}, 161$

Ray,E.W., S.C. Averil1, W.R. Lyons and R.E. Johnson (1955) Endocrinology 56,359

Reid,R.L,, and N,T. Hinks (1962a) Austr J Agric Res $\underline{13}, 1092$

Reid,R.L., and N,T. Hinks (1962b) Austr J Agric Res 13,1112

Reisfeld,R.A., U.J, Lewis and D.E. Williams (1972) Nature 195, 281

Riggi (1960) Endocrinology 79.709

Robertson, M.C, and H.G. Friesen (1974) Endocrinology submitted.

Roth,J, (1973) Metabo1ism 31, 1057

Sciarra, J.J., Kaplan, S.L. M.M. Grumbach (1963) Nature(London) 199,1005

Selye,H., Collip, J.B., and D.L. Thompson (1933) Proc Soc Exp Biol Med $\underline{30}, 589$

Sherwood, L.M., Handwerger, S., and W.D. McLauren (1971) in Ciba Foundation Symposium on Lactogenic Hormones, edited by GEW Wolstenholme, J, Knight. London, Churchi11-Livingstone, p 27

Shiu, R,P,C, Kel1y,P.A. and Friesen,H,G, (1973) Science 18, 968

Shome, B., and $\mathrm{H}, \mathrm{G}$, Friesen (1971) Endocrinology 89,631

Short, R.V, and N.W. Moore (1959) J Endocr $\underline{19}, 288$

Spellacy, W. W., Buki, W.C, Bìrt, S.A. and Holsinger,K.K.

(1972) Am J Obst \& Gynecol 144,803

Starling, E.H. (1905) Lancet ii,579 
Stock,R.J., J.B. Josimovich, B. Kosov, A. Klopper and G.P. Wilson (1971) J, Obstet Gynaec Brit Cwe1th 78,549

Talamates,F. (1973) the 55 th meeting of the Endocrine Society, Chicago. June (Abstract)

Thore11,J,I, and B,G. Johannson (1971) Biochem Biophys Acta 251,363

Tsushima, T, and H.G. Friesen (1973) J Clin Endocr \& Metab $\underline{37}, 334$

Turkington, R.W. (1971) J Clin Endocr Metab 33,210

Turt1e,J.R, , Beck, P. \& Daughaday,W.H. (1966) Endocrinology $\underline{79}, 187$

Vinik,A.I, , Grumbach;M.M., and S,L. Kaplan (1972) Abstracts, IV INternational Congress of Endocrinology

Washington. D.C. No 34, p 13 